\title{
From a Small Centre: \\ Joe Friday's Contemporary Art Collection
}

by
Amy Dawn Rose, B.A., M.L.I.S.
School for Studies in Art and Culture, Department of Art History

Thesis submitted to the Faculty of Graduate Studies and Research, in partial fulfilment of the requirement for the Degree of Master of Arts

Faculty of Arts and Social Sciences

Carleton University

Ottawa, Canada

(C) Amy Dawn Rose, 2006 


$\begin{array}{ll}\begin{array}{l}\text { Library and } \\ \text { Archives Canada }\end{array} & \begin{array}{l}\text { Bibliothèque et } \\ \text { Archives Canada }\end{array} \\ \begin{array}{l}\text { Published Heritage } \\ \text { Branch }\end{array} & \begin{array}{l}\text { Direction du } \\ \text { Patrimoine de l'édition }\end{array} \\ \begin{array}{l}\text { 395 Wellington Street } \\ \text { Ottawa ON K1A 0N4 } \\ \text { Canada }\end{array} & \begin{array}{l}\text { 395, rue Wellington } \\ \text { Ottawa ON K1A ON4 } \\ \text { Canada }\end{array}\end{array}$

Your file Votre référence

ISBN: 978-0-494-23316-0

Our file Notre référence

\section{NOTICE:}

The author has granted a nonexclusive license allowing Library and Archives Canada to reproduce, publish, archive, preserve, conserve, communicate to the public by telecommunication or on the Internet, loan, distribute and sell theses worldwide, for commercial or noncommercial purposes, in microform, paper, electronic and/or any other formats.

The author retains copyright ownership and moral rights in this thesis. Neither the thesis nor substantial extracts from it may be printed or otherwise reproduced without the author's permission.
AVIS:

L'auteur a accordé une licence non exclusive permettant à la Bibliothèque et Archives Canada de reproduire, publier, archiver, sauvegarder, conserver, transmettre au public par télécommunication ou par l'Internet, prêter, distribuer et vendre des thèses partout dans le monde, à des fins commerciales ou autres, sur support microforme, papier, électronique et/ou autres formats.

L'auteur conserve la propriété du droit d'auteur et des droits moraux qui protège cette thèse. $\mathrm{Ni}$ la thèse ni des extraits substantiels de celle-ci ne doivent être imprimés ou autrement reproduits sans son autorisation.
In compliance with the Canadian Privacy Act some supporting forms may have been removed from this thesis.

While these forms may be included in the document page count, their removal does not represent any loss of content from the thesis.
Conformément à la loi canadienne sur la protection de la vie privée, quelques formulaires secondaires ont été enlevés de cette thèse.

Bien que ces formulaires aient inclus dans la pagination, il n'y aura aucun contenu manquant. 


\begin{abstract}
This thesis discusses the contemporary art collection of Ottawa collector Joe Friday. Friday is situated within the larger context of Canadian collectors who function as his contemporaries. The strategies Friday has had to adopt while collecting from a small centre of art production are explored, as is his accrual of cultural and symbolic capital. To conclude, a case study examination is conducted to ascertain what different meanings are orchestrated within the collection during private as opposed to public display.
\end{abstract}




\section{ACKNOWLEDGEMENTS}

I wish to thank a number of individuals whose help and support were instrumental in the completion of this thesis. John Inca Anderson, Michelle McGeough, and Anne de Stecher, who spent many hours proofreading and taking photographs. To my supervisor, Dr. Jill Carrick, for her careful reading of drafts, insightful suggestions and faithful encouragement. To Bill Brown, Claudia Beck, Deborah Campbell, Catriona Jeffries, Germaine Koh, Paul Marks, John McKinven, and Kitty Scott, who all graciously agreed to be interviewed for this thesis. To my husband Jim, family and friends whose continued support saw this thesis to the end. And last, but not least, I wish to thank Joe Friday. I couldn't have asked for a more passionate and generous subject, who opened his home and his collection to me, and answered all of my questions, no matter how tedious, with much patience, care and thoughtfulness. 
FOR

D.G.R. 


\section{TABLE OF CONTENTS}

Abstract $\quad$ ii

Acknowledgements

Table of Contents $\quad$ v

Introduction 1

Chapter One: Friday and His Collecting Contemporaries $\quad 11$

Chapter Two: Friday and Bourdieu $\quad 45$

$\begin{array}{ll}\text { Chapter Three: Friday's House } & 75\end{array}$

$\begin{array}{ll}\text { Conclusion } & 107\end{array}$

$\begin{array}{ll}\text { List of Figures } & 109\end{array}$

$\begin{array}{ll}\text { Figures } & 115\end{array}$

$\begin{array}{ll}\text { Appendix A } & 145\end{array}$

$\begin{array}{ll}\text { Bibliography } & 146\end{array}$ 


\section{INTRODUCTION}

The subject of collecting is a topic that provokes enduring fascination, either with the collectors themselves or the objects they amass. From the Renaissance Wunderkammern, Cabinets of Curiosities consisting of rarities and oddities meant to provoke astonishment and wonder, to contemporary displays of collections (both public and private) in museums and galleries, we continue to be captivated by the act of accumulation. Much has been written on collecting, from biographies and profiles of famous collectors of the past and their collections to psychoanalytic and psychological attempts at understanding collectors' motivations. ${ }^{1}$ Much less has been written on the collecting of contemporary art by present-day collectors. The following study attempts to address this lack by exploring the till now largely unexamined collecting practices of Ottawa art collector Joe Friday. Friday has collected close to one hundred works of contemporary art over the last seventeen years by both Canadian and international artists, in a wide range of media. This is a private collection housed in a unique heritage home, though Friday does frequently open his doors to the public, permitting a glimpse into its enchanting interior.

Friday's collection first came to my attention while I was completing a practicum for the M.A. program at the Ottawa Art Gallery. My first reaction upon hearing, by wordof-mouth, of the type of art he collected and how it was displayed, was that this was a unique collection being assembled in the city of Ottawa and worthy of further exploration. He was collecting work that was neither being produced nor sold in his city of residence, and I wondered what kind of strategies he had had to adopt as a consequence. In some 
cases, his was the first collection, private or public, to acquire the work of particular artists. My discovery of, and interest in Friday also happened at a rather serendipitous time, as recognition of his collecting was being generated in local, national and international fora. This thesis seeks to situate Friday within the larger context of Canadian collectors who function as his contemporaries. I intend to explore what he collects, why he collects, how he collects, and the social function of his collection in order to analyse how Friday's collecting practices intersect with other collecting practices in Canada.

\section{Theoretical and Methodological Approaches}

To date little or nothing has been written about Friday's background, social networks and strategies for collecting. Therefore, one of the key sources of primary information that forms the basis of this thesis is a series of personal interviews conducted between February 2004 and October 2006. Proposed questions were distributed to the interviewees beforehand, but the informal and unstructured nature of the interviews allowed for fruitful and interesting digressions. My initial interview with Friday was conducted in-person at his home. There has since followed numerous email communications where clarifications have been required, or where new avenues of exploration have presented themselves. Local collectors Bill Brown and John McKinven were also interviewed in-person, while collectors Paul Marks and Claudia Beck and Andrew Gruft were interviewed via telephone. Interviews were also conducted with Catriona Jeffries, owner of Catriona Jeffries Gallery in Vancouver, and Deborah Campbell, author of Canadian Art's series on collectors (and also a resident of Vancouver), via telephone. Kitty Scott, formerly Curator of Contemporary Art at the 
National Gallery of Canada was interviewed in-person. Germaine Koh, artist and curator of Prototype, the exhibition of contemporary art selected from Friday's collection and shown at the Carleton University Art Gallery from September 13, 2004 until October 31, 2004, provided a written interview as she was completing a residency in Berlin at the time. All interviews were captured on tape and later loosely transcribed, and in all cases I have presented the information as it was provided to me.

The other key methodology centres on a visual analysis of installation photographs. Photographs were taken by me as well as by John Inca Anderson and Michelle McGeough under my direction. Photographs of the collection as it was found in its configuration in the Prototype exhibition were compared to how the collection was displayed in Friday's home in January 2005, following re-installation after the Prototype exhibit. As Friday frequently rearranges work in his home, it was necessary to document the collection at a specific moment in time. Archival records were also consulted while investigating the history of Friday's house, known as Beattie House.

Theoretical approaches are based on the work of French sociologist Pierre Bourdieu, in particular The Field of Cultural Production: Essays on Art and Literature 2 and Distinction: A Social Critique of the Judgement of Taste. ${ }^{3}$ Bourdieu's theories combine the best of objectivist and subjectivist approaches, and can be summarised as an ...attempt to understand how 'objective,' supra-individual social reality (cultural and institutional social structure) and the internalised 'subjective' mental worlds of individuals as cultural beings and social actors are inextricably bound up together... ${ }^{4}$

Bourdieu's interest in both objectivist and subjectivist concerns has been variously 
described as genetic structuralism ${ }^{5}$ or constructivist structuralism. ${ }^{6}$ I have chosen to employ Bourdieu's concepts as the unifying theoretical work for my thesis because I think they help illuminate the type of collector Friday has become, and the strategies he engages collecting from a small city of art production like Ottawa. Bourdieu's work suggests social networks are fundamental to collectors, borne out in a close analysis of Friday's collecting.

Though Bourdieu has been accused of being 'very French,' he argues in the Preface of the English edition of Distinction that his "model of the relationships between the universe of economic and social conditions and the universe of life-styles"' can be applied to any stratified society. It is perhaps due to these accusations of 'Frenchness' that

theorists Nicholas Brown and Imre Szeman ${ }^{8}$ as well as artist Hans Haacke ${ }^{9}$ have noted that little use has been made of Bourdieu's ideas in North America. With a few concessions to Canadian tradition and history, his theories dovetail nicely with Friday's collecting practices. By exploring Friday's collecting practices within this theoretical framework I hope to address this lacuna in North American scholarship.

\section{Chapter Breakdowns}

Chapter One examines the Canadian context of art collecting by looking at the collections and practices of collectors Paul Marks, Claudia Beck and Andrew Gruft, Bill Brown and John McKinven, in order to make comparisons with Joe Friday. I became familiar with the collections of Marks and Beck and Gruft through Campbell's articles for Canadian Art, and since both collections are being amassed in large cities of art production, they offer interesting counterpoints to Friday's collection. I was first 
introduced to the Brown and McKinven collection while I was working as a research assistant at the Carleton University Art Gallery, as they have made substantial donations to that institution. Like Friday, Brown and McKinven are Ottawa collectors, but unlike Friday, they have chosen to focus on locally available art. All of these collectors collect contemporary art, though the Beck and Gruft collection also includes historical photography. The collectors were asked questions such as: When did you start collecting?; What kind of art do you collect?; What strategies do you use?; Are there special relationships you have cultivated to aid in your collecting?; What kind of relationships do you have with the artists you collect?; and how do you display your collection in your home?

Chapter Two focuses on the social implications of Joe Friday's collecting practice, drawing in particular from Bourdieu's theories. It analyses Friday's accrual of cultural and symbolic capital and probes the comprehensive social networks Friday relies on to collect. Friday has developed a close personal relationship with commercial dealer Catriona Jeffries, from whom he has bought many of his works, as well as with Kitty Scott, formerly Curator of Contemporary Art at the National Gallery of Canada. ${ }^{10} \mathrm{He}$ also frequently entertains artists at his home, and his guests include artists whose work is found in his collection, but also others whose work is beyond his financial reach. The capital Friday has amassed in these diverse ways allows him to circulate readily in the cultural field that enables his acquisitive behaviours.

Interviews with Campbell, Koh, Scott and Jeffries were conducted to determine the nature of relationships between collectors and curators, gallerists, and artists, as well 
as to gauge Friday's personal reputation as a collector. Had they heard of Friday before meeting him? Do they think Friday is unique among Canadian collectors? How would they describe their relationship with Friday? Koh was also asked questions in relation to Prototype and her curatorial process: How did you come to be involved in curating Prototype?; How much input did Friday have to the curatorial process and/or the end result?; and did the hanging of works in Friday's home have any effect on your choice of works, or on how the works were hung in Prototype? Campbell was questioned about her motivation to write the series on collecting, and why she chose to profile the collectors that she did.

The final chapter provides a case study examination of different meanings orchestrated within the collection, during private as opposed to public display. Do the meanings of the works in fact change, depending on where they are displayed and which works they are displayed with? What effect does the architectural setting have on the artwork's meanings, if any? Do household objects have any effect on the artwork's meanings? Is Friday trying to construct a particular narrative in his home? If so, how is it accomplished? This chapter also provides the opportunity to discuss actual works in the collection, for example, a comparison of Prototype's side-by-side hanging of Shirin Neshat's Rapture (1999) with Thomas Ruff's Nudes vin05 (2000), two works which are displayed on entirely different floors in Friday's home.

\section{Literature Review}

As of yet, no in-depth study has been done on Joe Friday and his collection. Several short articles have been published, including Deborah Campbell's article for the 
Canadian Art magazine collector series, ${ }^{11}$ and two articles published in conjunction with Prototype, one in The Ottawa Citizen ${ }^{12}$ by Paul Gessell and the other by Lucianne Poole in Carleton University Magazine. ${ }^{13}$ Both Gessell's and Poole's articles provide cursory descriptions of Friday's collection and motivations, focussing on the works found in the exhibition. Campbell's highly descriptive journey through the collection, as well as its unique surroundings, also considers the pitfalls and rewards of collecting contemporary art and navigating the somewhat treacherous contemporary art market. A forthcoming Prototype exhibition catalogue is to be published. ${ }^{14}$ There is also a paucity of scholarly writing on other Canadian collectors or collections. Ken Thomson: Canada's Enigmatic Billionaire ${ }^{15}$ features one of Canada's best-known art collectors, but does not focus exclusively on his collecting practices. Georges Loranger's An Essay on Private and Public Art Collecting in Canada: The Tip of the Canadian Icejam ${ }^{16}$ published in 1985, is now dated. Toronto collector Ydessa Hendeles, perhaps Canada's best known collector, has been profiled in short articles, ${ }^{17}$ and she was also discussed in art historian Jennifer Fisher's dissertation Aesthetic Contingencies: Relational Enactments in Display Culture ${ }^{18}$ in terms of the aesthetic engagements of women collectors. Canadian Art magazine's recent collector series certainly attempts to fill this void, and has profiled Claudia Beck and Andrew Gruft, ${ }^{19}$ Paul Marks, ${ }^{20}$ and Ian Wallace ${ }^{21}$ in addition to Friday.

There have been several exhibitions (some with accompanying catalogues) in Canadian galleries on private collectors including the Vancouver Art Gallery's Real 
Pictures: Photographs from the Collection of Claudia Beck and Andrew Gruft ${ }^{22}$ the McMichael Canadian Art Collection's The Private Eye: Art, Collectors and Their Stories of 2004, the Vancouver Art Gallery's Vancouver Collects, ${ }^{23}$ the Edmonton Art Gallery's Hoarders, Packrats, and Connoisseurs (which did not limit itself to collectors of art), ${ }^{24}$ and the Art Gallery of Ontario's Collector's Canada: Selections from a Toronto Private Collection, ${ }^{25}$ to name a few. The Banff International Curatorial Institute's Obsession, Compulsion, Collection: On Objects, Display Culture, and Interpretation, ${ }^{26}$ included many Canadian perspectives on collecting, but was primarily focussed on curatorial concerns vis à vis collections. While there is certainly a body of literature on Canadian collecting, it does not even begin to approximate that of its American or European counterparts. This in-depth examination of one Canadian collector will be a step in remedying this disparity.

1. See for example Philipp Blom, To Have and to Hold: An Intimate History of Collectors and Collecting (London: Penguin Books, 2003); John Elsner and Roger Cardinal, The Cultures of Collecting (Cambridge, Mass.: Harvard University Press, 1994); and Werner Muensterberger, Collecting: An Unruly Passion, Psychological Perspectives (Princeton: Princeton University Press, 1994).

2. Pierre Bourdieu, The Field of Cultural Production, ed. Randal Johnson (New York: Columbia University Press, 1993).

3. Pierre Bourdieu, Distinction: A Social Critique of the Judgment of Taste, trans. Richard Nice (Cambridge, MA: Harvard University Press, 1984).

4. Richard Jenkins, Pierre Bourdieu (New York: Routledge, 1992), 19. 
5. Marty Hipsky, "Romancing Bourdieu: A Case Study in Gender Politics in the Literary Field," in Pierre Bourdieu: Fieldwork in Culture, eds. Nicholas Brown and Imre Szeman (New York: Rowman and Littlefield Publishers, 1999), 188.

6. Bridget Fowler, Reading Bourdieu on Society and Culture (Malden, MA: Blackwell Publishers, 2000), 1.

7. Bourdieu, Distinction, xi-xii.

8. Nicholas Brown and Imre Szeman, eds., Pierre Bourdieu: Fieldwork in Culture (New York: Rowman \& Littlefield, 1999), 1.

9. Hans Haacke, "A Public Servant," October 101 (summer 2002): 4.

10. Scott left the National Gallery of Canada in August 2006 and is now working in London at the Serpentine Gallery.

11. Deborah Campbell, "Joe Friday: Just the Facts," Canadian Art 21.2 (Summer 2004): 64-67.

12. Paul Gessell, "This Man is Looking for Art," Ottawa Citizen, 18 September 2004: F1-F2.

13. Lucianne Poole, "On Campus: The Collector," Carleton University Magazine Online, Fall 2004. 12 October $2004<$ http://www.magazine.carleton.ca/2004_Fall/1361pf.htm>.

14. Germaine Koh, Prototype: Contemporary Art from Joe Friday's Collection, unpublished catalogue essay (Ottawa: Carleton University Art Gallery, 2006, forthcoming).

15. Vic Parsons, Ken Thomson: Canada's Enigmatic Billionaire (Toronto: Burgher Books, c1996).

16. Georges Loranger, An Essay on Private and Public Art Collecting in Canada: The Tip of the Canadian Icejam (Toronto: G. Loranger, 1985).

17. Sarah Jennings, "Ydessa Hendeles: A Collector Who Curates," ARTNews 93.40 (December 1994): $97-$ 98; John Bentley Mays, "Bears," Canadian Art 19.3 (Fall 2002): 92-97; Sarah Milroy, "With Ydessa the Mind Makes Leaps," The Globe and Mail, 6 May 2006: R8-R9; Pierre Théberge, "The Ydessa Hendeles Art Foundation: Building a Museum as a Life Process," Parachute 54 (March - June 1989): 28-33.

18. Jennifer Fisher, Aesthetic Contingencies: Relational Enactments in Display Culture, dissertation, Concordia University, 1996.

19. Deborah Campbell, "Passion + Intellect," Canadian Art 21.1 (Spring 2004): 62-65.

20. Deborah Campbell, "Paul Marks: The Collector in the Age of Mechanical Reproduction," Canadian Art 21.3 (Fall 2004): 116-120.

21. Deborah Campbell, "Exchanges + Gatherings: In the Studio with Ian Wallace," Canadian Art 21.4 (Winter 2004): 60-64. 
22. Vancouver Art Gallery, Real Pictures: Photographs from the Collection of Claudia Beck and Andrew Gruft (Vancouver: Vancouver Art Gallery, 2005).

23. Vancouver Art Gallery, Vancouver Collects (Vancouver: Vancouver Art Gallery, 2001).

24. Edmonton Art Gallery, Hoarders, Packrats and Connoisseurs (Edmonton: Edmonton Art Gallery, 1994).

25. Dennis Reid, Collector's Canada: Selections from a Toronto Private Collection (Toronto: Art Gallery of Ontario, 1988).

26. Anthony Kiendl, ed., Obsession, Compulsion, Collection: On Objects, Display Culture, and Interpretation (Banff, Alta: Banff Centre Press, c2004). 


\section{CHAPTER ONE: Friday and His Collecting Contemporaries}

For inside him there are spirits, or at least little genii, which have seen to it that for a collector - and I mean a real collector, a collector as he ought to be - ownership is the most intimate relationship that one can have to things. Not that they come alive in him; it is he who lives in them.'

Everyone, at one time or another, has collected something. This impulse to collect often begins in childhood, extends into adulthood for many, and is pursued with varying degrees of dedication. No two collectors, and no two collections, however, are alike. This chapter will serve as both an introduction to Joe Friday's art collection, and will examine the Canadian context of collecting by looking at the collections and practices of the following collectors: Paul Marks, Claudia Beck and Andrew Gruft, and the collection of Bill Brown and John McKinven. These collectors are all contemporaries to Friday, and all the collections include, but are not necessarily limited to, works of contemporary art. Paul Marks, and Claudia Beck and Andrew Gruft all find themselves collecting from large centres of art production, namely Toronto and Vancouver. Brown and McKinven, who like Friday also collect from Ottawa, have amassed a notable collection which will provide an interesting counterpoint to Friday's own.

\section{The Collections}

Joe Friday's collection is comprised of roughly one hundred works of contemporary art, the majority of which fall into the conceptual realm. Some of his early purchases include photoconceptual works coming out of Vancouver, and his collection has since expanded to encompass works of sculpture, drawing, video, and sound. His collection includes, but is not limited to, the work of Brian Jungen, Germaine Koh, Spring 
Hurlbut, Ron Terada, Geoffrey Farmer, Myfanwy MacLeod, Damian Moppett, Ken Lum, General Idea, Ian Wallace, Kelly Wood, Simon Starling, Francis Alÿs, David Shrigley, and Shirley Tse. Although his collection includes a number of Canadian artists, he does not collect with the intent of amassing a definitive sample of Canadian contemporary art. The artists whom he collects "function comfortably within an international context;", Friday feels that to define their work simply as Canadian is limiting and does them a disservice.

Friday credits his nascent interest in contemporary art to the frustration, discomfort, and intimidation he experienced while visiting the National Gallery of Canada's 1986 exhibition Songs of Experience. ${ }^{3}$ Curated by Diana Nemiroff and Jessica Bradley, it featured the work of fifteen contemporary Canadian artists, including Wanda Koop, Joanne Tod, Jana Sterbak, Stan Douglas, Mary Scott, and Carol Wainio (Friday has since acquired work by Sterbak (Fig. 1), Tod (Fig. 2), and Wainio (Fig. 3) for his collection.). Spurred on by a desire to understand this art on his own terms, he switched the focus of his journalism degree to arts reporting, and started taking elective courses in the Art History department at Carleton University. He considers the Contemporary Canadian Art class he took under Professor Natalie Luckyj to be key in the development of his interest in this art. The class had a tremendous impact on his approach to collecting, particularly as Luckyj demonstrated contemporary art's unique way of providing a means of engaging in the times in which we live. ${ }^{4}$

His first purchase, made in 1989, was a work by local artist Russell Yuristy (Fig. 4). A self-portrait in the image of Van Gogh, Friday considers it a piece which manages to 
embody issues of appropriation, craft versus high art, and self-consciousness all at once.

This work continues to form an important part of his collection (as art historian Frederick Baekeland remarks, all but one of the numerous collectors he knows still own the first work of art they bought). ${ }^{5}$

Many of the works Friday buys have yet to enter scholarly art historical discourse, as he is often interested in an artist relatively early in his/her career, or in the recent work of a more established artist. These works rarely appear in exhibition catalogues or periodicals; if they have, prices have usually either increased beyond his reach, or the work is no longer commercially available. As photography collector Claudia Beck indicates

...most information is first located in sources other than books: photographers, artists, exhibitions, dealers, auction houses, institutional collections, curators, periodicals and other collectors. Sources expand and appear from unlikely places. ${ }^{6}$

This is not to say that Friday does not notice when works he has acquired do enter this discourse. The appearance of Simon Starling's Home-made Eames (Formers, Jigs and Molds)(2002)(Fig. 5) on the front cover of Artforum's February 2004 edition, a year after his purchase of the last number in the limited edition, was certainly met with pleasure and a sense of validation, as was Starling's nomination for the 2004 Hugo Boss Prize from the Solomon R. Guggenheim Museum. Although Friday stresses that he does not collect art as an investment, he does admit that he has been lucky, ${ }^{7}$ as many of his acquisitions have appreciated. For example, the Brian Jungen mask Prototype for a New Understanding \#7 (1999)(Fig. 6), was purchased just prior to the artist winning the 2002 Sobey Art Award, 
and the National Gallery of Canada's purchase of Shapeshifter (2000) in 2001. His purchase of the Fiona Banner work Arsewoman in Wonderland Black and Blue (2000) (Fig. 7) was also timely, a year before the artist was shortlisted for the 2002 Turner Prize. The work Friday acquires tends to be art historically self-reflexive, exploring the discourses of the art world. This appears to be a personal interest of his (although one has to wonder if it is a conscious decision on his part, or a pattern discovered in retrospect?). He firmly believes that knowledge of art history is essential to the understanding of much of contemporary art, and points, as example, to the work of Jonathan Monk. "Monk looks at the entire continuum of modern art history to not only investigate his place within it, but to explore the question of whether or not there is any such thing as an original thought." Two Monk works in Friday's collection, Untitled (2001) and Onkell Leopold Wellnitz, Erased (1999), in particular require a familiarity with the work of Gilbert and George, as well as Robert Rauschenberg's 1953 erasure of a Willem De Kooning work.

So why does Friday collect contemporary art? ${ }^{9}$ It does not appear to be for any of the reasons often attributed to art collectors: a need for power, the enhancement of feelings of security, as a trophy, or to engage in competition. ${ }^{10}$ It is also often assumed that those who buy art do so on the basis of aesthetics, but again this does not appear to be the case here. Friday claims he is not interested in being seduced by the image, and attempts to assume a position of disinterest when confronted with a work of art for the first time. If he finds himself immediately drawn to a work, he wonders if he is looking at it for the right reasons, suspicious of any piece that is too easily comprehended. Although he frequently describes works of art as "beautiful," he is in fact referring to the beauty and satisfaction 
these works offer in demanding that he work his way out of an intellectual conundrum. He describes the work of Lynne Cohen (such as Spa (1991)(Fig. 8) found in his collection), as "luscious, creamy, beautifully produced velvety photographs," but it isn't that velvety beauty which draws him to the work, but rather the conceptual underpinnings. This does not, however, rule out the possibility of scopophilic enjoyment.

Friday is not particularly drawn to painting either, a medium for which he has difficulty finding relevance. He concedes, however, that if a canvas can investigate the history of painting, or can juxtapose it with another medium that calls attention to its history and the very nature of the medium itself, this critical tension attracts him (Friday does in fact own several paintings that fulfill these criteria: Ken Lum's Untitled Language Painting (1988)(Fig. 9), Ron Terada's Jeopardy (Iggy Pop)(1998)(Fig. 10), and Carol Wainio's Speech Patterns (1991)). Both Fiona Banner's Arsewoman in Wonderland Black and Blue and Ian Wallace's Guggenheim (1992)(Fig. 11) are works which investigate the history of the monochrome. Wallace pairs a stripe painting with a photograph of the interior of the Guggenheim museum, not only regrounding photography within the problematic of painting, but also drawing attention to the discourse of art institutions. Banner's work, a silkscreen reminiscent of Abstract Expressionism, is comprised of the transcribed dialogue from a pornographic film, linking it to cinematic experience.

Nor is Friday interested in the concept of seriality, which in terms of contemporary art refers to either the entire production of any one artist in particular, or all of the works produced by an artist that make up a finite series or a period of production. If anything, Friday makes a conscious decision not to collect the entire oeuvre of any one artist. 
Though he owns four works by Ian Wallace (Guggenheim, Sarah: Heroes in the Street (1986)(Fig. 12), In the Studio (1995), and Poverty (1980)), he prefers instead to collect the work of other artists who may continue the ideas Wallace proposes, or who produce work that permits interesting juxtapositions. Rather than collecting with a goal towards completeness, he prefers incompleteness; he is never sure where any one road of inquiry will lead him, what works will come into the collection, what new connections will be made, and has no particular idea of an end in sight. To Friday this approach makes collecting that much more "confusing, defeating, exhausting, and rewarding."12

As with seriality, classification and categorization are likewise anathema to Friday. He is wary of structure impeding his ability to react to a work, and for this reason also limits how much he reads on collecting. He is concerned about becoming too immersed in theories of collecting, concerned that he might get distracted by the labels he may want to apply to himself, or feel that he has to rebel against a classification scheme. But is his collection really as unorganised as he thinks? Categories could be devised that would account for the collection on a fairly superficial level (i.e. by media, pieces that are textbased, humorous, etc.). When he looks at contemporary art with an eye to buying, he is using a sifting strategy, which is a cursory classification system in itself.

Vancouver-based Andrew Gruft and Claudia Beck have been collecting art for close to thirty five years, making them the longest practising collectors discussed in this thesis. They are also the only collectors in this discussion to have opened a commercial gallery. They did not intentionally set out to become collectors per se, and the 'collector' 
moniker has come slowly. Their entire collection is composed of roughly six hundred pieces (over four hundred and fifty of which were donated to the Vancouver Art Gallery in January 2005), which are predominantly photographs, though they also collect sculpture, drawings, masks and Northwest Coast art. They collect from the beginning of photography to what was made this year, but are careful to point out that their collection has gaps and does not provide a complete history of photography.$^{13}$ The collection includes work by artists such as Henry Fox Talbot, Robert Frank, Julia Margaret Cameron, Cindy Sherman, Larry Clark and Brian Jungen, and has been described by artist Roy Arden as humanist in nature, but without the sentimentality. ${ }^{14}$ Like Friday, the Beck and Gruft collection contains a number of works by Canadian artists, and Vancouver artists in particular. Brought about by a conviction that some of the most interesting contemporary art is being produced in that city, it is also easily accessible to them via galleries and artist's studios.

Beck and Gruft opened a commercial art gallery in Vancouver in 1976, the Nova Gallery, which pioneered photography at a time when there was no significant market for the medium (particularly in Canada). ${ }^{15}$ The venture was fuelled by their own passion and curiosity, and a strong belief in the medium's relevance as an artistic practice. Though the gallery was short-lived, closing after only six years of operation, it acted as a catalyst to their continuing collecting of photographs, and brought to Vancouver works previously unseen in the city.

Beck and Gruft were fortunate enough (as well as savvy) to have started collecting during initial attempts at establishing a photographic market. Due to this they were able to pick and choose from a large body of work that was also affordable. Today, it would be 
difficult for them to buy some of the pieces already found in their collection, or attempt to fill in some of the gaps, either because their value has accrued beyond their financial reach, or the works are simply no longer found on the market, having already been bought by other collectors or institutions. Similarly to Friday, Beck and Gruft's acquisition decisions have moved beyond a purely aesthetic exercise; they are also interested in content, cultural history - of the person making it or the genre of making - as well as price and availability. Unlike Friday, however, Beck does not separate a work's intellectual component from it's ability to seduce the viewer visually: "one looks at something and is compelled to keep looking, but one also asks a lot of questions."16

Beck believes they are rare as a collecting couple, due to the length of time they have been collecting, and their combined informed backgrounds. Collecting as a couple has its advantages, as it guarantees an increased exposure to work for acquisition consideration. When asked if their collection has a classification scheme, they responded no. Some have called the collection eclectic, but they disagree with that analysis, as it suggests there is no set of ideas working within it. Instead they prefer to think of it as exploratory, with various groupings of works that cohere. Acquisitions were also made piece by piece or group by group, with little consideration of the collection as a unified whole.

Paul Marks, an orthopaedic surgeon from Toronto, has the most carefully defined and focussed collecting parameters of all of the collectors here discussed. Although predominantly interested in contemporary work, his collection also contains many historical references, notably to the work of Marcel Duchamp. Referring to Duchamp as 
the father of Conceptualism, his work functions as a lynchpin in Marks' collection, providing a grounding or basis for many of the other pieces, as well as a strategy for looking at new work. ${ }^{17}$ Marks has been seriously collecting art for the past sixteen years or so, though the motivation to collect can be traced back to his childhood. Like Friday, Marks does not confine his collecting to one particular medium, having acquired drawings, prints, paintings, sculpture, video and photographs, as it is the conceptual component, and not the medium itself, that is of prime interest to him. His collection includes work by artists such as Andy Warhol, Roy Arden, Marcel Duchamp, Jeff Wall, Daniel Olson, Thomas Ruff, and Bernd and Hilla Becher. Also like Friday, his collecting interests have evolved over time, and he admits to not having a strategy when he began. He was originally interested in what he terms 'retinal' art (an interesting nod to his medical profession), or colour-field art, citing as an example the abstract expressionist artist Hans Hofmann, who, like Duchamp, influenced many other artists who followed. He is quick to point out that this original interest in colour was not purely aesthetic in nature, as much of the work he admired by artists such as Robert Motherwell, Barnett Newman and Mark Rothko, have strong intellectual underpinnings. Marks has a propensity to be drawn to artists who have influenced others, have slow trajectories, and whose works will have a life after himself, who have not "led to a dead-end." himself as a custodian of the art, and hopes someday that either his children will enjoy it, or it can go to auction or be donated to a museum. He has tried to use art as a scaffolding to study other things such as history and political science, areas which were beyond the scope of his medical training, though he still brings this training to bear on his collecting, 
admitting that, as a surgeon, he likes to 'dissect' works of art.

When making an acquisition decision, Marks says he frequently waits to be "kicked in the gut."19 These are works he finds he can't stop thinking about, even though he may not have understood them, and they set a benchmark for future decisions. There is now so much to see and sift through (especially in Toronto), that he waits for this feeling to make a judgement, knowing there will be more along shortly. Like Friday, he often takes a considerable length of time to make an acquisition decision, even when time is of the essence. As a result he sometimes misses opportunities, or later realises he was correct in passing something up. When asked if his collection had a classification scheme, he replied "Who knows how the collection is evolving, really?," certain themes he tends to follow more than others: time, "nothing," process orientation and multiplicity. And there may well be others; Campbell, in her article on Marks for Canadian Art, comments on how many of the works in his collection reference the hand, "a theme that resonates with his work as a surgeon." 1

The collection of retired teachers Bill Brown and John McKinven was mostly purchased after the two met and became partners in the 1970s. Brown was initiated into the world of collecting following a birthday gift of a piece of art from a past partner. McKinven was also influenced by and introduced to collecting by a former lover, whose own collection of historical Canadian art informed and inspired him to a certain extent, though McKinven preferred work that was less "staid."22 They have always bought things they liked, without any concern for what others may think, and for this reason the collection has evolved into a very personal and private testament to their life together. 
The Brown/McKinven collection is predominantly composed of work from Ottawa artists. They never intentionally set out to build a local collection, but finding the pool of local art particularly rich, were not compelled to look beyond it. Discovering this pattern in retrospect, they then let it guide their collecting further. With the exception of the artist Edna Lemyre, they have come to know (and frequently befriend) the artists in their collection. Their exposure to artworks through an ever-broadening circle of art connections and via public institutions is certainly reflected in the evolution of the collection; today the collection, which numbers roughly eighty to ninety works, is heavily photographic, but also includes mixed media works, etchings, and sketches. McKinven admits to an early distaste for photography, preferring oil paintings, until he became familiar with the work of Jennifer Dickson and Evergon.

In terms of content, Brown and McKinven are drawn to work that is figurative, or at least suggests a lingering human presence. Many of their works are humorous, or as Brown and McKinven like to describe it, "saucy,"23 and frequently contain unexpected juxtapositions. They describe many of the works as "difficult," in that they openly address themes of homoeroticism, bondage, and loneliness. Any work they purchased was work they had to respond to on a visceral rather than an intellectual level. Their lack of interest in the future commercial value of the works removed the pressure of making the 'right' investment choice.

\section{How They Collect}

Collecting from a city outside of a large centre of contemporary art production poses problems in maintaining an active acquisition schedule. For a collector such as 
Friday, building an extensive network comprised of curators, dealers, and critics is essential. ${ }^{24}$ Dealers and curators are heavily valued for the informed contexts they provide within which to look at contemporary art. Dealers keep him apprised of new work and new artists, but most importantly help him make good acquisition decisions. As Friday points out, "it is the best dealers who are careful to place work in the best possible collections." ${ }^{25}$ Friday holds Vancouver dealer Catriona Jeffries in the highest regard, someone with whom he can have a frank, open discussion about what he does or doesn't understand, what he does or does not like. She has worked with lan Wallace and Ken Lum, both artists in whose work he is very interested, and also works with the second generation of Vancouver photoconceptual artists such as Brian Jungen, Kelly Wood, Damian Moppett and Geoffrey Farmer. Jeffries has offered advice on work he was considering purchasing from dealers other than herself, and she is thrilled when he buys a piece that allows work he has bought through her to be seen in a new context or which contrasts and complements that work in a new way. Friday also works closely with Toronto dealers Susan Hobbs, as well as John Goodwin and Roger Bywater of Goodwater Gallery, whose approaches, he feels, tie in with the best in contemporary practice at an international level.

Attendance at art fairs is another essential tool for Friday, permitting exposure to a large number of dealers, the artists they represent, and what is being produced in the contemporary art world at the moment, all in a short period of time. Drawbacks include the pressure to buy quickly before the work is bought by someone else, which necessitates doing a lot of groundwork beforehand to establish a list of artists who may be of interest. 
The Internet also plays a large role in Friday's collecting strategy. He frequently visits gallery web sites to keep apprised of upcoming exhibitions, discovers new artists by looking at past exhibition lists, reading press releases, and looking at images of their work. He has bought work off of the Internet, sometimes sight unseen, having only read descriptions of the work (for example Fiona Banner's Arsewoman in Wonderland Black and Blue). In this respect, Friday fits neatly within the contours of a new generation of young collectors profiled by the March 2004 issue of ARTnews: "The current crop differentiates itself from previous generations by its financial sophistication, its enthusiasm bordering on obsession, and its full-bodied engagement with the arts scene...." ${ }^{26}$ Like Friday, the lives of these collectors revolve around art; they are highly educated, socialize actively in art circles, spend their time at biennials, are more familiar with emerging artists, collect in depth, and use the resources of the Internet heavily. ${ }^{27}$

Collecting from a large and vibrant centre of art production like Vancouver, Beck and Gruft's strong interest in local artists enables their collecting in ways not available to Friday, and decreases their dependance on the tools he uses most. They get to see a great deal of work in situ, rather than relying on reproduced images. These reproductions, frequently viewed on a computer, often give a false impression due to the backglow of the screen, and rarely accurately convey scale and detail of surface. Beck and Gruft do use the Internet to check prices, to determine which dealer is representing an artist they are interested in, or to look at artist's web sites, but used in this manner, the Internet - so important a tool for Friday - plays only a peripheral role in their collecting. 
Like Friday, they scour art books, magazines and catalogues regularly, and talk to people within the art community. Beck and Gruft have built up relationships with curators and dealers, though one gets the impression they rely on them less than Friday. They have ongoing dialogues with dealers Catriona Jeffries, Monte Clark, Susan Almrud of State Gallery, and Andy Sylvester of Equinox Gallery, all of whom work in Vancouver. These dealers show Gruft and Beck things as they come in, introduce them to new artists, provide background information, but ultimately their thirty years of experience bears more heavily on acquisition decisions. They too attend art fairs, though not as frequently as they would like. They have travelled often to Spain over the last fifteen years, and as a result were once guests of the ARCO fair in Madrid, which they subsequently attended two more times, along with fairs in Toronto. Beck has also attended Basel on her own. They also try to attend the bigger, more curated biennials such as Documenta, which they feel gives them a larger overview of what is happening in the contemporary art world than is possible by visiting a single city.

Beck and Gruft believe their strategy is somewhat 'looser' than those collectors who have begun acquiring work in the last ten years or so, buying works that appeal to them, that they think are good, and that are affordable. Collecting from a large city of art production means that they can easily adopt this 'loose' strategy, and still be exposed to a lot of work, including that from emerging artists. Friday does not have this luxury, and his strategy has been shaped accordingly.

In terms of acquisition decisions, Marks mentioned the importance of developing strong relationships with good galleries, who are interested in educating you as a collector 
and send you material to consider. He learns from these dealers, but points out he does not rely on them to make decisions for him. Galleries he has worked with include David Zwirner, Miriam Goodman, Sonnabend, Gagosian, Tanya Bonakdar, Jim Kempner, and Virginia Green, all located in New York City. In Toronto he has dealt with Clint Roenisch, Stephen Bulger, and Paul Petro.

Marks attends art fairs (but never as a speaker or a special guest as Friday has), usually two a year in addition to the Toronto International Art Fair, though concedes it is unlikely he will actually make a purchase there. He attends them for the opportunities they afford to make contacts, let dealers know he is a serious collector, and obtain further information. Since he, like Beck and Gruft, lives in a large centre of art production where there are numerous galleries and practising artists, art fairs are not intrinsic to his purchasing. Nor does Marks use the Internet to collect, aside from receiving digital images of works from dealers that he has already made contact with. He needs to see a work of art "in the flesh" before buying. He is the only collector mentioned in this study who has done very much reading on collecting itself, and has amassed some books on important collections throughout history, finding it interesting to see what great museums have put together.

Brown and McKinven have built up their collection in a variety of ways. They have bought works both outright and through installment plans, and have received many of the pieces as gifts from the artists, or in exchange for services. They have relied little on the expertise of dealers, curators, or critics to expand their collection, opting instead to rely predominantly on the personal and direct friendships they have developed with local 
artists. The exception to this would be Victoria Henry, owner of the now defunct Ufundi Gallery (1975-1992). They have bought the most work from the Ufundi, and Henry led them to discover many new local artists, such as Mark Marsters. Due to the closely-knit local art community of the 1970s and 1980s, artists often introduced them to other artists. Also, because they relied little on commercial dealers, they met with few obstacles in the early days. In other larger centres of art production, like Toronto or Montreal, it can sometimes be difficult for new collectors to establish relationships with dealers, who frequently sell only to clients who have already proven themselves to be committed, knowledgeable and astute collectors. Neither are Brown and McKinven interested in attending art fairs, McKinven being particularly turned off by his sense of the air of snobbery and competition.

\section{Relationships With Artists}

Friday considers his primary relationship to be with the works of art themselves, but he relies heavily on the dealer or gallerist to mediate between himself and the artist. Unlike many collectors who cultivate relationships with artists and take on the role of patron, ${ }^{28}$ Friday prefers to maintain a distance from artists, feeling any need for communication is fulfilled by the art work itself. ${ }^{29}$ Though he has become acquainted with many of the artists he collects (and has had quite a few over for dinner), Friday realizes it is carefully negotiated terrain, easily compromised by commerce. He is not interested in having an artist come to explain his/her work to him, or thank him for buying it, nor does he want to be put in a position where he feels that he has to flatter them. ${ }^{30}$ In some ways, collecting from a "small art centre" city such as Ottawa can be beneficial. As Friday 
enumerates, he does not get caught up in the pressures of a local art scene, there is little competition from other collectors, and he is not influenced by short-term trends. Indeed, it may be that his arm's length position allows him to make more deliberate and informed choices.

Unlike Friday, Beck and Gruft do not shy away from developing relationships with the artists they collect. They make studio visits on a regular basis, and in some cases these relationships have developed into intimate friendships. These artists visit their home frequently, and do comment on their own work, but are never critical of where, or with which other works their own works are hung. They are just pleased to see their work. Outside of purchasing an artist's work, Beck and Gruft have developed no system that guarantees an artist support; they have never commissioned a work of art, nor have they loaned an artist money in return for work, although they have been given pieces. This approach ensures, they hope, that friendships will not be compromised.

Marks doesn't mind meeting and talking with artists, but most times he would rather not meet with them, wishing instead to make his own conclusions about their work. $\mathrm{He}$ is the only collector here to find himself in the role of patron. He pays Toronto artist Kelly Mark yearly for the time she devotes to her art practice. The conceptual piece, entitled In \& Out, has her punching a time clock to keep track. Every January, Marks pays her a wage based on the accumulated time cards. ${ }^{31}$ When asked to elaborate on how this relationship came about, Marks replied he would rather not discuss a specific artist. ${ }^{32}$ When asked if there were other special relationships he had cultivated that play a role in 
his collecting, he replied that "I would say only that of other collectors."

Brown and McKinven's collection is all about relationships, and they have made intense, lasting friendships with artists Evergon and Jane Martin, for example. Brown first connected to Jane Martin; McKinven to Robert Houle. He and Houle socialised, and his first serious art purchase was from Houle. Early in their relationship, Brown introduced McKinven to Martin, at a sale of her work. Brown and McKinven have since become particularly close to other artists whose work is represented in their collection, including Jennifer Dickson, Evergon, Myriam Laplante, and Leslie Reid. ${ }^{34}$

\section{Going Public}

When asked if he thought his collecting choices have any impact on museums or galleries (for example the National Gallery of Canada), Friday concedes that he is not buying at a level that will make institutions notice, although he can think of some individual purchases that were also being considered by larger institutions, among them Geoffrey Farmer's Puppet Kit (2001)(Fig. 13) by the Art Gallery of Ontario. He firmly believes that curators should be talking to collectors, particularly one such as himself, as he is very knowledgeable about current art practice. "Canadian art institutions should be adding the best of international contemporary art to their collections," ${ }^{, 35}$ and he has no qualms about making his views known to a gallery regarding a possible purchase.

Friday has built up a reputation as a collector of some renown locally, nationally, and on the international scene. He has been invited to the Berlin Art Fair for the last five consecutive years to participate in a special program for collectors, organized by the fair administrators. In October 2003, he was also asked to speak on a private collecting panel, 
composed of two Berliners and two other Canadians, as part of the fair's focus on Canada. Kitty Scott (former Curator, National Gallery of Canada), Germaine Koh (artist and independent curator), Wayne Baerwaldt (Director, The Power Plant Contemporary Art Gallery), and Daina Augaitis (Chief Curator, Vancouver Art Gallery) also spoke on a separate panel. In November 2003 he was an invitee to the Artissima art fair in Turin, Italy, and spoke at the 2003 Toronto International Art Fair on personal, private, and public collecting, and was interviewed that same November by CBC's Eleanor Wachtel for "The Arts Today." He has been a member of the Carleton University Art Gallery board since 1993 and is currently the chair, and was also on the board of the Ottawa School of Art from 1991-1993.

His interest in creating a public discourse around his collecting is a fairly recent development, spurred by his desire to demonstrate to others that you don't have to be wealthy to indulge a passion for contemporary art. ${ }^{36} \mathrm{He}$ is surprised and gratified to know that people find what he has to say both interesting and useful, though he is not at all interested in telling people what to buy or think, and avoids explaining an artist's work, or writing about it as a curator would. Confidence is a key issue here; instilling confidence in others to collect contemporary art, while at the same time increasing his own confidence in what he is doing. At this point in time he feels very comfortable with the work he is presently considering buying, and is certain that this is work he should be looking at. Candidly, however, he admits that he would never have agreed to interviews for this thesis five years ago, and concedes he stills feels overwhelmed and intimidated when he attends art fairs. ${ }^{37}$ He has come to terms with this, aware that it is part of the process to reach a 
confident place, and also a characteristic of contemporary art in general. Many people are intimidated by art, galleries, and dealers, and think they should have all the answers. In contrast, Friday believes you should go in with questions.

People often wonder about the attribution statement on the labels of works Friday lends to institutions. Do they indicate an anonymous donor? Friday in fact clearly indicates his name, and his place of residence as Ottawa, Canada. He wants it known that people in Ottawa do collect contemporary art, despite the fact it is not a collecting centre, and that art should be part of everyone's existence. Many of the pieces he collects are by artists who would otherwise not be seen in Ottawa, sometimes even in Canada. There is not a lot of Michael Elmgreen and Ingar Dragset (Powerless Structure Fig. 176 (2001))(Fig. 14) or Kirsten Pieroth (Untitled (2003)) in Canadian collections, and his will be the only collection in the country with a Richard Hughes piece (Crust (2003)). Though there are other collectors of contemporary art in Canada, many of whom collect on a grander scale than him (for example foundation owner and curator Ydessa Hendeles), he does not think of Canada as having a collecting culture, especially of contemporary art (though he is optimistic that this will change).

Friday is fascinated with people's reactions to his collection. He likes to interact with curators such as Kitty Scott and Diana Nemiroff, Director of the Carleton University Art Gallery, and Renee Baert (formerly with the Ottawa Art Gallery, and the Saidye Bronfman Centre for the Arts) and is interested in how people with and without strong informed backgrounds interpret his collection. He is intrigued when people inquire as to why he has made certain purchases, and is willing to put up a fight to explain what he is 
and is not interested in. He is pleased when people approach his collection with an open mind, are curious about why they are interested in certain pieces, or even ask for help in interpreting them. ${ }^{38} \mathrm{He}$ abhors people who make no attempt to understand, and react with the blanket statement that something is 'ugly.' Friday concedes that conceptual art takes work to understand and appreciate, but the return on the investment, he assures, is immense. In this respect, Friday's collection is fulfilling a dual role; it offers a concrete device by which others can judge him, but it also allows him to make assumptions about those who are viewing it, with the collector's ability to reveal the "inquisitiveness and intellectual curiosity"39 of the viewer. As Baekeland suggests, such strategies can also be interpreted in terms of a narcissistic satisfaction generated by an unconscious desire to make an audience feel the same emotions the collector feels when looking at the collection. $^{40}$

When asked if he feels his collecting has changed since 'going public,' Friday replied that

...talking about my collecting has allowed me to focus more intently on my own goals, motivations and practices, which is a good thing. I think it has made me see that there is a role for collecting at a number of levels of engagement, and that the personal commitment over time is what makes a collection and a collector. ${ }^{41}$

Just recently, while considering a new acquisition, he was seriously questioning what he wants to get out of this ongoing commitment

...other than a house full of art objects. What I actually am distracted by these days is the notion of selling or donating a LOT of work and then using my knowledge and experience to try a different form of collecting, perhaps focussing on a single artist or small group of artists, or even a single medium, hoping to achieve some tightly focussed study. I am getting 
tired of being the 'Ottawa' collector, whose activities are looked at in contrast to those of collectors in other locations, and think it might be interesting to use the act of collecting in a more study-oriented or academic way. I guess what I'm thinking is that anyone can listen to a curator or read reviews and collect, and what happens is that a lot of collections look the same, with all the same name-brand artists. While I hope my collection is not such a beast, and while I have endeavoured to give it some unique texture and rhythm, part of me wishes to pursue that impulse or idea further, all of this may point to my desire to burrow back down into the comfort of anonymity, after a relatively (at least for me) public period (including the upcoming Canadian Art profile for which I was photographed last week), and a need to focus on the pleasure and satisfaction that I derive from collecting, far from the critical eye of anyone else. $^{42}$

Up until Beck and Gruft's donation of roughly four hundred and fifty pieces to the Vancouver Art Gallery in the Winter of 2005, as well as their participation in VAG's Vancouver Collects show in the Fall of 2001, their collecting has been primarily only known to the small Canadian art community. As Beck pointed out, both she and Gruft have always tried to remain discreet about their collecting. Since their donation, and the accompanying exhibition and catalogue Real Pictures: Photographs from the Collection of Claudia Beck and Andrew Gruft, January 29 - May 29, 2005, their reputation has most certainly spread beyond this circumscribed aforementioned art community to include members of the general public. They have done a few speaking engagements in conjunction with the two exhibitions, ${ }^{43}$ were part of the Canada's Top Collectors series written by Deborah Campbell for the Spring 2004 issue of Canadian Art magazine, and their donation has been the subject of several radio, television and newspaper articles. When asked if all of this attention has become unwieldy, Beck answered in the negative, 
thanks in part to the superficial and fleeting manner in which popular and mass media tend to treat such topics.

Beck and Gruft's decision to donate to the Vancouver Art Gallery was facilitated by their relationship with the gallery's Director, Kathleen Bartels, which grew out of the Vancouver Collects exhibition. Bartels was one of the first to find their collection interesting, particularly its intersection with the city of Vancouver as place, and the direction VAG was taking. ${ }^{44}$ They feel their gift gives a larger context for work being done in Vancouver contemporaneously, and also sets an example for other collectors and philanthropists to support local and national institutions, who require patronage above and beyond what is available to them through government grants. This setting of an example is also a motivating force in Friday's interest in taking his collecting public. Beyond that, Beck and Gruft simply felt it was time to let the collection go and have another life. As to what new directions their collecting may take, they are currently in a moment of pause, due in part by the fact they are still overwhelmed by their gift. They do however doubt any new direction they take will be away from photographs; there are still some nineteenth century gaps in the collection Beck would like to fill.

Like Friday, Beck has also participated on the boards and committees of several local institutions, including the Vancouver Art Gallery, and the Contemporary Art Gallery. Both she and Gruft think of the Vancouver art community as a large extended family, and because of this feel it is important to give of their time, either by sitting on boards or participating in fundraising initiatives. When asked if any of these institutions play a role in their collecting, beyond being venues where they can see new work, the response was 
that they do not collect with a specific institution in mind, and nor have they been asked to. They agree that their collecting has had a public impact, as in the case of the VAG donation, as well as an impact on the art market, particularly in the case of emerging artists where purchase prices can set a bar for a dealer or an auction house. Nevertheless, like Friday, they feel their collecting does not have the impact exerted by someone like Ydessa Hendeles. As Beck stated, "She's a one of a kind in that way.",45

Marks has also extended his local networks to include public institutions: he has sat on the boards of the Power Plant Gallery, the Art Gallery of Ontario and the Art Gallery of York University, and joined the AGO's Master Print and Drawing Society as a young collector. Though he denies that any public institutions have played a role in his collecting, he does admit that he has made purchases with the thought of gifting them, in particular to the AGO. As a result of this he communicates with the curators and the Director. He was also among the collectors profiled by Canadian Art magazine. Overall, however, his collection has received little press, and he prefers to leave it to others to say whether or not he is becoming known as a collector. He certainly does not collect to be known. ${ }^{46}$

Brown and Mckinven, who visit public art institutions purely for educational purposes and to enjoy the work, feel that there is no direct relationship between these institutions and their collection. Except for the support they provide the artists they choose to acquire, these collectors see their collection as private, and of limited outside influence. Their collection can be considered a reflection of their identification with a particular social milieu, that of Ottawa's vibrant art scene of the 1970s and 1980s. Many of the 
artists in their collection worked together and were close friends, and a complex network of links can be drawn between the artists and collectors, which bypassed the conventional institutional networks (i.e. commercial dealers, curators, critics). They have chosen to donate parts of their collection to the Carleton University Art Gallery, and in the Fall of 2004 I curated the exhibition Going Public: Two Local Collections at the Carleton University Art Gallery. Works were selected from the Brown/McKinven collection as well as from the collection of local gallerist Pierre Luc St. Laurent, so there has been some local exposure to their collecting activities.

\section{The Private Realm}

Living with his art collection is of paramount importance to Friday. His home does not have the cold, sterile atmosphere of a gallery, nor the works themselves that of rarefied objects. ${ }^{47}$ His collection sprawls throughout the house and pieces can be found in every nook and cranny, so much so that it can be easy to miss a work, or mistake an everyday object for a piece of art (or vice versa). ${ }^{48}$ There is an obvious element of play at work; he believes it is important to have pieces in his collection that are not untouchable, serious works, an approach he considers intrinsic towards building an environment wherein art is a fundamental feature. His collecting of multiples, for example Allan McCollum's Visible Markers (1997-2002)(Fig. 15), and Kelly Mark's Dirty Rice Bowl (2002)(Fig. 16), fulfills an interest in art that is emblematic of an interesting conceptual practice. This also explains his attraction to the works of artists such as Germaine Koh, her Signs series of 1997-2001 (One Begins (2001))(Fig. 17), and Ian Wallace's My Heroes in the Street (Sarah: Heroes in the Street) series, works which are grounded in day-to-day lived life, 
and "resuscitate meaning from those daily things to which we give no thought." ${ }^{, 49}$ Much of the work found in his collection belongs to a genre that is of interest to institutions, but not necessarily to private collectors. This is not work that everyone could live with.

Guidelines for hanging work in institutional settings are completely different from domestic settings; this change in context offers a different way of looking at the work, influenced by an intimate setting, rather than the often antiseptic one of a gallery or museum. "Collecting also implies a kind of wrenching - knowing that an object significant in a particular realm can gain a different significance when placed in another realm." ${ }^{50}$ But this is not a typical domestic setting. Friday's home is one of only four in Ottawa that has received heritage designation both inside and out, thanks in part to the ornate plasterwork ceiling in the living room. This juxtaposition of heritage interior and contemporary art is surprisingly successful, particularly the placement of Spring Hurlbut's Artemis (1990)(Fig. 18) in the living room, which allows the classical capital of the column to engage in an interesting dialogue with the plasterwork (Fig. 19).

Friday enjoys the role of curator, moving things around, testing out the new connections formed by the work's proximity to each other. In contrast to his speaking engagements, this is a private discourse Friday constructs. While on the one hand he enjoys opening his home to others, and seeing how they react to his collection, on the other he is also his own private audience of one, and admits to having developed personal relationships with the pieces. In effect, Friday has constructed a miniature museum, or gallery. ${ }^{51}$

When asked if he considers his collecting to be an obsession, Friday readily 
agreed. "Part of every day, at some level, is involved in looking at and thinking about contemporary art." 52 As fellow collector Claudia Beck points out, "expert knowledge is important to collecting." ${ }^{93}$ Friday's daily mail delivery frequently includes invitations to gallery openings, art fairs, and art magazine subscriptions; he browses the Internet daily and is constantly reading exhibition catalogues. He is always in negotiation with various dealers to purchase work. Art is not simply a luxury, it is a necessity.

Friday sees collecting contemporary art as different from collecting other kinds of art or objects. He believes it takes courage to buy and display art, but contemporary art in particular. Historical art has already been judged and carries with it an authoritative weight. "When you buy a piece of contemporary art, however, you are buying something against which you yourself can be judged." ${ }^{, 54}$ Collecting jewellery is one thing, but much of the work in the Friday collection can be considered aggressive in scope because of its size and subject matter (for example Ken Lum's Untitled Language Painting, and Bronson's Felix Partz, June 5, 1994 (1999)(Fig. 20)) - this is not a collection that can be discreetly tucked away. Nor does he want to tuck anything away. Collecting contemporary art is about engaging in the times in which we live, and

...exists at that point where emotion and intellect either intersect or collide, but are no longer two different things. There is a wonderful balancing point; you don't want it to tip over into mawkish, maudlin emotion, and you don't want it to be completely bloodless, or intellectual either. ${ }^{55}$

Beck and Gruft's collection has grown to include over six hundred works, and like Friday, they admit to being obsessed with collecting, and collecting more than they can 
afford. Since much of the collection is photographic in nature, it is stored matted in print drawers and solander cases. Larger works are in stacks or stored and leaned against walls. With the exception of work produced in the last twenty years or so, photographs do not take up a lot of room. Due to this, space constraints were not factors in their decision to donate such a large portion of their collection to the VAG. They live in a large, early twentieth century house, with many windows to take advantage of the views, and as Beck describes it, work is "displayed in very small portion in the rooms of their house, in a normal way. It doesn't look like there is an art collection on view; it doesn't look like Marks' or Friday's home's." ${ }^{96}$ Work is rotated frequently to ensure conservation, and carefully hung.

They too think of contemporary art as a unique category of collecting. As it is of our time, they have more connections to what is happening within art and within our larger culture. It is possible to have contact with the producer of this art, to have a conversation with them, to watch them work. Collecting historical art requires a reconstruction of the context in which it was produced. Not that this makes collecting contemporary art easier; in fact Beck thinks it is more difficult because the risk is greater, you are taking a chance that what you buy will be significant.

Like Friday, Marks likes to find interesting relationships between the works in his collection by putting certain pieces into juxtaposition. He is unique amongst the collectors in that an art gallery-type area was built in his new house in order to create installations and explore connections between works. And like all the collectors he admits to being obsessed: "Obsession, passion, hobby all seem to fit. The final psychological diagnosis is 
not yet determined." 57

Prior to the donation to CUAG, the entirety of the Brown/McKinven collection was found within their home, though sometimes stored in closets and under beds. They like to move works around as well, experimenting with new juxtapositions. A recent repainting of the living room, which used to be filled entirely with Jane Martin's work, provoked such a shift; the room now also contains the work of Evergon, Danny Hussey, and Eliza Griffiths. The apartment, built in 1930 in the Art Deco style, is a draw to artists and friends, who like to see their work hanging in the unique, colourful space, replete with period detail and decorative paint techniques and finishes, such as trompe l'oeil, ragging, marbling, and faux wood grain.

Brown and McKinven no longer think of themselves as obsessed with collecting as they once did, but as having a strong interest, and admit they could stop today. In their heyday, during the 1980s and early 1990s, it was not unusual to buy a new piece every month, and they could not attend an exhibition and leave empty-handed. Nowadays they buy perhaps one piece a year, and can attend a show, admire the work, but not feel the compulsion to buy. Their collection gives them a lot of personal enjoyment, and has greatly enriched their relationship, since the bulk of it was amassed together.

Collecting is a competitive activity. With the exception of Brown and McKinven, all of the collectors discussed had heard of each other, read Canadian Art's collector profiles, and had frequently met each other, and other collectors, as well. As Beck described it, discretion is essential considering the fragile ecology of the art community. ${ }^{58}$ 
How you are ranked amongst dealers is important, and it can be frustrating to see if a dealer will sell to you, rather than to another collector, or if you can get on the waiting list for a piece. Beck believes young collectors may have a harder time building up credible reputations these days, particularly as they seem to be judged more on their first moves. Despite this competitive atmosphere, Beck does have contact with other collectors, and will be less discrete if she knows one may be helpful to her concerning an acquisition. Marks believes Canadian collectors are more thoughtful than most, are not trying to complete checklists of important works, and as such have garnered more respect from dealers. ${ }^{59}$ Even though there may be overlaps amongst the better-known collections in this country, he feels they each have their own flavour. It is clearly apparent from this discussion that these collections are all unique, from the type of art the collectors are motivated to buy to the strategies they employ to make their acquisitions. Beck and Gruft, and Marks, collecting from large cities of art production, rely less on the Internet and on art fairs to make acquisitions. The art that interests them is easily accessible in person, via galleries and studio tours. Brown and McKinven, even though they live in a small city of art production, have chosen to focus on work that is locally available, frequently through personal relationships they have cultivated with the artists. Friday, conversely, now looks beyond what is locally available and has adopted effective strategies that have allowed him to expand the scope of his collecting. In so doing, he has amassed a thoughtful collection that successfully negotiates his city of residence as well as the international art world. 
1. Walter Benjamin, "Unpacking My Library: A Talk About Collecting," in Selected Writings 1927-34, v. 2., eds. Michael W. Jennings, Howard Eiland, and Gary Smith (Cambridge, Mass.: Belknap Press, 1999), 492.

2. Joe Friday, interview with the author, 19 February 2004.

3. It should be noted that while this exhibit provoked all these feelings in Friday, it did not provoke disapproval.

4. Joe Friday and Catriona Jeffries, interview with Eleanor Wachtel, The Arts Today, CBC Radio. 18 November 2003.

5. Frederick Baekeland, "Psychological Aspects of Art Collecting," Psychiatry 44 (February 1981): 48.

6. Claudia Beck, "The Chaos of Memories: Some Personal Remarks about Collecting Photographs," in Vancouver Collects (Vancouver: Vancouver Art Gallery, 2001), 92.

7. There may very well be an element of luck involved, but the amount of research Friday conducts and the deliberation involved in any purchase, strongly points to shrewd decision-making.

8. Friday, interview with the author, 19 February 2004.

9. Friday did not set out to 'collect' per se, nor did he have a strategy or a model. "I have certainly watched other people buying work at the same time I am, and I am always interested in knowing what others are buying (and sometimes feeling pressured to follow suit in the heat of the competitive atmosphere that sometimes characterizes the collector's world), but I don't have a model. For this, I am glad. It has allowed me, I think to work out ideas, approaches and goals on my own, without feeling the need to follow or distinguish myself from anyone else whose influence I was trying either to acknowledge or escape." Joe Friday, email correspondence to author, 20 April 2004.

10. Baekeland, 49.

11. Friday, interview with the author, 19 February 2004.

12. Friday, interview with the author, 19 February 2004.

13. Claudia Beck and Andrew Gruft, interview with the author, 15 February 2005.

14. Ibid.

15. Ibid.

16. Ibid.

17. Paul Marks, interview with the author, 13 April 2005.

18. Ibid.

19. Ibid. 
20. Paul Marks, written communication with the author, 29 May 2005.

21. Deborah Campbell, "Paul Marks: The Collector in the Age of Mechanical Reproduction," Canadian Art 21.3 (Fall 2004): 120.

22. Russell W. Belk remarks on how many collections have incidental or accidental starts. Many are begun by gifts or other serendipitous discoveries of items. Russell W. Belk, "Collectors and Collecting," in Interpreting Objects and Collections, ed. Susan M. Pearce (New York: Routledge, 1994), 318.

23. Bill Brown and John McKinven, interview with the author, 18 March 2005.

24. For example, Friday has made contacts in galleries in Toronto and Vancouver, as well as New York, London, Copenhagen, and Berlin.

25. Friday, interview with the author, 19 February 2004.

26. Michelle Falkenstein, "Waiting for an A+ Picture," ARTnews 103.3 (March 2004): 108.

27. Ibid.

28. Baekeland, 57.

29. Even though Friday is adamant about the marginal role aesthetics play in his collecting, it can be argued that his lack of connection to the artist as well as to the process of art creates a highly aestheticised environment.

30. Interestingly enough, when artists have been to his home, it is usually the work of other artists in the collection that they want to discuss. Friday, interview with the author, 19 February 2004.

31. Campbell, "Paul Marks," 120.

32. Marks, written communication with the author, 29 May 2005.

33. Ibid.

34. There have been many documented instances of well-known collectors developing strong friendships with the artists they collected. Betty Kronsky describes the friendship that developed between Pablo Picasso and writer and collector Gertrude Stein, memorialised in Picasso's portrait of Stein, and Stein's verbal portraits of Picasso. Betty Kronsky, "The Psychology of Art," American Artist 49.510 (January 1985): 16, 96-98.

35. Friday, interview with the author, 19 February 2004.

36. Even though Friday's wealth falls short of that of collectors such as Ydessa Hendeles or Ken Thompson, he is a lawyer, and is certainly more comfortable than most Canadians.

37. This is an interesting contrast with the international acclaim and acknowledgement he has received. There is an intriguing dialectic at work here: he has gained the confidence to participate in speaking engagements, as well as give advice to curators at the National Gallery of Canada, but while in conversation with him, I was struck by his modesty and his tendency to be self-deprecating. Also, one can't help but feel his ambivalence towards the public turn his collecting has taken. 
38. This is in contrast to his previous statement that he does not like to interpret the work of artists, feeling it is better left to curators and art historians.

39. Friday, interview with the author, 19 February 2004.

40. Baekeland, 56.

41. Friday, email correspondence with the author, 20 April 2004.

42. Ibid.

43. Beck, whose background is in Art History, taught at the University of British Columbia when she first moved to Canada from the United States. Nowadays, she occasionally gives lectures at UBC and the Emily Carr Institute of Art and Design on contemporary photographic art. She has also written about their collection in the catalogues for Vancouver Collects and Real Pictures. Andrew Gruft, an architect, also taught at UBC.

44. Beck and Gruft, interview with the author, 15 February 2005.

45. Ibid.

46. Marks, written communication with the author, 29 May 2005.

47. This is in striking contrast to the private collections included in the Musée d'Art moderne de la Ville de Paris' exhibition Passions Privées: Collections particulières d'art moderne et contemporain en France. In situ photographs of the collections were included in the catalogue, and despite being of domestic settings, many of the collectors followed the hanging and display conventions of galleries and museums. Musée d'Art Moderne de la Ville de Paris, Passions Privées: collections particulières d'art moderne et contemporain en France (Paris: Musée d'Art Moderne de la Ville de Paris, 1995).

48. Friday has begun to purchase pieces that cannot be displayed in his home due to lack of space. This collecting without regard to space constraints will undoubtedly have an impact on the collection, and change its meaning.

49. Germaine Koh, lecture, University of Ottawa, Ottawa, 20 January 2004.

50. Beck, 93 .

51. Miniaturization, according to Susan Stewart, has the ability to abstract the mirror into microcosm, and "presents the desiring subject with an illusion of mastery, of time into space and heterogeneity into order." Miniature time transcends the duration of everyday life, and creates an interior temporality of the subject. Particularly relevant to Friday is the notion of miniaturized objects representing a particular form of interiority, a form of interiority Stewart suggests the subject experiences as a sanctuary: a sanctuary Friday is becoming more and more willing to reveal. Susan Stewart, On Longing: Narratives of the Miniature, the Gigantic, the Souvenir, the Collection (Baltimore: Johns Hopkins University Press, c1984), 172, 66, 65.

52. Friday, interview with the author, 19 February 2004.

53. Beck, 91.

54. Friday, interview with the author, 19 February 2004. 
55. Ibid.

56. Beck and Gruft, interview with the author, 15 February 2005.

57. Marks, interview with the author, 13 April 2005.

58. Beck and Gruft, interview with the author, 15 February 2005.

59. Marks, interview with the author, 13 April 2005. 


\section{CHAPTER TWO: Friday and Bourdieu}

Serious collectors need a work to fulfill a picture of their idea of what art is about right now. There are collectors who buy art to cover wall space or because they happen to like this, that or the other, but the really serious collector participates in the production of the work, which is about a certain social and cultural concept of how we create images that represent the world around us. The collector participates in what it is to have something to say about our culture. ${ }^{1}$

The collecting of objects, be they works of art, kitsch, fetishes or articles of every day use, occurs within the framework of the collector's social context and cultural environment. Collectors are constrained by the availability of objects on the open market, access to which can be further limited by the city from which they collect. A collector such as Friday, who started collecting locally but has since expanded his interests to the artists of Europe and beyond, must employ strategies different from those of collectors who find themselves living in centres of considerable art production. ${ }^{2}$ More significantly, it is the development of extensive social networks (in tandem with Friday's exhaustive personal research) which has contributed to his success as a collector. A desire to better understand this sphere, as well as the social logic underlying Friday's practices, led me to the work of French sociologist Pierre Bourdieu, whose attempts to theorise social practice take into account not only the behaviour of agents, but also the social arenas in which their behaviour is expressed and the impact of institutions on this behaviour. ${ }^{3}$

Bourdieu's theoretical framework sheds new light on some of the seemingly paradoxical aspects of Friday's collecting, notably his relationships with artists, and his willingness to allow his private collection to become increasingly public. This raises the 
question of what audience Friday is collecting for. Bourdieu's concepts of habitus, capital and field shape the focus of my project, though I do not intend a full Bourdieusian analysis. ${ }^{4}$ These key concepts open up new understanding of Friday's collecting practices.

\section{Friday's Habitus}

Pierre Bourdieu defines habitus as

...systems of durable, transposable dispositions, structured structures predisposed to function as structuring structures, that is, as principles which generate and organize practices and representations that can be objectively adapted to their outcomes without presupposing a conscious aiming at ends or an express mastery of the operations necessary in order to attain them. Objectively 'regulated' and 'regular' without being in any way the product of obedience to rules, they can be collectively orchestrated without being the product of the organizing action of a conductor. ${ }^{5}$

The habitus is characterised by durability, the capacity to influence agents' behaviour in ways that are not calculated and may be unconscious while allowing for improvisation, ${ }^{6}$ transposability to diverse fields of activity, and its reality as a product of historical antecedents. ${ }^{7}$ Habitus is the result of a long process of inculcation, beginning in early childhood, which becomes a 'second sense' or a second nature; ${ }^{8}$ in short, our social background and upbringing profoundly impact our ways of seeing and doing in the world. This influence extends to the things with which we choose to surround ourselves. As Bourdieu demonstrates in Distinction, systematicity is present in our choice in houses, food, furniture, paintings, books, cars, clothes and in the practices in which they manifest their distinction, such as sports, games, and entertainments, "only because it is in the synthetic unity of the habitus, the unifying, generative principle of all practices." The word lifestyle comes to mind, a term Bourdieu uses in tandem with taste. He defines taste 
as "the propensity and capacity to appropriate (materially or symbolically) a given class of classified, classifying objects or practices..." Nothing could provide clearer evidence of this than Friday's house, which is not simply a repository for his collection, but is in effect a Gesamtkunstwerk, whereby all elements have been carefully chosen in accordance with precepts of 'good taste.'

Habitus profoundly impacts one's relationship with culture. Distinction states that cultural needs are the product of upbringing and education, though the influence of social origin is strongest in 'extra-curricular' and avant-garde culture. ${ }^{11}$ Bourdieu stresses that a "work of art only has meaning for someone who holds the cultural competence, or code, in which it was encoded."12 This "internalised code called culture functions as cultural capital owing to the fact that, being unequally distributed, it secures profits of distinction."13 Furthermore, Bourdieu sees the need for distinction as basic to social identity: we constantly seek ways to distinguish ourselves from others both within and beyond our communities of identity (one need look no further than this thesis for an example) ${ }^{14}$ In Bourdieu's terms, Friday holds the code for interpreting works of art, and has refined that code further to include the collecting of art, and in so doing, to distinguish himself from other collectors. What kind of habitus was he born into, and what other dispositions and structures has he encountered that have informed his cultural competence?

I wish also to refer to Bourdieu's use of the word 'synthetic' in discussing the habitus. According to Webb et al., the most crucial aspect of the habitus is that it naturalises itself and its attendant cultural rules, agendas and values. ${ }^{15}$ The habitus is an 
entirely arbitrary construction, and there is nothing natural or essential about the values we hold, the desires we pursue, or the practices in which we engage. ${ }^{16}$ It is in the best interest of the agents of the field of cultural production to maintain these constructions, for it ensures that the balance of power remains with them.

There is evidence of the importance Bourdieu assigns to the habitus as a predictor of interest in arts and culture (and even taste in clothing and home decor) in Friday's case, however there is a need to adapt Bourdieu's theories to a Canadian context. Canada does not share the lengthy political or cultural history of Bourdieu's native France. Nor does it have the same history of immigration, which plays a large role not only in Friday's heritage, but also for the majority of Canadians. Bourdieu's rigid division of classes into working, middle ("petit bourgeoisie") and upper class ("bourgeoisie"), and his further stratification of the classes into "new petit bourgeoisie," "new bourgeoisie," "executant petit bourgeoisie," etc., can be sometimes confusing (at least to this Canadian). While I don't deny that there exists in Canada a similar social stratification of working, middle and upper class, I would argue that there is a fluidity and permeability between these classes in Canada that was perhaps not present in France at the time Distinction was originally published (1979).

Friday was brought up in a home where art and culture were celebrated and valued, and music in particular. In e-mail correspondence, he has described how his maternal grandfather, an immigrant from Czechoslovakia, worked the port docks of Thunder Bay by day, but by night was a master fiddler and leader of a lively band. Friday's mother is a talented pianist, and many of her siblings and their children became musicians (both 
professional and amateur); there is also a cousin who was a professional dancer. Friday himself took piano lessons as a child, as did his sister. Though visual arts were not a particular focus, Friday grew up in a family where there was a generally supportive environment for any interest in the arts. ${ }^{17}$

Friday's father, a master brewer, worked for the Doran Brewery (now part of Carling-O'Keefe) in Thunder Bay for a number of years, where Friday was born. He later relocated his family to Timmins to work for the same company. While there Friday's father created a beer by the name of Edelbrau, a popular beer which can still be purchased today, indicating he identified an enduring market and 'taste.' When Friday was twelve years old, his father suffered a fatal heart attack. His mother, reluctant to move back to Thunder Bay where she still had family, re-entered the workforce after an absence of sixteen years in order to support her three children, and not uproot them from home and school. Friday believes she was the first female millwright in Timmins, ${ }^{18}$ hired by the town's largest mining company, from which she retired in 1998. One can only imagine how difficult it must have been breaking gender barriers as she did.

Bourdieu considered a father's occupation to be an indicator of social origin: $;{ }^{19}$ in this light, Friday's father's work as an artisan ${ }^{20}$ would place Friday firmly in the middle class (Bourdieu located intellectuals within the dominated fraction of the dominant class, except when the cultural practices in question comprise what is referred to as 'folklore.' I would argue that Bourdieu would see artisans as falling within the folklore category). ${ }^{21}$ This social categorization would have been maintained by his mother, also a skilled craftsperson, who in effect stepped into his father's shoes. But what would Bourdieu make 
of Friday's grandfather? His occupation as a longshoreman would identify him as lower working class, but his music practices would situate him within the upper classes. Furthermore, his legal and social status as an immigrant could have meant only certain occupations would have been open to him, due either to issues of language, or Canada's failure to recognise accreditation and education from foreign countries. Friday's grandfather, in fact, came to Canada as a young, uneducated man, part of the early twentieth century wave of immigrants seeking a new life in a land of opportunity. Friday's understanding is that

...he worked at what was available by day and pursued his love of music at home and also professionally. ...he also had 11 children with my grandmother, 9 of whom made it to adulthood. So, he had his hands full, to say the least. I don't think he was actively denied anything, but rather that he was representative of the immigrant experience in the early twentieth century in Canada. ${ }^{22}$

It is in such a situation as this that the rigidity of Bourdieu's classificatory schemes becomes very apparent, breaking apart as it fails to take into account contextual (i.e. Canadian immigrant) realities.

Friday's hobbies as a child included the aforementioned piano lessons as well as singing in the school choir. He also skied, joined the boy scouts, and was an altar boy, fairly typical of middle-class Canadian backgrounds. Friday was also, and still is, an avid reader. This has had a profound influence on his collecting in terms of his willingness to constantly educate himself and seek out new artists and works of art. He was educated in Catholic schools, even paying his own tuition during his last years of high school. ${ }^{23} \mathrm{His}$ graduating class was small (twenty students), and as the school's focus was strongly 
academic, all but two went on to post-secondary education. In addition to Friday, three of his classmates also went on to study law.

What is perhaps most indicative of Friday's burgeoning interest in the arts were his actions when opportunity brought him to New York, a key center of the art world, on a class field trip in high school. While there, Friday insisted upon securing tickets to Sweeney Todd (then the hottest show on Broadway) and reservations post-show at Sardi's - pretty sophisticated for a teenager from the small, blue-collar town of Timmins. He even snuck out of the hotel while chaperones and classmates were having a nap, to go shopping on his own, returning with a silk Yves St. Laurent blazer that he wore that night to the theatre and dinner. As Friday admits, most of his youthful knowledge of the 'outside world' was taken from reading Time magazine, later replaced by Interview ${ }^{24}$ his curiosity of the world and thirst for knowledge certainly has not dissipated with age. Once in Ottawa to study journalism at Carleton University, his solo forays expanded to include galleries, both private and public. With friends he attended film and theatre performances, but his decision to start taking art history courses was completely self-motivated, and not borne out of any discussions he may have had with others. Friday still considers himself "a solo flyer in the art world, as it feeds something very personal."25

It is no surprise that Friday has developed such an interest in contemporary art. He is well educated, grew up in a cultured household, and so possesses both the habitus that has allowed him to enter the field of cultural production, and the code to decipher works of art. Bourdieu believed that exposure to art at home was more critical than exposure via educational institutions and that "Those who have acquired the bulk of their cultural 
capital in and for school have more 'classical', safer cultural investments than those who have received a large cultural inheritance. ${ }^{26}$ Though Friday's exposure to culture at home did not expressly include visual art, I would argue it is exposure to any type of culture which predicates the development of the proper habitus, and his parent's creative occupations would certainly have had an impact (Bourdieu, in fact, refers to culture as Culture, and does not differentiate between visual or aural, etc.). Though Friday's formal exposure to visual culture did not occur until his undergraduate degree, it certainly has not led to his embracing 'safer,' more 'classical' forms of art. He has always gravitated towards difficult, cutting-edge, conceptual art. Bourdieu further elaborates on studying culture:

But above all - and this is why aesthetes so abhor pedagogues and pedagogy - the rational teaching of art provides substitutes for direct experience, it offers short cuts on the long path of familiarization, it makes possible practices which are the product of concepts and rules instead of springing from the supposed spontaneity of taste, thereby offering a solution to those who hope to make up for lost time. ${ }^{27}$

Friday, who has certainly embraced the self-study of art, does so by incorporating direct experience, via gallery and museum visits, as well as frequent trips to art fairs.

Lastly, Friday's origins in small, northern Ontario towns (2001 census data reports a population of 43686 for Timmins and 109016 for Thunder Bay $)^{28}$ provides additional credence to the concept of the habitus. As Bourdieu points out, place of residence is linked to the density of cultural capital and to opportunities for cultural consumption. ${ }^{29}$ For Distinction, his sample contained the same number of Parisians and what he terms 'provincials,' and he found there to be an under-representation of individuals rich in 
cultural capital in the rural regions. ${ }^{30}$ Given Bourdieu's conclusions, and the provincialtype similar characteristics found in Timmins and Thunder Bay (their size, and primary industries of mining and forestry, respectively), one can conclude that exposure to culture is limited, particularly when compared to large cities such as Vancouver and Toronto. That Friday developed such a strong interest in contemporary art despite the cities of his upbringing, is a strong testament to the habitus, and I propose, to his family's European ancestry.

\section{The Accrual of Capital}

Bourdieu identifies four different types of capital: economic, social, cultural and symbolic. ${ }^{31}$ Economic and social capital are governed by the amount of wealth and social connections, respectively, that an individual has accrued. The possession of these various forms of capital has important consequences: it defines class membership; determines position within the field of power; and determines the strategies available for use in the struggles that occur within the field of power. ${ }^{32}$

Johnson states that two forms of capital are particularly important in the field of cultural production: symbolic capital, which refers to the degree of accumulated prestige or celebrity and is founded on a dialectic of knowledge and recognition, and cultural capital, which concerns forms of cultural knowledge, competences or dispositions. ${ }^{33}$ Symbolic capital is just that, symbolic, and means nothing in itself:

Neither one's literary allusions nor one's objets d'art nor one's social connections can function as valuable unless they are recognized as valuable by those individuals and groups who form one's social context. ${ }^{34}$

Cultural capital is the internalized code required to understand works of art discussed 
earlier, and is acquired through "pedagogical action of the family or group members (family education), educated members of the social formation (diffuse education) and social institutions (institutionalized education). ${ }^{, 35}$

The relationship between economic capital and the other forms of capital is an interesting one. Possession of economic capital does not necessarily imply possession of cultural and symbolic capital and vice versa. Bourdieu sees the field of cultural production as an 'economic world reversed,' whereby possession of economic capital can actually be an impediment to the accrual of symbolic capital. ${ }^{36}$ Take as an example an avant-garde artist, whose commercial success could be seen as 'selling out.' Similarly, collecting poses some interesting issues. The renowned contemporary art collector, Charles Saatchi, has accrued large amounts of economic capital through his advertising empire. This has permitted him controlling interest in the field of contemporary art in Britain, though theorist Roger Cook casts doubt on

...whether he possesses the symbolic capital in terms of educational and cultural capital to enable him to join the ranks of the great dealers and collectors of modern art; those who through an intimate and embodied aesthetic connoisseurship are able to collect 'ahead of the game. ${ }^{37}$

Saatchi's reputation for buying in bulk, and the fact he has gone on the record as saying "90\% of the art I buy will be worthless in ten years," $" 38$ does not contribute to a recognition of his symbolic power by his art world peers. Also consider ARTnews magazine's annual survey of the world's top two hundred collectors, now in its sixteenth year. While the publication does not explicitly outline the criteria used to compile their who's who list, decisions were made as to who constituted the world's most 'active' collectors based on 
interviews with collectors, dealers, auctioneers, museum directors, curators, and consultants, ${ }^{39}$ members of the same social context as the collectors themselves. Most of these collectors are also the world's wealthiest collectors, a list so compiled amounts to little more than a defacto index of the ' 200 Wealthiest Collectors' rather than the '200 Best or Savviest Collectors.' Is this a case of economic capital being mistaken for symbolic capital (Charles Saatchi makes it into the top 10, and has been on the list every year it has been published)? Presumably there are cases where the two are not mutually exclusive, but it clearly appears that those collectors with the greatest economic capital garner the most attention. Also at issue is ARTnews' symbolic capital; is it a well respected publication in the art world? It certainly does not find itself in the same league as academic journals. Friday, for instance finds it rather superficial, describing it as a consumer magazine masquerading as something more serious, "and it gets away with it, because its readership doesn't know any better. ${ }^{, 40}$ Friday prefers to read $A R T F O R U M$ (to which he also subscribes), Contemporary, Parkett, Frieze and Canadian Art.

Friday has gradually accumulated various types of capital: educational, cultural, social and symbolic, through various means and strategies. Without question, his educational capital is high. He has a bachelor degree in journalism from Carleton University, a recognised leader in journalism education. Friday then went on to study law at the University of Ottawa and graduated Magna Cum Laude. Eventually he interned at one of Toronto's largest Bay Street law firms, McCarthy \& McCarthy (now McCarthy Tétrault). They offered him an articling position there as well, but he decided to remain in Ottawa, where he accepted an articling offer from another large Bay St. firm, Osler, 
Hoskin \& Harcourt. Of the five articling students that year, Friday was the only one offered a job as an associate following his Call to Bar, and he joined the company in 1990 in the Litigation Department. After three years, he decided he did not want to remain in private practice, and accepted a position with the Department of Justice in the Comprehensive Claims area, negotiating aboriginal land claims, where he remained for two years. In 1994, an opportunity arose in the then-emerging field of Alternative Dispute Resolution (ADR); he remained there for six and a half years and briefly managed the section. He was then approached to head up a new recruitment initiative, the Legal Excellence Program, where he continues to work as the National Coordinator. Friday points out that the majority of his time working at the Department of Justice has been in new and emerging, non-traditional areas of legal practice. ${ }^{41}$ This personal desire to forge new ground professionally, I would argue, is also evident in his collecting practices, and is perhaps a legacy from his mother.

Friday has received considerable recognition for his professional efforts: a departmental Leadership Award for his work in Alternative Dispute Resolution, a Merit Award for the role he played in the negotiation of the Nisga'a Treaty, and a nomination for the Head of the Public Service Award. ${ }^{42}$ His solid reputation in the area of Alternative Dispute Resolution has led to his involvement with the University of Ottawa's ADR program, where he has contributed in teaching, panel discussions, and mediation coaching for the last eight years (all on a voluntary basis) ${ }^{43}$ Evidently, Friday's professional and educational capital is substantial, and though it might not have a direct impact on his collecting, I would argue that it has elevated his social capital. As Bourdieu points out, 
cultural capital attracts cultural capital, ${ }^{44}$ and it holds that this cumulative effect applies to all other types of capital as well.

Friday began his collection by first buying the work of local artists such as Russel Yuristy, Betty Davison, Mark Marsters, Jane Martin, and Evergon, or artists whose work was being shown in Ottawa, such as Robert Houle, Carl Beam, and Shelley Niro. These early collection pieces were bought from local galleries such as Ufundi (now defunct) and L'Autre Equivoque (the precursor to St. Laurent + Hill). These acquisitions were made not in a conscious decision to collect local art, but simply because that was what was easily available to Friday at that juncture (before the advent of the Internet and sending jpegs). Soon thereafter, he began looking outward, and started looking for work in Toronto, ${ }^{45}$ as there were too few galleries in Ottawa that satisfied his conceptual bent. His connection to work outside of Ottawa was found through Toronto dealer Sandra Simpson (whose gallery is now closed), where he was exposed to the work of influential artists such as Ian Wallace, Rodney Graham, General Idea, Karl Blossfeldt, Carol Wainio, Cindy Sherman, Steven Shearer and Allan McCollum, among others. It was through Simpson's connections that Friday made what he now considers to be his first "major" art purchase, Joanne Tod's Johannesburg Suite (1983), purchased in $1994 .{ }^{46}$ Friday recalls the "wonderful feeling of truly connecting with a philosophy/approach/focus that was represented by Sandy's presentation of conceptual artists, both Canadian and nonCanadian." 47

In 1995, Friday bought (again through Simpson) a Carol Wainio work, and met more and more gallerists in Toronto, acquiring John Massey's Three Eyes from the well- 
known dealer, Olga Korper. It was Toronto gallerist Linda Genereux who suggested, upon hearing of Friday's travelling to Vancouver for the first time, that he visit the gallery of Catriona Jeffries with whom, she felt, he shared an aesthetic ${ }^{48}$ Friday simply walked into the gallery and struck up a conversation with Nigel Harrison, Jeffries' co-director and husband, and Friday purchased Ian Wallace's Guggenheim (1992) shortly thereafter (when Jeffries was asked if she had heard of Friday prior to this, she responded "there was nothing to hear of Joe Friday." This has radically changed, for he is now a name to know in Vancouver. $)^{49}$ Friday has gone on to make numerous purchases from Jeffries over the years (he has bought more work from her than any other dealer), and they have developed a very strong bond, both personally and professionally.

Friday considers Vancouver and Sandra Simpson to be logical connections to the larger contemporary art world, particularly in light of the fact that many Vancouver artists were recognised outside of Canada before they were recognised within. ${ }^{50}$ For him, the leap to the international contemporary art scene was an easy one. ${ }^{51}$ Today, Friday considers his focus to be on both Canadian and non-Canadian work, his goal to show domestic conceptual art in context with what is developing internationally, and vice versa. Despite his broader international horizons, he is still very much open to buying local art again, particularly if there are Ottawa artists working as a counterpoint or complement to what is happening in the larger international contemporary practice. As he says, "I am hopeful and watchful about Ottawa artists." ${ }^{2}$

The trajectory of Friday's very first art purchase in 1989 (Yuristy's The Painter), to his first international purchases (Neshat's Rapture from Los Angeles' Patrick Painter 
Gallery and Shrigley's Drink This from Paris gallery Yvon Lambert, both in 1999) spans a ten year period. During this time he was building up capital that would ensure his first contact with international galleries would be successful. By this point his reputation as a collector would have spread via networks of gallerists and artists who knew him sufficiently enough to enable him to present himself as a serious, committed collector. Friday has this to say about capital:

With the activities that build up my cultural capital comes a certain credibility that is based on something other than cash. As for my awareness of it, I certainly didn't set out consciously to build up that capital as a strategy for collecting. It has all been more organic and far less strategic than that. My instinct is to do my thing and retreat to my home to enjoy it, being a natural introvert. However, with attention comes increased confidence and increased opportunity to play a more public/active role. I won't pretend that I am not aware of the effects of having built up that capital. $^{53}$

Strong relationships within the art world are paramount to a collector's success, particularly when collecting from a small centre of art production. Friday has a very close relationship with gallerist Catriona Jeffries. Similarly, he has also developed a close relationship to Toronto dealer Susan Hobbs. They frequently discuss art and artists, and his personal friendship with her is based on his visiting the gallery as a potential client (even though he has yet to make a purchase from her). Others dealers with whom he feels a strong connection include: Nicolai Wallner in Copenhagen; Casey Kaplan in New York; Janice Guy and Margaret Murray in New York; Pierre-François Ouellette in Montreal; Jessica Bradley in Toronto; Art Metropole in Toronto (Art Metropole is in fact a non-profit artist-run archive and distribution agency for artists' publications rather than a commercial dealer); and to a lesser degree, the Lisson Gallery and Anthony Wilkinson, 
both in London..$^{54}$

Friday's art world relationships extend to curators, gallery directors, and other notable figures of the contemporary art scene, many of whom he has invited to his home to view the collection, for example Shirley Thomson (formerly Director of both the Canada Council and the National Gallery of Canada), Christina Ritchie (Director, Contemporary Art Gallery, Vancouver), Reesa Greenberg (curator, professor, author), Sabrina Van der Lay (Director, Art Forum Berlin), and Katherine Stout (Curator, Tate Gallery). In particular, Friday has developed a close relationship with Kitty Scott while she was Curator of Contemporary Art at the National Gallery of Canada. Friday frequently entertained artists who were in town to visit Scott; she let him know when she would be meeting with an artist whose work he was interested in, as she believed his collection was interesting for artists to see. ${ }^{55}$ Friday has opened his home to students (Carleton University Art History students, University of Ottawa Fine Arts students, the NGC summer student interns) as well as Board Members and supporters of various museums and galleries, such as the Birmingham Museum of Art, and a group of novice collectors from the Ottawa Art Gallery membership. This willingness to open his home to the public may generate questions as to who Friday is really collecting for, but if we see it simply as a method to build cultural capital, his assertions that his private collection is in fact private is not in itself incongruous.

Originally I was somewhat perplexed with Friday's relationships with artists. He is adamant about his reluctance to speak to artists about their work, preferring to speak instead to their dealers, and goes on few studio tours. ${ }^{56} \mathrm{He}$ finds it difficult to talk to artists 
about their work, and is wary of any contact being compromised by financial realities: "I hate to think that artists feel they must be trotted out like animals in a zoo or as grateful supplicants to collectors. ${ }^{957}$ Despite this hesitation, however, he has had many artists over to his house (Thomas Demand, Brian Jungen, Geoffrey Farmer, Lynne Cohen, Germaine Koh, Derek Sullivan, John Massey, Christine Davis, Max Dean, Kelly Wood, Ron Terada), and attended the NGC's Anniversary Gala with Brian Jungen. As Koh asserted, "Joe is really conscientious about not being the kind of collector who expects that his collecting an artwork somehow buys him a social right to the artist as well." by considering Friday's contact with artists through the lens of Bourdieu's theories that this apparent contradiction can be seen as Friday's building up of cultural capital. These varied relationships with art world figures, apart from artists, aid him in his collecting. $\mathrm{He}$ is close to the work of artists he may consider for purchase, and he expands his social networks and thus his social capital. This can then be converted to symbolic capital. Friday's symbolic capital as a collector is significant. He has been invited to several art fairs, ${ }^{59}$ including Art Forum in Berlin (September 2001-2005), Frieze in London (October 2004 and 2005) and Artissima in Turin, Italy (Fall 2003). He has been asked to speak on collecting panels at Art Forum (2003) and at the Toronto International Art Fair (November 2003). He has been invited to the Governor General's Awards for the last three years, has been the Chair of the Advisory Committee for the Carleton University Art Galley since 1993, and was on the Board of the Ottawa School of Art from 19911993. He was asked to join: the Toronto International Art Fair committee responsible for inviting emerging international galleries in 1995; the Vancouver Art Gallery (VAG) 
committee responsible for promoting support of the gallery in the United States in 2004, for which he is the Vice-President; and was approached in 2005 to join the VAG Board of Trustees (which he declined). In addition to his committee work, other philanthropic endeavours which build up his capital include his lending of works to exhibitions, most notably the Prototype for a New Understanding mask which is included in the Brian Jungen survey show curated by the VAG. The exhibition, which opened in New York at the New Museum in September 2005, has travelled to Vancouver, Montreal and wraps up in Rotterdam at the Witte de With in January 2007. This work has also been loaned for a Jungen solo show at the Secession in Vienna in 2003, and to the Castello di Rivoli for a group show entitled The Moderns in 2003. Not only does Friday's name appear on the exhibition labels, but in the catalogues as well. Sometimes the work he owns appears on the front cover, as Kirsten Pieroth's Dead Ant (2005) did in the Spring 2005 Secession publication. Nor does it hurt when the artists whose work he owns win awards. Not only does the value of the work increase, but so does his reputation for identifying talented upand-coming artists, before they have been consecrated by the restricted field of cultural production.

There are two significant events which increased Friday's reputation as an accomplished collector beyond this restricted field of cultural production, and also significantly raised his cultural capital. These were the article that appeared on him in Canadian Art magazine, and the Prototype exhibit at the Carleton University Art Gallery in the Fall of 2004. Campbell's article, part of a series on collectors for Canadian Art magazine, also profiled Claudia Beck and Andrew Gruft, Paul Marks and Ian Wallace, 
also a renowned artist. That he should be profiled amongst other notable Canadian collectors by one of Canada's most highly regarded art periodicals was certainly a recognition of his maturity as a collector. The exhibition which followed shortly afterwards at the prestigious Carleton University Art Gallery (CUAG), curated by one of Canada's rising art stars (Germaine Koh), was another mark of his growing reputation. Having his private collection displayed in a public gallery, a space that Bourdieu describes as both consecrated and consecrating ${ }^{60}$ and the attention generated by the exhibition certainly solidified Friday's profile as a collector.

In tandem with the exhibition, Friday received further press in the Ottawa Citizen and Carleton University Magazine. It should be noted that not only was this media attention having an impact on Friday's capital, but also on the capital of the artists he collected, particularly when their works were singled out as examples of the type of art Friday collects. Canadian Art featured photographs of Lum's Untitled Language Painting, and the photographs of Friday's living room highlighted Neshat's Rapture, Starling's Formers, Jigs and Molds, Tod's Johannesburg Suite and Douglas Gordon's Croque Mort (2000). Following the Canadian Art profile and Ottawa Citizen stories, Friday was approached by a freelance journalist working for the National Post, who wished to do a story for the Homes section on living with art. Friday declined, concerned the approach would "dumb down" the coverage of his collection, and that the paper's right-wing editorial position was at odds with his own politics (an example of Friday's conscious desire to preserve the integrity of his capital). He was also concerned that he had had enough publicity by this time, considering the Ottawa Citizen article had attracted some 
unwanted attention (from a potential stalker).$^{61}$ It must also be acknowledged that this thesis is also playing a role in Friday's accrual of capital. Bourdieu, referring specifically to artist biographies, posits the discourse of celebration, whereby the artist is established as a memorable character, worthy of historical account. ${ }^{62}$ The CUAG exhibition, the attention Friday has received in the press, and to an extent this thesis, contribute to Friday's discourse of celebration.

When Friday, an established, respected collector, decides to purchase the work of a particular artist, he is in fact 'investing his prestige' in the artist's cause, acting as a 'symbolic banker' who offers as security all the symbolic capital he has accumulated (which he is liable to forfeit if he backs a 'loser'). This investment of symbolic capital, of which the accompanying economic investments are themselves only a guarantee, is what brings the producer into the cycle of consecration. ${ }^{63}$ The collector has a powerful role to play, but at stake is the symbolic capital that has been accumulated, and I believe this is one of the reasons Friday deliberates carefully over acquisition decisions. Though his symbolic capital is high, in comparison to many collectors (Saatchi and Hendeles readily come to mind), his economic capital is relatively low. This places even greater emphasis on his need to 'spend' his symbolic capital wisely. This imbalance between symbolic and economic capital places Friday as a legitimate agent in the field of restricted production, where economic capital is disavowed. But it is a precarious position for collectors, for even though symbolic capital is more highly prized, economic capital is still required to engage in the act of collecting. 


\section{Collecting Within the Field of Cultural Production}

As with capital, Bourdieu posits various types of hierarchically organised fields: economic, educational, political and cultural. Each is designed as a structured space with its own laws of functioning and its own relations of force independent of those of politics and the economy, except in the cases of the economic and political fields. ${ }^{64}$ Each field is relatively autonomous but structurally homologous with the others, and its structure is determined by the relations between the positions agents occupy in the field. Fields are dynamic; a change in agents' positions necessarily entails a change in the fields's structure. $^{65}$

According to Bourdieu, the field is a site of struggle, often between established figures and young challengers. ${ }^{66}$ Agents within a field are in constant competition (not always consciously) for resources or capital specific to that field:

The social geography of the field is a function of the distribution of occupied positions and, by homology, the position-takings of the residents. ...agents in a position of dominance will tactically deploy their capital in order to conserve their position, whereas agents looking to outflank, displace or over-take those in a dominant position (arrivistes, avantgardistes, heretics - the 'dominated fraction of the dominant social class') will attempt strategies of succession or subversion. ${ }^{67}$

Being in possession of power within a field (which is dependent not only on the amount of capital one holds, but also the position one occupies within the field) carries with it the right of consecration, or the ability to designate what is authentic capital. ${ }^{68}$

To enter a field, one must first possess the appropriate habitus which predisposes the agent to enter that field. One must also possess the minimum amount of knowledge or skill to be accepted as a legitimate player. ${ }^{69}$ Collector Paul Marks has emphasised the 
difficulty of starting out as a collector, and the necessity of appearing as a serious, educated connoisseur to some dealers in order to buy the work of artists in their stable, is an excellent example. ${ }^{70}$ Johnson states that:

Entering the game, furthermore, means attempting to use that knowledge, or skill, or 'talent' in the most advantageous way possible. It means, in short, 'investing' one's (academic, cultural, symbolic) capital in such a way as to derive maximum benefit or 'profit' from participation. Under normal circumstances, no one enters a game to lose. ${ }^{71}$

The field of cultural production is found within the field of power, which is found within social space (see Appendix A). The field of 'power' operates as a meta-field to describe the way in which individuals and institutions in dominant fields relate to one another and the whole social field. ${ }^{72}$ The field of cultural production finds itself in a dominated position within the field of power - within the field of power because of its ample possession of symbolic capital, but subordinate because of its low degree of economic capital. The field of cultural production is further subdivided in two: the field of restricted production, which addresses 'high art' wherein the stakes of competition are largely symbolic, and the field of large-scale production, which addresses 'mass' or 'popular' culture, in which the stakes of competition are largely economic. ${ }^{73}$

To conclude, Bourdieu saw social space as a three dimensional map, with an individual's location within that space determined by the volume of capital possessed, the structure of that capital (i.e. the type of capital, be it symbolic, economic, etc.,), and finally the evolution of these two properties over time (manifested by past and potential trajectory in social space).$^{74}$ Agents can convert forms of capital into alternate types, for example economic into educational, social into symbolic. The existence of various fields into 
which capital can be invested opens up the possibility of different trajectories an agent can choose to follow, trajectories whose outcome is not determined solely by social origin, but which reflects the meeting of class habitus and the 'field of possibles. ${ }^{75}$

According to Bourdieu, the use of field as a research concept requires the following: the analysis of the relation of the field under question to the field of power; the mapping out of the positions available within the field, and especially those positions that are the subject of competition for field-specific capital; and finally, the analysis of the habitus of the individuals who occupy the field.$^{76}$ It is beyond the scope or intent of this project to analyse the habitus of all of the individuals who occupy the collecting field, and to map out all of the positions available within the field. Instead, this section will briefly map the collecting of contemporary art within the field of cultural production.

Though art is produced by individual artists, the meaning of their work is ultimately the collective product of the entire cultural field:

Thus, as the field is constituted as such, it becomes clear that the 'subject' of the production of the art-work - of its value but also of its meaning - is not the producer who actually creates the object in its materiality but rather the entire set of agents engaged in the field. Among these are the producers of works classified as artistic (great or minor, famous or unknown), critics of all persuasions (who themselves are established within the field), collectors, middlemen, curators, etc., in short, all those who have ties with art, who live for art and, to varying degrees, from it, and who confront each other in struggles where the imposition of not only a world view but also a vision of the artworld is at stake, and who through these struggles, participate in the production of the value of the artists and of art. ${ }^{77}$

Collectors then play an intrinsic role in the field of cultural production, though, as Deborah Campbell points out, sometimes invisibly. It is the collectors who frequently keep the galleries alive and the artists, and in the case of Friday, provide a salon. They 
play an interesting role in terms of influencing trends and what is considered art worth collecting and what is not. Many collectors volunteer on boards, and a lot of them are quietly doing things to make the art world flourish. In some cases, they are direct patrons of the artists (for example Paul Marks and Kelly Mark), or network them to other powerful people who can help them. Without such support a lot of artists wouldn't survive, as the museum system can only do so much to aid them. ${ }^{78}$ But, for all of the collectors who receive some recognition for their activities, there are many who collect in obscurity, known only to the dealers and artists from whom they make their purchases. Friday's collecting of contemporary conceptual art positions him within the restricted sub-field, a dominated position within the field of power, concerned with 'high' art, as opposed to commercial bourgeois art and commercial-industrial (popular art). Bourdieu defines high art as art destined for a public of producers of cultural goods, and the field of restricted production in which this high art is produced as tending to ...develop its own criteria for the evaluation of its products, thus achieving the truly cultural recognition accorded by the peer group whose members are both privileged clients and competitors. ${ }^{79}$

Friday is collecting art which is produced for a small, specialised group, art which functions as an element of social distinction, since the code required to decipher these works is held by a small group. Let us not forget that if the function of collectors is to buy art, to do so they must possess economic capital. Even though the art Friday is buying belongs to the field of restricted cultural production, he is in fact a dominant member of this field, and the artist a dominated member. Friday, however, possesses much less economic capital than many collectors, and so relies more heavily on his accumulated 
symbolic capital. 'Making one's mark', means winning recognition of one's difference from other collectors, especially the most consecrated of them. It means creating a new position, ahead of the positions already occupied, in the vanguard. ${ }^{80}$ Friday is distinguishing himself not only from moneyed collectors, but also from those collecting from large cities of art production.

All fields are sites of struggle, and the field of restricted art production is particularly competitive for collectors, who are negotiating overtly with gallerists to make acquisitions, but who are also covertly in competition with other collectors and institutions. Waiting lists frequently exist for work by certain artists, and it is the gallerist who decides who is added to these lists, and where on the list a collector might fall. The more cultural or symbolic capital one has, the easier it is to acquire these sought-after works. As Campbell concedes, a lot of gallerists are concerned with who buys the work; there is a vetting process that goes on with preference seemingly accorded to collectors who are passionately engaged and educated about the work and not just trying to play a social game. ${ }^{81}$ Jeffries concurs, maintaining that as a new collector presents themselves to being a committed collector, she would make sure that access to work would happen. ${ }^{82}$ A private collector also has to vie with public institutions for these artworks. Works found in public collections have a greater chance of being seen, which increases the amount of capital the artists themselves accrue, and subsequently increases the capital the gallerist accrues. As Scott says, there is a tendency with good dealers to want to have an artist they represent in the National Gallery of Canada, and if she is interested in a particular work, she will be given priority. ${ }^{83}$ It is in the private collector's best interest to 
find opportunities to also display their collections publicly, occasions which Friday has certainly embraced.

As Scott further points out, the Canadian contemporary art scene is very small. Most curators know each other, and know most Canadian artists, dealers, and collectors. Within this small group the role of the collector is very important; their support is necessary to ensure the viability of commercial galleries, and the artists they support. Collecting contemporary art in Canada is on the rise; Scott believes there are more collectors of this type of art than ever before, but that the press has been slow to pick up on it. She is pleased that Canadian Art has done a series on collectors, and is hopeful it will provide examples to other Canadians that by going about it slowly and methodically, it is possible to amass a significant collection over time with modest means. ${ }^{84}$

1. Ian Wallace, "Exchanges + Gatherings: In the Studio with Ian Wallace," Canadian Art 21.4 (Winter 2004): 62 .

2. Living in a centre of considerable art production not only means greater access to art, but also greater opportunity to spend and build capital.

3. Richard Jenkins, Pierre Bourdieu (New York: Routledge, 1992), 74.

4. I am not attempting to replicate the scope of his work in Distinction. In Bourdieu's study, participants were interviewed to determine their knowledge and preferences in painting, music and museum-going, radio programmes and books, knowledge of film actors, directors and personal photography, as well as choices in clothing and domestic interiors, including furniture and cooking.

5. Pierre Bourdieu, The Logic of Practice, trans. Richard Nice (Stanford, CA: Stanford University Press, 1990), 53.

6. Jen Webb et al., Understanding Bourdieu (London: Sage Publications, 2002), 37.

7. Jerry D. Moore, Visions of Culture: An Introduction to Anthropological Theories and Theorists (Toronto: Altamira Press, 2004), 329.

8. Randal Johnson, ed., The Field of Cultural Production (New York: Columbia University Press, 1993), 5. 
9. Pierre Bourdieu, Distinction: A Social Critique of the Judgment of Taste (Cambridge, MA: Harvard University Press, 1984), 173.

10. Ibid.

11. Ibid., 1.

12. Ibid., 2.

13. Ibid., 562.

14. Robert Holton, "Bourdieu and Common Sense," in Pierre Bourdieu: Fieldwork in Culture, eds. Nicholas Brown and Imre Szeman (New York: Rowman and Littlefield Publishers, 1999), 90.

15. Webb et al., 40.

16. Ibid., 38 .

17. Joe Friday, e-mail correspondence with the author, 27 August 2006.

18. Ibid.

19. Bourdieu, Distinction, 13.

20. Traditionally, master brewers were considered artists.

21. Johnson, 15 .

22. Joe Friday, email correspondence with the author, 15 October 2006.

23. "Technically, this was a private school, but any elitist connotations do not attach, in the circumstances." Friday, e-mail correspondence with the author, 27 August 2006.

24. Ibid.

25. Ibid.

26. Bourdieu, Distinction, 65.

27. Ibid., 68.

28. Canada. Statistics Canada, Population and Dwelling Counts, for Canada, Provinces and Territories, and Census Subdivisions (Municipalities), 2001 and 1996 Censuses, 16 August 2002, 29 August 2006

$<$ http://www12.statcan.ca/english/census01/products/standard/popdwell/Table-CSD-P.cfm?T=1\&PR=35\&S $\mathrm{R}=526 \& \mathrm{~S}=1 \& \mathrm{O}=\mathrm{A}>$.

29. Bourdieu, Distinction, 105 .

30. Ibid., 602.

31. Jenkins, 85. 
32. Bourdieu, Distinction, 315 .

33. Johnson, 7.

34. Marty Hipsky, "Romancing Bourdieu: A Case Study in Gender Politics in the Literary Field," in Pierre Bourdieu: Fieldwork in Culture, eds. Nicholas Brown and Imre Szeman (New York: Rowman and Littlefield Publishers, 1999), 192.

35. Johnson, 7.

36. Ibid., 7-8.

37. Roger Cook, "The Mediated Manufacture of an 'Avant-Garde'," in Reading Bourdieu on Society and Culture, ed. Bridget Fowler (Oxford: Blackwell Publishers, 2000), 169.

38. Ibid., 175.

39. Milton Esterow, "The ARTnews 200 Top Collectors," ARTnews 105.7 (Summer 2006): 135.

40. Joe Friday, email correspondence with the author, 30 August 2006.

41. Joe Friday, email correspondence with the author, 29 August 2006.

42. Unfortunately Friday did not win the award.

43. Friday also taught a course called Professional Responsibility at the request of the then Vice Dean several years ago, but turned down the offer to continue, feeling the course needed to be completely revamped, for which he did not have the time. Friday, email correspondence with the author, 29 August 2006.

44. Pierre Bourdieu, The Field of Cultural Production, ed. Randal Johnson (New York: Columbia University Press, 1993), 233.

45. This surprised me, as I had expected him to collect locally for some time in order to build up cultural capital before looking farther afield. This demonstrates an early focus to, and confidence in, his collecting.

46. This was made just shortly after he joined the Department of Justice. His salary at the time was $\$ 38000$, and the work cost $\$ 12000$, though Simpson gave him a 10\% discount. Friday, email correspondence with the author, 29 August 2006.

47. Ibid.

48. Ibid.

49. Catriona Jeffries, telephone interview with the author, 20 April 2005.

50. Friday, email correspondence with the author, 29 August 2006.

51. Joe Friday, email correspondence with the author, 30 May 2005.

52. Friday, email correspondence with the author, 29 August 2006. 
53. Friday, email correspondence with the author, 15 Ocotber 2006.

54. Friday, email correspondence with the author, 30 August 2006.

55. Kitty Scott, interview with the author, 8 February 2005.

56. With the exception of Toirac and Carlos Garacoia in Havana; Daniel Richter, Thomas Demand, and Germain Koh in Berlin; and Kelly Wood in Vancouver. Friday, email correspondence with the author, 30 August 2006.

57. Ibid.

58. Germaine Koh, written interview with the author, 28 May 2005.

59. This frequently entails complementary accommodations, invitations to private parties, and tours of private collections.

60. Bourdieu, Field of Cultural Production, 257.

61. Friday, email correspondence with the author, 30 August 2006.

62. Bourdieu, Field of Cultural Production, 260.

63. Ibid., 77.

64. Johnson, 6 .

65. Ibid.

66. Bourdieu, The Field of Cultural Production, 60.

67. Nick Prior, "A Different Field of Vision: Gentlemen and Players in Edinburgh, 1826-1851," in Reading Bourdieu on Society and Culture, ed. Bridget Fowler (Oxford: Blackwell Publishers, 2000), 143.

68. Webb et al., 23.

69. Johnson, 8.

70. Paul Marks, telephone interview with author, 13 April 2005.

71. Johnson, 8.

72. Webb et al., xii.

73. Johnson, 15-16.

74. Bourdieu, Distinction, 114.

75. Jeremy F. Lane, Pierre Bourdieu: A Critical Introduction (Sterling, Virginia: Pluto Press, 2000), 153.

76. Webb et al., 82 . 
77. Bourdieu, The Field of Cultural Production, 261.

78. Deborah Campbell, telephone interview with the author, 4 February 2005.

79. Bourdieu, The Field of Cultural Production, 115.

80. Ibid., 60

81. Campbell, telephone interview with the author, 4 February 2005.

82. Jeffries, telephone interview with the author, 20 April 2005.

83. Scott, interview with the author, 8 February 2005 .

84. Ibid. 


\section{CHAPTER THREE: Friday's House}

Public collections may be less problematical from a social point of view, and can be scientifically more useful than private ones, yet they lack the greatest possibilities of private ones. The collector's passion is his divining rod and turns him into a finder of new sources. ${ }^{\prime}$

One of the first works of art encountered when entering Friday's heritage home is his business card, which in the hands of artist Jonathan Monk now more closely resembles a miniature Abstract Expressionist painting (Fig. 21). Monk's series People I Have Met (2000 and 2003) is composed of business cards of just such people, though their identity will remain a mystery as he has obliterated the text with white correction fluid. Friday purchased one of these works in Turin in 2004, at which time he also coincidentally met Monk. The artist asked for two of Friday's business cards, and when Friday returned home he received one in the mail, his personal information obscured with Liquid Paper, and Monk's signature on the back. The second card became an artwork for Monk's dealer to sell, and now likely finds itself in another collector's collection, though that collector will never know to whom it originally belonged. Only the artist knows whose cards are whose, thus functioning as "the link between two anonymous strangers,"2 in this amusing series of exchanges. Not any two strangers however, but two collectors of conceptual art, who, if they do know of each other, could possibly be unaware to their having both purchased work by the same artist from the same series, and unaware to knowing they are now connected by this common business card. The artist has cleverly inserted himself into the middle of this clandestine relationship, reappropriated the indices to their public personas, and offered them back up for sale to their contemporaries. 
The works found directly across from Friday's business card frequently change. At one time visitors were confronted with A. A. Bronson's photograph Felix Partz, June 5, 1994. Taken shortly after Felix's death, precipitated by AIDS, Felix's emaciated corpse is colourfully dressed and surrounded by an assortment of his worldly possessions, a fitting welcome into a collector's home. At once horrifying and compelling, this piece embodies Friday's attraction to contemporary art, to work that is multivalent and conceptual, and in the specific case of Felix, to art that is capable of being touching, witty, offensive, and haunting. Approximately two years ago, Felix was replaced by Jeremy Deller's Give Music a Chance (2003)(Fig. 22), a photograph taken of a pawn shop in upstate New York while the artist was completing a residency at Bard College. The shelves in the shop are home to kitschy ceramics and various musical instruments, notably a flute with an attached sign declaring "Will Swap for a Gun." Though much less visually shocking than its predecessor, Give Music a Chance is still capable of provoking a multitude of reactions, as the viewer's initial response to laugh is quickly checked by a realisation of the photograph's documentary nature, and a further reflection on American gun culture. This initial encounter with Friday's collection sets the scene for what is to come. Our tour will start with Friday's house and will include an overview of its historic origins and a description of its decorative scheme. Next we will make our way to the Carleton University Art Gallery where we will explore two sections of the Prototype exhibit in detail before we return to Friday's house. Here we will look at the same artworks from Prototype, but in their domestic setting, with the goal of investigating how a private collection can shift when moved to an institutional setting. 
The House

Joe Friday's house has been designated under Part IV (Grade 1) of the Ontario Heritage Act, including a heritage designation for its interior. This is a rare occurrence in Ottawa; most houses which have received heritage designation have done so for their exteriors only, as few original interiors have remained intact. Friday's house is one of only three vernacular houses in Ottawa to achieve this designation (the other two are Foisy House at 188 St. Andrew St. and a Bauhaus-inspired house at 339 Pleasant Park Road), which recognises not simply original interiors, but an unusual level of craftsmanship as well. ${ }^{3}$ Friday's house, which Ottawa: A Guide to Heritage Structures calls Beattie House, is noted for its intricate plasterwork. It was built circa 1867 (though an earlier date of 1862 has been proposed $)^{4}$ by plasterer William M. Beattie, who came to Canada from Scotland to work on the construction of the Parliament Buildings. He was first listed as a citizen of Ottawa in the $1864-65$ city directory. It is not clear whether Beattie himself ever lived in the house, but by 1876 it was being rented to two brothers, Eugene and J.M. Tétu. Beattie's mortgage was foreclosed in 1879 and ownership of the house assumed by Almira Foley. The house was sold to John A. Butterfield the following year, and again in 1901 to another craftsman, stone mason Honor Robillard. ${ }^{5}$ The house continued to be rented to a long procession of civil servants: L.N. Fortier (1883-1890), Isadore Côté (1891-1903), and Joseph Langlois (1904). Frederick H. Paget, chief clerk with the Department of Indian Affairs bought the house in 1907 and lived there until 1932, after which it was again rented. The house was sold in 1944 to Carl F. Yallean, in 1959 to John and Catherine Dickson, and in 1961 to Louis Audette. ${ }^{6}$ Joe Friday and Grant Jameson (Friday's life 
partner) bought the house from Audette in 1996. Jameson was Audette's solicitor at the time Audette was considering having the house designated a heritage structure. Audette was initially reluctant to do so, concerned the brass heritage plaques would be an "invitation to those with burglarious intent to break and enter." Heritage status was granted in 1978, though the plaque was not installed until Friday and Jameson took ownership. $^{8}$

Beattie House was constructed in the Italianate style, which in the domestic form features flat pitched roofs, stucco finishes, stilted hood mouldings around windows and venetian triple windows with the centre sash raised. ${ }^{9}$ It is noted for its "unusual entablatures over the windows, which are supported by carved brackets or "corbels" [with] ornamental heads and acanthus leaves... rare in Ottawa." ${ }^{10}$ The enclosed porch, or tambour, is also claimed to be unique in Ottawa; it is in a style usually found in Quebec. This porch was added to the house in $1912 .{ }^{11}$ That year also saw a change in the roofing material from wood or shingle to metal or tin; another modification was the addition of a wooden cornice in 1888. Up until Friday and Jameson took ownership of the house, few significant changes were made, a detail supported by Taylor's Historical Building report of 1975 .

Friday and Jameson hired a contractor to update the house, including refinishing the hardwood floors, repairing the plaster and repainting the walls. Several earlier renovations were undone: built-in shelves in the front hallway were removed as was a built-in closet. The kitchen and bathroom as well as the rooms above the kitchen were the focus of the renovations. The rooms above the kitchen, originally a bathroom and 
bedroom occupied by Louis Audette's valet, were completely gutted and turned into one room, now used as the television room, and a sky-light was punched into the ceiling. The kitchen and bathroom proved more problematic for Friday and Jameson. They vacillated back and forth between a sleek, modern, minimalist design to something they felt better respected the history and age of the house. In the end they went for the latter, though Friday is still unsure if they did the right thing. ${ }^{12}$ Local ceramicist Mimi Cabri painted the tiles in both the kitchen and bath (Figs. 23 and 24). Cabri, known for her zaftig, exuberant naked ladies, also immortalised Friday's in-house menagerie: Beatrice and Wilhelmina (his pugs) in the kitchen, Phoebe and Hazel (the cats) in the bathroom. As Friday says of the tiles, "we blew the minimalist approach out the window with rather Baroque abandon." Friday continues:

My aim with the design was to pursue clean lines but not to shrink away from decoration. I had in mind the philosophy that I projected on to William Beattie as I imagined him designing and completing the living room ceiling. I have always felt that if I followed a pure modernist approach, it would be simply aping what has been decreed to be appropriate and fitting for a collector of contemporary art; that is, it would be someone else's determination of what was right for me, not necessarily my own. I love modernist design, but one can fall easily into cliché with it, thus losing the mark of the person who inhabits the space. I prefer to think of myself as more Eurotrash in my approach, than sleekly modern. ${ }^{13}$

Though the exterior is certainly impressive (Friday and Jameson have painted the brickwork a light yellow with white detailing, and have had circular motifs etched on the glass of the enclosed porch which is mimicked by stone orbs perched outside (Fig. 25), it is really the interior of the house that is so remarkable, particularly the elaborate plaster ceiling found in the living room (described by journalist Gladys Blair as 'patisserie' plasterwork). Featuring a large central medallion in scroll-and-leaf pattern, it is adjoined 
by two smaller medallions, further encircled by curved mouldings. The periphery of the room is decorated with a row of morning glories, a row of acanthus leaves and a third row of egg-and-dart motifs. ${ }^{14}$ The walls of the entire house are painted a matte white with the exception of two rooms: the ground floor study/library which is a "deep matte brownishblackish-eggplant colour called "Mahogany" by Farrow \& Ball paints," and the adjoining dining room which is a "matte very pale putty/stone colour."15 They consulted with other collectors and gallerists before settling on a particular shade of white. Finding their recommendations too yellowish, they finally chose one with bluish undertones that matched the aged shade of the plaster ceiling.

The house is furnished with a mixture of antique and contemporary furnishings. Friday and Jameson bought several antiques from the previous occupant, Louis Audette's estate, including an eighteenth century Neo-Gothic bookcase (Fig. 26), ${ }^{16}$ which is found in the library and houses Friday's extensive collection of exhibition catalogues and artist's books. ${ }^{17}$ They also purchased a late nineteenth century Chinese chest and table, which sit in the living room, which they think were bought by Audette's brother during a world trip. These pieces are mixed with two reproduction Le Corbusier "Grand Confort" armchairs in beige leather and chrome, and their sofa is based on a simple Michel Franck design from the 1940s (Fig. 27). Their coffee table was manufactured according to Friday's directions: "I wanted plain and hard-edged to contrast with all that plaster busy-ness on the ceiling, and I wanted it weighty and substantial but still light and transparent."18 There is an Art Nouveau floor lamp (Fig. 28) in a corner of the room "that makes no sense but is great fun."19 
If we pass back through the library and into the dining room, we find a French cellarette also purchased from Audette's estate. Built as a liquor cabinet (which is how it continues to be used), it has lion-paw feet and is casket shaped (Fig. 29). Audette always referred to it as Napoleon's Tomb, as it bears a resemblance to his tomb at Les Invalides in Paris. ${ }^{20}$ Another animal-inspired object in the room is a nineteenth century Russian samovar with rooster feet (Fig. 30), which has been cleverly rewired as a lamp. The custom lampshade includes rooster references in the form of gold leaf feathers along the border. Climbing to the second floor, Friday has several examples of mid-century modern furniture, the iconic Eames lounge chair in black leather and mahogany in the t.v. room, and an Eames aluminum and leather desk chair in the computer room (off the t.v. room), both of which were manufactured by Knoll under the Eames estate. Friday has also displayed his collection of antique wooden hat forms (Fig. 31) in the television room, and above the Eames lounge chair hang three Eames leg braces from the 1940s (Fig. 32). The latter were designed to be used during the Second World War. Manufactured by the same steam-bent wood process that was used for many of Eames' chairs, they apparently did not go into mass production. Friday considers them "gems."21

Friday has intentionally kept the colour scheme and furnishings in his home fairly neutral (beiges and browns predominate), "to complement and support the artwork." 22 The mixing of modern and antique furniture is successful, in harmony with both the heritage surroundings and the contemporary artworks. The overall effect is harmonious but eclectic, with a touch of whimsy. The display of multiples alongside more serious works of art is a nod to the importance Friday places on the irreverent. New York artist Jennifer 
Lew's Ca Ca (2003)(felted turds), are displayed on a silver plate (Fig. 33), as are Koh's copper tokens with "I WILL" minted on them. The marble foot Friday has sitting beside his antique bookcase, which he bought from a local headstone-maker, has frequently been mistaken for a work of art (Fig. 34). These multiples and decorative items, while injecting humour, also serve to re-inscribe those aspects of contemporary art Fridays finds important, such as social exchange and interaction. In addition to the art works, the whole house can be considered a work of art, a Gesamtkunstwerk, in which we find multiple staged exhibitions: the house itself, the furniture, the books and catalogues, and the wooden hat forms.

The house's structure is that of a triple brick design, essentially a box within a box within a box. ${ }^{23}$ The autonomous shifting of these boxes has lead to a bowing of the floor, and a subsequent unsettling of the walls, their crookedness (more obvious from the outside) lending an air of mischievousness. Germaine Koh, curator of the exhibit Prototype comments on the idiosyncracies of the house, describing it as "up in the air,"24 giving us a sense of not knowing what the house will do next, nor the collector who inhabits it.

\section{Prototype}

Let's leave Beattie House behind for a few moments, and make our way to the Carleton University Art Gallery to visit Prototype: Contemporary Art from Joe Friday's Collection, and to look in detail at two particular sections of the exhibition. The show, which opened September 13, 2004 and ran until October 31, 2004, was curated by Germaine Koh, not only an internationally recognised artist but a well respected curator. 
Sandra Dyck, CUAG's then Acting Director and Joe Friday approached Koh to curate the show, as they wanted to involve an artist whose work was included in the collection, and because she was already known to them as a curator. ${ }^{25}$ Koh was intrigued by the proposition of an artist in the collection getting to respond in such an accessible venue. ${ }^{26}$ Koh was also interested in structuring the exhibition in the form of a public conversation, especially as it would be the first time Friday's collection would be displayed in such a public fashion. This constructing of a forum for open discussion was paramount (and in her curator talk Koh described the end-result as a rhetorical exercise), playing a key role in the shift of this collection from a private to a public entity.

The title choice for the exhibition was inspired by two works included in the show, Brian Jungen's Prototype for a New Understanding \#7 and Liam Gillick's Prototype (2002). Originally titled Wanting, to acknowledge the impulse behind collecting as well as to give a sense of a lot of the works being in a deliberate state of incompletion, ${ }^{27} \mathrm{Koh}$ changed her mind in order to focus on the open-ended nature of many of the works in the collection, and because she saw Friday's collection as "a remarkable evolutionary object, a prototype that embraces its own state of want." ${ }^{98}$

The exhibition represents approximately half of Friday's larger collection, and focuses primarily on work acquired in the last ten years or so (when Koh feels Friday had really hit his stride), ${ }^{29}$ by artists rarely, if ever, exhibited in Ottawa previously. Koh also chose work which she argues demonstrates Friday's "increasing tendency to favour works that harbour an interesting attitude of productive doubt, ${ }^{, 30}$ as well as uncertainty, failure, loneliness and desire. These curatorial choices, focussing as they did on recent works (and 
dictated by space constraints, the house being larger than the gallery space), unfortunately do not give a sense of how the collection has evolved over time, an issue Koh openly acknowledges. ${ }^{31}$ Koh included few of Friday's early purchases (many of which were made locally) in order to focus on the collection's function as an "evolving proposition." 32 Luckily Friday does open his home to the public on occasion, so that viewers can get a sense of how the collection has developed, and also how the collection changes within the house itself. The house is in fact a continuously evolving exhibition space, and provides an interesting counterpoint to the freezing of aspects of the collection within CUAG.

Before coming to this project, Koh and Friday knew each other well enough to have art-related conversations in art-world situations, but they had never discussed her work or his collection in depth. ${ }^{33} \mathrm{Koh}$ insists that Friday was careful not to shape her curatorial decisions, though she did preserve some of the juxtapositions from the domestic installation. Koh explains:

I thought the pairing in the house of Douglas Gordon's bite marks and Joyce Wieland's "The Artic Belongs to Itself" was insouciant, so I expanded on it by making it part of a whole section of body parts and functions - which I hope came across as playful at the same time as drawing out one thread within the collection. ${ }^{34}$

Many of the groupings, however, were of her own devising, and she mentions that the installation at CUAG may have given Friday some ideas about how to reinstall the work upon its return to Beattie house. "Of course, I inevitably took cues from how the collection was installed in the house, because those kinds of decisions must reveal something about how the collector understands his own collection."${ }^{935}$

This next segment will examine the different meanings that are orchestrated within 
the collection, governed by their private or public display. Two discrete sections of the Prototype exhibition will be discussed in an effort to discern the meanings which have been constructed by the various juxtapositions of works in the gallery. These same works will then be situated in Beattie House, and the resulting conversations between the works themselves, and between this distinct architectural space will be explored. This will be accomplished by the visual analysis of installation photographs of Prototype, and of Beattie House taken in January 2005, following the return of the works to their domestic setting.

The High Gallery

The Carleton University Art Gallery (CUAG) is typical of most contemporary art galleries, the unadorned white cube. The high gallery, the exhibition space immediately to one's right when the gallery is first entered, is the only section with continuous high ceilings, and is where this tour will begin. The first grouping of works we encounter is composed of Candice Breitz's DVD Soliloquy (Clint) (2000), Tracey Moffatt's Piss Bags and Kwong Sisters from the Scarred for Life series (1998), and Alex Morrison's Every House I Have Ever Lived in Drawn From Memory (1998)(Fig. 35). Breitz's DVD, Soliloquy (Clint), takes up the entire two-storey wall, and immediately grabs the viewer's attention thanks to its size, and the nature of it being a moving image. Breitz has re-edited all of Clint Eastwood's dialogue from the film Dirty Harry, resulting in a 6:57 minute film clip from a feature length film. Our assumptions about the cinematic are exposed: our preoccupations with pop culture and celebrity, and particularly our expectations that the speaking parts of the central character would have a longer duration. Like Soliloquy, 
Moffatt's work is fragmented, manipulated, a fictional moment of childhood being restaged for the viewer's benefit, which also calls in to question the works' authenticity. Whereas Breitz takes inspiration from Hollywood imagery, Moffatt turns to soap opera and print imagery, in this instance borrowing stylistically from the American magazine Life. $^{36}$

Morrison's attempt to recreate from memory all the places he has lived, and Moffatt's distillation of adult neuroses to specific childhood events allude to less than happy childhoods. How did Morrison come to move so frequently? Are Moffatt's works purely the product of an active imagination, or is she also incorporating autobiography? These pieces also attempt to fix specific moments in time, slow it down, make them more accessible to memory. Breitz's work, conversely, speeds time up, and we are forced to simultaneously contemplate time's permeability, manipulability, and unfixedness, enhanced by the media the artists have chosen to use.

The next grouping of works include Ken Lum's Untitled Language Painting, Fiona Banner's Corrections to the Text of Apocalypse Now (1996), Julia Loktev's DVD Press Shots (2001), and Banner's Arsewoman in Wonderland Black and Blue (Fig. 36). The Lum work commands the most attention of any work along that wall, thanks to its hanging in the middle, and its aggressive graphic nature which makes it easy to 'read' from a distance. Presumably viewers spend a lot of time in front of the canvas trying to do just that, as its sign-based conventions demand, before realising the text is completely nonsensical. The two Banner works are also text-based, except that they are the artist's attempt to transcribe the elusive visual language of two films (the punctuation for her 
transcription of Apocalypse Now and the film Asswoman in Wonderland, a pornographic telling of Alice in Wonderland) into written language. The resulting text is a visual form as well. Arsewoman in Wonderland Black and Blue, a blue silkscreen print with the transcribed text from the pornographic film, is messy and drippy, and the text handwritten, implicating the artist and her body. The drippyness also hints at bodily fluids produced by the actors during the film's 'action' sequences. Apocalypse Now is more impersonal - the artist has erased the actual words from her transcription (this act of excising the essential text is a counterpoint to Breitz's preservation of essential dialogue), leaving only the punctuation, but in this case they have been typed, rather than handwritten. As with the Lum piece, viewers find themselves trying to read the works, often unsuccessfully. Curator Bruce Grenville, in speaking of a Banner work in the same series as Arsewoman in Wonderland points out "the density of the surface makes it almost impossible to read as a continuous narrative. Instead the eye leaps from point to point, settling on individual words or short strings of words. Within this matrix of bodies - the actors', the artist's and the viewer's - a new body is configured, a body that is shaped and defined by language." 37 This representation of one media via another, or the transcribing of visual imagery into textual always falls short, and the viewer is left perpetually unsatisfied.

Loktev's DVD Press Shots plays on a plinth situated in front of and between the two Banner works (while still permitting an up-close viewing of these pieces). The proximity of Press Shots to Arsewoman is not accidental. Reading Banner's pornographic text first would certainly influence one's attempt to decipher what the figures in Loktev's video are doing, leading them to interpret them as being engaged in a sexual act, with the 
artist carefully recording their final moment of release. The plinth upon which the video monitor has been placed is an obvious phallic symbol, further influencing the viewer's interpretation. The figures are in fact lifting weights, their orgasmic facial movements relief at setting the weights back in their racks. Pleasure and pain are conflated; the pain one must endure to arrive at a beautifully sculpted and toned body (which presumably increases one's access to sexual partners and sexual acts and its consequent pleasure), the look of pain that crosses one's face at the moment of la petite mort, and the discomfiture at such a public enactment of so private a moment.

This erotic thread is continued along the back wall of the high gallery, with Shirin Neshat's Rapture and Thomas Ruff's Nudes vin05 (Fig. 37). Neshat's work is a still from her video installation composed of two opposing projections exploring Islamic society. One screen depicts the realm assigned to men within conservative Islamic society, the other that assigned to women, literally and figuratively separating the genders. ${ }^{38}$ The two narratives depict ritualised acts that grow in momentum, the men's within the confines of an abandoned fortress, the women's in a desert-like setting, that culminates in the departure of some of the women in a boat. Ruff's Nudes, on the other hand, allow the sexes to openly and graphically commingle, composed as it is of pornographic images found on the Internet, that the artist then manipulates (for example blowing up thumbnails to large format works). The blurriness of the series offers a hint to its appropriated nature, the identities of the original photographers and subjects never to be revealed. There is a dialogue of opposition going on between these two works: the obvious crispness of the Neshat emphasising the haziness of the Ruff, but more importantly the visual aesthetic of 
the Neshat, which follows traditional notions of beauty, creating easily the most visually seductive work in the Prototype exhibit, as well as Friday's collection as a whole. That this seductiveness can be translated to a bodily desire connects this work further to the others in this section. This seductiveness is at odds with the Ruff work in particular. The outright sexuality of the Ruff may also seem at odds with Neshat's veiled women, though the title Rapture suggests otherwise, and the women's chadors, by completely covering their wearers' bodies, invite one to imagine what may lie underneath.

The next grouping of work extends this erotic thread, by concentrating on the body itself, in particular the mouth (Fig. 38). The mouth, one of the most eroticised parts of the human body in terms of its form, with full, fleshy lips being the most prized (and some say highly reminiscent of genitalia), as well as function, with our lips, teeth and tongue's ability to suck, kiss, lick and nibble. Douglas Gordon's Croque Mort (2000), depicts a baby biting her own toes (which also resembles a penis being fellated), the title a nod to the old practice of assuring a body was dead by biting its toes. Spring Hurlbut's Ritual Scream (1997), a section of entablature which incorporates horse teeth dipped in blood, is part of a series which investigates the roots of classical architectural motifs in pagan sacrificial rituals. Hurlbut takes inspiration from art historian George Hersey, whose work The Lost Meaning of Classical Architecture (1988, MIT Press) traces the origins of Greek temples to wooded groves, where the inedible parts of animal sacrifices were frequently suspended in the trees, as they too assumed the divinity of the god or goddess in whose name the sacrifice was offered. Hersey further posits that these sacrificial remains became memorialized in the decorative aspects found in classical architecture. ${ }^{39}$ Hurlbut, by 
including the horse teeth, is simply helping them reclaim their original place, and also succeeds in evoking the act of eating or devouring, by the horse itself, as well as by the sacrifice participants. Though both works are openly sensuous, there is an underlying investigation of mortality and our own death customs.

Joyce Wieland's The Arctic Belongs to Itself(1973) represents a lipstick trace of the artist speaking the words of the title, and Douglas Gordon's Signature (1997) is just that, but as a bite mark rather than a handwritten vestige. Sterbak's Cones on Fingers (1995) displays a woman's hand with rolled up tape measures on the end of her fingers, thus subverting their original use, among them the measurement of the human body. Though this piece does not literally depict a mouth or the traces left by a mouth as the other works in this section do, it does refer to it at a distance. The units of bodily measurement suggest a preoccupation with the thin ideals women are expected to meet, a preoccupation which could lead to the restriction of what is allowed into the body via the mouth, i.e. food. This idea of the mouth once removed is repeated in the tape measures themselves, which prevent direct contact by the hand they entwine. Smith's My Secret Business (1993), an image of the artist licking the cracks in either a wall or along the floorboards, celebrates the body in all of its states, including the bizarre or distasteful.

A second piece from Hurlbut's series exploring the origins of classical architecture can be found in the centre of this room, Artemis, along with Richard Hughes' sculpture Crust (Fig. 39). Hurlbut's sculpture, which features ram's horns attached to an Ionic capital, is cleverly named after the goddess of the hunt; we can imagine that the artist is asking us to contemplate the ram's life shortly before its sacrificial death. Hughes' 
facsimile of a discarded and burned mattress, industriously recreated by hand, is suggestive of the bodies that have come into contact with it, and ties into the sexual undercurrent already present in the gallery. These two works refocus the viewer's attention on aspects of our surroundings easily ignored, thereby reconnecting us to the history of these objects. This, along with a focus on sexuality, text and language, and conventions of the cinematic, are the predominant themes which run through the works displayed in the high gallery. Humour and preoccupations with pop culture are also evident. This candid display of human kind's insecurities and private moments is somewhat at odds with such a public forum, perhaps indicating the collector's (and curator's) desire to connect with others, and to understand the world in which we live and their places within it. It explains Friday's willingness to share his private collection in such a public venue, something that would fill many collectors with trepidation. This change in context for the collection I would argue amplifies the threads of loneliness, desire and wanting Koh identified, particularly when displayed in the stark, impersonal gallery space. Back at Beattie house, these emotions are no less present, but muted by their cozy, domestic setting.

\section{The Far Gallery}

Let's make our way through the body of the exhibition (Fig. 40) to the farthest reaches of the gallery, to a small, self-contained 'room' created by the presence of a temporary wall. In this second section of Prototype we find Brian Jungen's sculpture Prototype for a New Understanding, with Ian Wallace's In the Studio, Simon Starling's Bicycle Wheel (Failed)(2004), N.E. Thing Co.'s $A C T \# 50$ - Saskatchewan Wheat Pool (1968), and Karl Blossfeldt's Rough Horsetail (1989) hung together on the back wall (Fig. 
41). The temporary wall adjacent to this displays Kirsten Pieroth's Untitled, with Starling's Home-Made Eames (Formers, Jigs and Molds) completing this section on the side wall (Fig. 42). All of these pieces share concepts and preoccupations very different from those works in the first section. There is a definite moving away from explorations of the body and sexuality towards themes of transformation and experimentation.

Jungen's Prototype for a New Understanding \#7 is part of a series of sculptures created by the clever disassembling of Nike Air Jordan running shoes and their subsequent reassembling into replicas of North West Coast masks. It is this idea of transformation that is central to the work; the transformation of a popular commodity imbued with an aura due to its association with the American basketball star Michael Jordan, into an object whose aura is now attributable to its status as an object of art, as well as an object with special ceremonial meaning for North West Coast First Nations. That this transformation is executed by the hand of the artist himself is also worth noting. As critic David Garneau writes, Jungen does not contract out the craft aspect of his work as many conceptual artists do, but instead hand-stitches these sculptures "to emphasize his presence and intervention,"and further suggests this gesture is a "symbolic reversal of the mechanized labour that went into the originals." 40

It is no accident that there is a commonality in design between these two seemingly disparate objects of shoe and mask. Jungen was interested in commenting on the appropriation of Aboriginal art by museums ${ }^{41}$ as exemplary of Native art practice as well as British Columbian identity:

I wanted to use material that was completely paradoxical to that, but merged some ideas of commodification, globalization and [the] work 
production of material. So, I used Nike Air Jordan trainers which had a very similar red, white and black color scheme and graduated curved lines, and proved to be very flexible working material. ${ }^{42}$

By keeping the 'made in Indonesia' tags intact on the insides of the masks, Jungen (who is of Swiss and Native parentage, specifically Dene-Zaa) coolly draws parallels between the subjugation of workers in developing countries and that of First Nations peoples by colonizing westerners. The masks' hybridity is also shared by the artist himself.

Jungen chose to title these works Prototype because they don't actually function as masks, but "only mimic them." 43 The word prototype not only indicates an examplar or a model, but also suggests experimentation, a thread that also runs through the work of Simon Starling. Both Home-Made Eames (Formers, Jigs and Molds) and Bicycle Wheel (Failed), are attempts by the artist to re-create historical artifacts or circumstances by hand, "practising his own craftmanship in homage to past craftsmen." 44 This interest in craftmanship is also shared by Jungen. In the case of Home-Made Eames (Formers, Jigs and Molds), the series of photographs document the tools the artist used to create replicas of Charles and Ray Eames' 1948 DSS chair. The chairs were the first to be made of industrially produced plastic, and were meant to bring affordable, good design to the masses. The failure of this modernist utopian dream is today evident in the high prices the original chairs fetch. Starling refers to these as "remades," whereby the object is completely reconstructed, in an attempt to "use the new product as a way to highlight the aesthetic, technical and practical qualities of the original."45

Bicycle Wheel (Failed) more overtly addresses experimentation and failure, while also referencing Duchamp. The photograph of the bent bicycle wheel documents his 
attempts to build a prototype for a five-man bicycle based on lightweight bridge designs by pioneering Danish engineer, Mikael Pederson. ${ }^{46}$ As we can see by the bent wheel, the first test run failed. Starling's work, like Jungen's, investigates the mass production and commodification of objects, and reveals an interest in the aura of both the original and reconstructed object. This attempt to literally recreate modernist icons, and ultimate failure, disrupts them.

Kirsten Pieroth's Untitled is also an attempt to recreate an object of historical interest, a photograph the artist found in the archives of inventor Thomas Edison. This work is part of an exhibition inspired by a letter he wrote that reads 'I regret that a previous engagement prevents me from accepting your kind invitation to dinner at your home, on Thursday evening, September seventeenth.' Pieroth, in an attempt to discover if Edison had 'invented' the excuse, further explores his persona "outside of the verifiable facts of his biography in order to pursue the fictional tangents of his life and discoveries. ${ }^{247}$ That Pieroth takes Edison as her source for inspiration is an overt continuation of the preoccupation with experimentation found amongst the works in this section of the gallery; literally because Edison himself was a scientist, and figuratively as the artist herself pursued modes of scientific inquiry. These methods include her thorough research into his archive, and her attempts at reproducing objects Edison used in his own experiments, analogous to the practice of scientists reproducing the results of other scientists to establish validity.

The photograph, entitled Experimental Garden, Fort Myers, Florida, is of a bench with two beehives perched on it, taken at Edison's winter home, which had a lab and an 
experimental garden on the premises. He liked to conduct botanical experiments here, and kept bees to pollinate the garden, as well as to produce wax for his experiments. ${ }^{48}$ The artist, in her recreation of the photograph, was only able to find one antique beehive, so she decided to rip the photograph in two, and then saw the bench in half to match. This compulsion to reproduce little-known, peripheral aspects of Edison's life and work questions how we come to know people through history, what details of their lives are perpetuated and mythologised, what constructs identity. The work is also very much object and process based, like Starling's and Jungen's.

The work of Karl Blossfeldt may at first seem out of place in this exhibition (it is the only historical piece Friday owns), but the photographer built his own camera to take his micro-photographs of plant parts. It is this spirit of invention which ties his work to that of Starling and Pieroth. Blossfeldt's teacher Moritz Meurer encouraged his pupil's attempt at compiling a collection of natural forms as an inspiration for art students. Meurer believed "that the study of nature would invigorate his students' design sensibilities, which, he felt, had been coarsened by exposure to modern machine production." seen in the work of Starling and Jungen. Paradoxically, the architectural forms resulting from Blossfeldt's magnification of plant parts obscure the subject's natural origins, suggesting an affinity with things more technological.

Blossfeldt's interest in documentation is also found in the work of Starling, who documented the tools he used in Home-made Eames and the result of his bicycle experiment, as well as Pieroth, not interested in the process of documentation per se, but 
in documents themselves. Even though Blossfeldt never considered himself an artist, more a scientist, his magnified images of plants made visible things which had been previously concealed, a project common amongst most of the conceptual artists in Friday's collection..$^{50}$

The process of documentation is also a preoccupation of artist Ian Wallace, whose photograph In the Studio is but one of many works he has produced since 1969 that have recorded his work space in detail. Wallace's intent was to relate "the intellectual aspects of conceptual art with direct references to the material production of the art object, a selfconsciously modernist strategy which still informs my work." This concern with the materiality of the work itself is shared by all of the artists in this section, though Wallace's project extends to the space of art production, and the tools of production. It is not difficult to conflate the idea of the artist at work in his studio to that of the scientist at work in his laboratory.

The work of N.E. Thing Co., like that of Jungen, disturbed preconceived notions of what was considered art, and demanded that it not be understood primarily as a marketable commodity. Their piece $A C T \# 50$ - Saskatchewan Wheat Pool, a photograph of an industrial building to which they affixed their ACT seal (Aesthetically Claimed Thing), was in antagonism to their ART (Aesthetically Rejected Thing) category. This recuperation of non-art objects as art has parallels in Blossfeldt's work, where the viewer is required to acknowledge beauty in everyday objects, a practice which ultimately has its roots in Marcel Duchamp's Readymades. NETCO's attempt at demystifying art and linking it to the real world also had the effect of extending the space of experimentation 
beyond the lab or studio. The business-inspired incorporation of their art practice suggests an institutional mockery and emphasis on humour, also evident in the work of Jungen, Pieroth and Starling.

The works in this section of the exhibition deal with very different themes than those in the previously discussed section. Whereas the high gallery focussed on the body, sexuality, and the experiences of the individual, this section explored themes of technology, transformation, experimentation, and the primacy of the object over the individual. An intense desire by the artists to document was also evident; all of the works, with the exception of the Jungen, were photographs or incorporated photography, the favoured medium of the documentarist.

\section{Back at Beattie House}

These themes are much more diffuse within Friday's home, simply because of the nature of the house. There are no large expanses of wall on which to display sizeable portions of his collection simultaneously, which the gallery effortlessly allows. Unlike some collectors, for example Paul Marks, Friday's home does not contain spaces specifically designated for the display of his collection. Threads which can easily be discerned in the gallery space are less cohesive in the house, though no less powerful. The intimacy of the domestic setting allows viewers to focus on single works with fewer diversions, rather than being distracted by the large space of CUAG. ${ }^{52}$

Friday not only deliberates at length before making his purchases, but devotes much time to where and how these acquisitions will be displayed. There is an appropriateness to the rooms some of the works are found in, or placed close to. Works 
derive meaning not only from other works close by, but also by their locations in the house, and the domestic objects placed near them. Such derivations would be frustrated in the white cube of a gallery space. Friday frequently moves things around (locations of many of the works have already changed several times since the photographs were taken), and is acquiring new works on an ongoing basis, hence the meaning-making process occurring in the house never ends. Prototype was but a brief snapshot of a collection in progress, a collection which has retreated back, for the time being at least, to its private shell.

The first familiar works we encounter from Prototype are Neshat's Rapture (Fig. 43) and Lum's Untitled Language Painting (Fig. 44). Rapture has not been hung up, but instead leans against the front staircase, and is perhaps an embodiment of Friday's continuing ambivalence towards this work. Lum's piece, by contrast, has been installed, its bold graphics intensified by the narrow hallway, the loud voice the work 'spoke' with in the exhibition now a shout. The series of circular rugs on the floor which echo the exclamation mark present in the work also serve to heighten its graphic nature. Jungen's mask Prototype sits directly across from the Lum work, and shares the same black and white colour scheme, which is further picked up by the black staircase banister as it winds its way to the second floor. The energy of these works as they feed off of each other is palpable, and the viewer finds their eyes bouncing from the art to the decorative rugs to the architecture in rapid succession. This ability of household objects to enter into whimsical and playful dialogue with the collection is something that would be difficult to reproduce in a gallery setting. 
The Alex Morrison work Every House I Have Ever Lived in Drawn From Memory (Fig. 45) is found further along this hallway, just outside the dining room. This work could be appropriately hung in any room of the house as it is a reflection on one's own origins and memories, and serves to bring Beattie House's heritage into sharper focus. As writer Rosemary Heather points out "Houses, if not homes, begin with people and families before you; their experience is its residue." ${ }^{53}$ Morrison has, in the past, drawn these remembered dwellings directly on to the walls of galleries, recreating architecture within architecture. It is easy to imagine that a similar direct transposition onto the walls of Beattie House would be especially poignant. The transiency of these remembered houses is also an interesting counterpoint to the permanence and solidity of Friday's home.

On the opposite wall of this same hallway, which also leads to the kitchen, we encounter three works hung one below the other, two of which appeared in the same configuration in Prototype, Wieland's The Arctic Belongs to Itself and Gordon's Signature (Fig. 46). Hurlbut's Ritual Scream has been replaced by David Shrigley's Drink This (1998), a photograph of a jar of what appears to be urine, with an attached label encouraging its drinking, reminiscent of instructions to Alice in Alice in Wonderland. Ritual Scream, still in close proximity, appears above the entryway to the kitchen (its location well above eye level, underscoring its identity as architecture) (Fig. 47), and Banner's Arsewoman in Wonderland is the final work to be found in this section. The theme of the mouth found in Prototype is echoed here, appropriate for the dining room and the threshold to the kitchen: Friday's sly introduction of humour. While the inclusion of the Banner piece may seem incongruous at first (pornographic content in the 
diningroom?!), its messy corporeality is entirely appropriate, pointing to the inherent eroticism of food. There is also the more literal Alice in Wonderland connection to the Shrigley piece. These oral and sexual allusions are appropriately continued in the kitchen, where we find Kiki Smith's My Secret Business (Fig. 48).

If we turn left instead of continuing into the kitchen, we find ourselves in Friday's diningroom, along with Starling's Bicycle Wheel (Fig. 49) and N.E. Thing Co.'s $A C T \# 50$ - Saskatchewan Wheat Pool (Fig. 50), works which were also displayed together in Prototype. Their demand that we reconsider as art traditionally non-art objects, as well as their undercurrent of humour, plays off the repurposed samovar with the rooster feet as a light fixture and Napoleon's Tomb as a liquor cabinet. This room is entirely furnished with antiques and a large oriental carpet (Fig. 51), and these works help lighten the mood of this fairly formal dining room. ${ }^{54}$

A quick detour through the library brings us to the living room where Hurlbut's Artemis is displayed to great effect, the piece's capital emphasized by the plaster ceiling and mouldings, as well as the dramatic backlighting. Artemis sits on the same plinth it did in Prototype, the only object in the house displayed in a matter more suggestive of a gallery space than a domestic space, so that this piece fully commands the viewer's attention. The architectural conversation carried on by the work and its surroundings not only demands the viewer contemplate the origins of classical architecture, but the history of the house itself. Starling's Home-made Eames, diagonally across from Artemis, also investigates the history of an object, and is appropriately placed adjacent to the reproduction Franck sofa and across from the copies of Le Corbusier's armchairs. This 
grouping of 'reproductions' is noteworthy.

Climbing up the graceful staircase to the second floor, we encounter Gordon's Croque Mort hanging over the staircase (Fig. 52), with Ruff's Nudes vin05 diagonally across from it (Fig. 53), installed just outside the door of the spare bedroom.

Conveniently, anyone standing in front of the Ruff also has a direct sight line to the spare bedroom's bed, so that one could easily imagine the couple from the photograph frolicking on the bed, in the flesh. Both of these works hang alone on their respective walls, with no additional works to distract from or temper their meanings. In the spare bedroom, just adjacent to the Ruff, we find Ian Wallace's In the Studio hanging (Fig. 54). Its representation of an interior is appropriate for a spare bedroom, usually a private space reserved for close friends and family. It contrasts nicely with another Wallace piece in Friday's collection, Sarah: Heroes in the Street, a street scene hung in the living room, probably the most public of rooms in a private home.

Sterbak's Cones on Fingers (Fig. 55) and Banner's Corrections to the Text of Apocalypse Now (Fig. 56) have both been installed in Friday's bedroom, as well as Moffatt's Piss Bags and Kwong Sisters (Fig. 57) and the Blossfeldt piece (Fig. 58). The bedroom, a room which automatically evokes associations with the body in its most intimate behaviours, is a fitting location for these pieces. While Sterbak's work deals more obviously with the body, Banner's evokes the absent body. It is after all the artist herself who transcribed the visual language of Apocalypse Now, and then erased the text leaving only the punctuation marks. The pairing of this work with Cones on Fingers, and its placement in the bedroom bring its bodily intimations to the foreground. Without its 
placement next to Banner's Arsewoman in Wonderland and Lum's Untitled Language

Painting, its textual themes recede into the background.

Blossfeldt's Rough Horsetail, which is not obviously a magnified plant part at first glance, and by virtue of its placement in the master bedroom, could be easily mistaken for a body part, specifically a penis. The Moffatt photographs, staged re-enactments of fictional childhood incidents, are hung in a room that encourages reflection on and dissection of their meanings, preferably from the comfort of a bed. One can easily enter into imaginative daydreams about these poor children, and the abuse heaped on their physical and metaphorical bodies.

Friday also has two monitors in the house on which he plays his DVD collection. One is in the study (a good place to contemplate a DVD) and the other in the spare bedroom (Fig. 59), also a space of contemplation. Watching Loktev's Press Shots would be particularly meaningful in the spare bedroom, just around the corner from Ruff's frolicking nudes. Two sculptures from Prototype, Hughes' Crust and Pieroth's Untitled were not on display in Friday's home at the time the photographs were taken, as they are difficult pieces to display due to their size (and the presence of animals!). In fact, it is only recently that Friday uncrated the Pieroth work and placed it in the spare bedroom after emptying the room of its previous artworks. ${ }^{55}$

This concludes our tour of Friday's house, a Gesamtkunstwerk whose architecture, household objects and decorative scheme enters into meaningful dialogue with the art collection housed within. Prototype permitted the public display of Friday's collection and generated significant discussion. However, it is the polysemous dialogue enabled by 
Beattie House that reveals the true complexity of the collection and its collector.

1. Walter Benjamin, "Eduard Fuchs: Collector and Historian," in The Essential Frankfurt School Reader, eds. Andrew Arato and Eike Gebhardt (New York: Urizen Books, 1978), 250.

2. Joe Friday, e-mail correspondence with the author, 9 September 2006.

3. Louisa Coates, Ottawa: A Guide to Heritage Structures (Ottawa: City of Ottawa, 2000), 115.

4. Historical and Architectural Committee of Action Sandy Hill, Walking in Sandy Hill (Ottawa: Heritage Ottawa, 1977), 39.

5. C. J. Taylor, Canadian Inventory of Historic Buildings: Historical Building Report, February 1975

(LACAL file, City of Ottawa, Ottawa, Ontario), 3.

6. Ibid.

7. Louis Audette, Letter to Robert Bailey, 12 September 1980. File on 451 Besserer St. (City of Ottawa, Ottawa, Ontario).

8. Friday, e-mail correspondence with the author, 9 September 2006.

9. John Leaning and Lyette Fortin, Our Architectural Ancestry (Ottawa: Haig and Haig Publishing Co., 1983), 48 .

10. Gladys Blair, "Historic Home: 451 Besserer St.," Ottawa Journal, 14 March 1970, Saturday Section, n.p.

11. File on 451 Besserer St, compiled May 1975 (City of Ottawa, Ottawa, Ontario).

12. Friday, e-mail correspondence with the author, 9 September 2006.

13. Ibid.

14. Angela Mangiacasale, "Ageless Beauty," The Ottawa Citizen, 10 May 1997, D1.

15. Friday, e-mail correspondence with the author, 9 September 2006.

16. This bookcase was part of a pair, the second of which Audette bequeathed to the Canadiana Fund and which is now found at Rideau Hall. Ibid.

17. Friday believes his collection contains roughly 200 items, and is an obvious extension of his collecting activities. Highlights include General Idea's XXX Voto: To the Spirit of Miss General Idea, a book Friday also gave Michael Bell upon his retirement from CUAG, and three bookworks by Rodney Graham: $\mathrm{Dr}$. No, The System of Landor's Cottage, and The Piazza, editioned works Friday considers essential to the artist's practice. He has also collected all of David Shrigley's book works. Ibid.

18. Ibid. 
19. Ibid.

20. Ibid.

21. Ibid.

22. Ibid.

23. Mangiacasale, D1.

24. Germaine Koh, curator talk, Carleton University Art Gallery, Ottawa, 17 October 2004.

25. In many ways, Koh was the perfect choice to curate this show. In her catalogue essay she refers to Friday's collection as having a certain "coolness" and intellectual rigour that is also found in her own work as well as her persona. In the written interview with her, she admitted "my thought processes do not lend themselves to being shared before I have been able to formulate them fairly well," a deliberateness and cautiousness which I would argue is analogous to Friday's acquisition processes. The existence of a work of Koh's in Friday's collection, I believe, provided Koh with special insight particularly as the ideas her work grapples with are prevalent throughout the collection.

26. Koh, curator talk, Carleton University Art Gallery, Ottawa, 17 October 2004.

27. Ibid.

28. Germaine Koh, Prototype: Contemporary Art from Joe Friday's Collection, unpublished catalogue essay (Ottawa: Carleton University Art Gallery, 2004), n.p.

29. Germaine Koh, written interview with author, 28 May 2005.

30. Koh, Prototype, n.p.

31. Koh, Prototype, n.p.

32. Koh, Prototype, n.p.

33. Koh, written interview with author, 28 May 2005.

34. Ibid.

35. Ibid.

36. Eve Sullivan, "The Juvenilia of Tracey Moffatt," Art and Australia 41.2 (2003): 238.

37. Bruce Grenville, "Body," in Body: New Art from the UK (Vancouver: Vancouver Art Gallery, 2005), 12.

38. Bill Horrigan, "A Double Tour," in Shirin Neshat: Two Installations (Columbus, Ohio: The Wexner Center for the Arts, 2000), 11.

39. Jerry McGrath, "Ritual Ornament/Decorative Dream," Parachute 72 (October-December 1993): 12.

40. David Garneau, "Beyond the One-Liner: The Masks of Brian Jungen," Border Crossings 19.4

(November 2000): 91. 
41. Ironically, the artist intended the masks to be displayed in museum vitrines, though it was not a condition Jungen attached to their purchase. Following discussions with Jungen and his dealer Catriona Jeffries, Friday is considering having a vitrine built. Friday, email correspondence with the author, 9 September 2006.

42. Nancy Tousley, "Spotlight: Brian Jungen: Cool, Cooler, Coolest," Canadian Art 20.2 (summer 2003); 43.

43. Jens Hoffman, "Brian Jungen: Prototypes for a New Understanding," Flash Art 231 (July - September 2003): 86.

44. Daniel Birnbaum, "Transporting Visions: Daniel Birnbaum on the Art of Simon Starling," Artforum 42.6 (February 2004): 106.

45. Paul Ardenne, "Simon Starling's Nest of Associations," Art Press 273 (2001): 50.

46. Michael Kimmelman, "Art in Review; Simon Starling," New York Times, 12 March 2004, February 2006 <http://www.nytimes.com/2004/03/12/arts/design/12GALL.html?ex=1394514000\&en=c2ff643dd73b8185\& $\mathrm{e}=5007 \&$ partner $=$ USERLAND $>$.

47. "Artists: Pieroth, Kirsten," Manifesta 5 date unknown, February 2006 $<$ http://www.manifesta.es/eng/artistas/artistas/pieroth.htm>.

48. Contemporary Art Gallery, I don't know if Thomas Edison invented the excuse: Kirsten Pieroth, poster (Vancouver: Contemporary Art Gallery, 2004).

49. Dorothea Dietrich, "Micro-Vision: Karl Blossfeldt's Urformen der Kunst," Art on Paper 3.1 (September/October 1998): 35.

50. A further link between Blossfeldt and Starling occurs in a work not in Friday's collection. Starling's Work, Made-Ready, in Light of Nature (2003), a project connecting the cities of Rome and Berlin through an intricate narrative involving Blossfeldt's models of plants, a Roman foundry, a brown aluminum bike frame, and a deconstructed green-upholstered aluminum chair. Bimbaum, 106. Blossfeldt, in addition to producing photographs of plants, also created bronze replicas, which were produced at the Nisini foundry in Rome. Starling, fusing portions of a bicycle and chair into forms that recall Blossfeld's plants, also used melted aluminum fragments from the same chair and bicycle to produce further copies of Blossfeldt's models using the lost wax casting method. These objects, along with detritus from the casting process, were then displayed in vitrines following Gottfried Semper's models of exhibition, which aimed to show the processes by which materials are transformed, in particular the transformation of industrial materials into works of art, a desire also shared by Starling. Gianfranco di Maraniello, "Simon Starling's "Formation"," MACRO date unknown, February $2006<$ http://www.macro.roma.museum/english/press/starling/maraniello_starling.pdf $>$. Whether or not Koh knew about this work when placing Blossfeldt's Rough Horsetail in the same section as the two Starling pieces is unknown, I never posed this question directly to her, having discovered the connection myself post-interview. I can speculate that she did in fact know of it.

51. Ian Wallace, Ian Wallace: Corner of the Studio; El Taller (Cantabria, Spain: Sala Robayera, 1994), n.p.

52. Art historian Reesa Greenberg, writing about the changes in exhibition spaces for contemporary art in the last decades of the twentieth century, comments on the disappearance of seating from gallery spaces which she considers an "index of changed attitudes towards the gallery as a temporary "home" for art and its transformation into a place of and for work." The lack of seating demands the viewer to work, as they are no longer able to contemplate art from a comfortable couch or chair. Greenberg continues: "Without the invitation extended by seating to linger in an assignation with art, the encounter becomes pedestrian." Reesa 
Greenberg, "The Exhibited Redistributed: A Case for Reassessing Space," in Thinking About Exhibitions, eds. Reesa Greenberg, Bruce W. Ferguson, and Sandy Nairne (New York: Routledge, 1996), 351.

53. Rosemary Heather, "mnemonic construction in progress," in Every House I have Ever Lived in Drawn from Memory (Halifax: Eyelevel Gallery, 1998), n.p.

54. In an e-mail from Friday telling me of the addition of a recent purchase to the dining room, Geoffrey Farmer's photograph that "depicts two tables, one overturned on the other, that were part of a group of cast-off furniture that didn't (at least at the point the work was made) get burned in his show at the Power Plant last year. I wanted the Geoffrey work in there for a number of reasons, including its reference to the destruction and reconstruction of cultural histories through consumer/industrial production. ... it has an interesting and hidden relevance in that particular room as it is now furnished. Our creaky old dining room chairs come from the estate of the former head of protocol for the Governor General (so there is a fun sort of Canadian/Ottawa cultural reference there), and each of them has stamped on the bottom, the name of the manufacturing company and "Berlin, Ontario." During the First World War, Berlin, ON changed its name to Kitchener, as you likely know, in an effort to avoid any perception of German connections and the potential for misinterpretion, purposeful or otherwise, of alliances and links. And many pieces of furniture bearing the Berlin mark were destroyed or the name erased on them, from what I have been told. So, our old chairs themselves, have a quirky, but secret (until now) role to play in the interpretation of the art work in that room." Joe Friday, email correspondence with the author, 5 September 2006.

55. Ibid. 


\section{CONCLUSION}

Understanding the collecting practices of Joe Friday, his accrual of capital and reliance on social networks, and the environment in which his collection is housed, is essential to an understanding of his collection. This exploration has revealed an exceptional and astute collection being amassed in the city of Ottawa, a collection of contemporary art featuring the cutting edge of Canadian and international conceptualism. Contrary to his counterpoints who are collecting from the large centres of art production of Toronto and Vancouver, he has had to adopt different strategies of acquisition. These strategies have included a heavy reliance on the Internet, frequent visits to art fairs, and the development of strong relationships with gallerists and other players in the art world. These strategies have proven to be successful, as he has without a doubt amassed a collection of contemporary art unrivalled in this country. That he has done so with modest financial means is a testament to his passion and erudition.

Friday has accumulated considerable quantities of educational, cultural and symbolic capital. His shrewd purchasing of work by emerging artists prior to their winning prestigious awards, or preceding widespread recognition by the art establishment, means that his collection has not only appreciated in value, but that his financial capital has also increased. This substantial accrual of all forms of capital, in conjunction with his artistic habitus, allows Friday to easily manoeuver the art world and continue to acquire works of art.

The distinctive environment Friday has created for his collection hinges on intriguing juxtapositions such as weighty conceptual art paired with playful multiples and 
decorative objects, in a heritage home furnished in both antique and contemporary styles. Beattie House has become a salon of sorts, frequented by artists, gallerists, academics and art lovers from the local, national, and international art scenes. We can all benefit from Friday's willingness to open his home and collection to the public, and it can be argued that he has become an excellent role model for other Canadians wishing to collect art, or to make art an integral aspect of their lives. This promotion of arts and culture supports all those who make up the fragile ecology of the Canadian art milieu, and may lead to Canada one day boasting of a culture of collecting to rival that of Europe and the United States. There remain many unexplored avenues of collecting in Canada. Although the preceding analysis offered a comprehensive study of one collector, there continue to be hundreds, if not thousands, of private collections left unexamined. Collections found in public institutions, either amassed by the institutions themselves, or donated by private collectors are worthy of further study. A detailed investigation of the Canadian field of cultural production, which fell beyond the scope of this thesis, would be another fruitful area for further research. The individuals and institutions that are actors in this field, and a dissection of the networks that exist between them would prove fascinating subjects for future study. 


\section{LIST OF FIGURES}

1 Installation view, at top: Jana Sterbak, Cones on Fingers (1995), silver gelatin print. Beattie House, Ottawa, April 2004.

Source: Author's photograph.

2 Installation view, on the left: Joanne Tod, Johannesburg Suite (1983), acrylic on canvas. Prototype exhibition, Carleton University Art Gallery, Ottawa, October 2004.

Source: Photograph courtesy of Michelle McGeough.

3 Installation view, Carol Wainio, Speech Patterns (1984), mixed media on paper. Beattie House, Ottawa, January 2005.

Source: Photograph courtesy of Michelle McGeough.

4 Russell Yuristy, The Painter (1987), cast paper. Collection of Joe Friday. Source: Photograph courtesy of John Inca Anderson.

5 Installation view, Simon Starling, Home-made Eames (Formers, Jigs and Molds)(2002), 4 c-prints. Beattie House, Ottawa, January 2005.

Source: Photograph courtesy of Michelle McGeough.

6 Installation view, Brian Jungen, Prototype for a New Understanding \#7 (1999), Nike Air Jordans. Beattie House, Ottawa, April 2004.

Source: Author's photograph.

7 Installation view, Fiona Banner, Arsewoman in Wonderland Black and Blue (2000), screenprint. Beattie House, Ottawa, November 2006.

Source: Photograph courtesy of John Inca Anderson.

8 Lynne Cohen, Spa (1991), silver gelatin print. Collection of Joe Friday. Source: Author's photograph.

9 Installation view, Ken Lum, Untitled Language Painting (1988), oil on plywood. Beattie House, Ottawa, Spring 2004.

Source: Photograph courtesy of Joe Friday. Taken by Alex Meyboom for Canadian Art magazine.

10 Installation view, Ron Terada, Jeopardy (Iggy Pop)(1998), acrylic on canvas. Beattie House, Ottawa, Spring 2004.

Source: Photograph courtesy of Joe Friday. Taken by Alex Meyboom for Canadian Art magazine. 
11 Installation view, Ian Wallace, Guggenheim (1992), acrylic and photo-laminate on canvas. Beattie House, Ottawa, January 2005.

Source: Photograph courtesy of Michelle McGeough.

12 Installation view, above the couch: Ian Wallace, Sarah: Heroes in the Street (1986), photo-laminate on canvas. Beattie House, Ottawa, January 2005.

Source: Photograph courtesy of Michelle McGeough.

13 Installation view, Geoffrey Farmer, Puppet Kit (2001), crate containing various media and video. Beattie House, Ottawa, April 2004.

Source: Author's photograph.

14 Installation view, Michael Elmgreen and Ingar Dragset, Powerless Structure Fig. 176 (2001), aluminum cans, paint and shelf. Beattie House, Ottawa, January 2005. Source: Photograph courtesy of Michelle McGeough.

15 Installation view, Allan McCollum, Visible Markers (1997-2002), concrete ingot. Beattie House, Ottawa, January 2005.

Source: Photograph courtesy of Michelle McGeough.

16 Installation view, far right: Kelly Mark, Dirty Rice Bowl (2002), rice bowl and chopsticks. Beattie House, Ottawa, April 2004.

Source: Author's photograph.

17 Installation view, Germaine Koh, One Begins (2001), 2 c-prints. Beattie House, Ottawa, April 2004.

Source: Author's photograph.

18 Installation view, Spring Hurlbut, Artemis (1990), concrete, rams' horns, and wooden plinth. Beattie House, Ottawa, January 2005.

Source: Photograph courtesy of Michelle McGeough.

19 Interior view, livingroom plaster ceiling. Beattie House, Ottawa, November 2006. Source: Photograph courtesy of John Inca Anderson.

20 Installation view, far right: A. A. Bronson, Felix Partz, June 5, 1994 (1999), cprint. Beattie House, Ottawa, Spring 2004.

Source: Photograph courtesy of Joe Friday. Taken by Alex Meyboom for Canadian Art magazine.

21 Installation view, Jonathan Monk, People I Have Met (2000 and 2003), two business cards with "whiteout." Beattie House, Ottawa, January 2005.

Source: Photograph courtesy of Michelle McGeough. 
22 Installation view, Jeremy Deller, Give Music a Chance (2003), colour photograph. Beattie House, Ottawa, November 2006.

Source: Photograph courtesy of John Inca Anderson.

23 Interior view, kitchen and tiles. Beattie House, Ottawa, November 2006.

Source: Photograph courtesy of John Inca Anderson.

24 Interior view, bathroom and tiles. Beattie House, Ottawa, November 2006.

Source: Photograph courtesy of John Inca Anderson.

25 Exterior view, Beattie House, Ottawa, January 2005.

Source: Photograph courtesy of John Inca Anderson.

26 Interior view, bookcase with catalogue collection. Beattie House, Ottawa, November 2006.

Source: Photograph courtesy of John Inca Anderson.

27 Interior view, livingroom sofa and coffee table. Beattie House, Ottawa, January 2005.

Source: Photograph courtesy of Michelle McGeough.

28 Interior view, Art Nouveau floor lamp. Beattie House, Ottawa, November 2006. Source: Photograph courtesy of John Inca Anderson.

29 Interior view, cellarette in dining room. Beattie House, Ottawa, November 2006. Source: Photograph courtesy of John Inca Anderson.

30 Interior view, samovar/lamp. Beattie House, Ottawa, November 2006.

Source: Photograph courtesy of John Inca Anderson.

31 Interior view, wooden hat forms. Beattie House, Ottawa, November 2006.

Source: Photograph courtesy of John Inca Anderson.

32 Interior view, Eames lounge chair with Eames leg braces. Beattie House, Ottawa, November 2006.

Source: Photograph courtesy of John Inca Anderson.

33 Installation view, front to back: Jennifer Lew, $\mathrm{Ca} \mathrm{Ca}$ (2003), felted turds, and Germain Koh, I Will (2002), copper tokens. Beattie House, Ottawa, November 2006.

Source: Photograph courtesy of John Inca Anderson. 
34 Interior view, statuary foot, marble. Beattie House, Ottawa, November 2006. Source: Photograph courtesy of John Inca Anderson.

35 Installation view, from left to right: Ken Lum, Untitled Language Painting; Alex Morrison, Every House I Have Ever Lived in Drawn From Memory (1998), graphite drawings; Tracey Moffatt, Piss Bags and Kwong Sisters (1998), offset prints; and Candice Breitz, Soliloquy (Clint)(2000), DVD. Prototype exhibition, Carleton University Art Gallery, Ottawa, October 2004.

Source: Photograph courtesy of Michelle McGeough.

36 Installation view, from left to right: Fiona Banner, Arsewoman in Wonderland Black and Blue; Julia Loktev, Press Shots (2001), DVD; Fiona Banner, Corrections to the Text of Apocalypse Now (1996), hydrostatic print; and Ken Lum, Untitled Language Painting. Prototype exhibition, Carleton University Art Gallery, Ottawa, October 2004.

Source: Photograph courtesy of Michelle McGeough.

37 Installation view, back wall, left to right: Thomas Ruff, Nudes vin05 (2000), laserchrome and Diasec; and Shirin Neshat, Rapture (1999), silver gelatin print. Prototype exhibition, Carleton University Art Gallery, Ottawa, October 2004. Source: Photograph courtesy of Michelle McGeough.

38 Installation view, left to right: Kiki Smith, My Secret Business (1993), offset print; Jana Sterbak, Cones on Fingers; Spring Hurlbut, Ritual Scream (1997), horse teeth, blood, and wood; Joyce Weiland, The Arctic Belongs to Itself(1973), print; Douglas Gordon, Signature (1997), bite mark on paper; and Douglas Gordon, Croque Mort (2000), colour photograph. Prototype exhibition, Carleton University Art Gallery, Ottawa, October 2004.

Source: Photograph courtesy of Michelle McGeough.

39 Installation view, foreground, left to right: Spring Hurlbut, Artemis; and Richard Hughes, Crust (2003), mixed media (cloth, cotton stuffing, wire, thread, and paint). Prototype exhibition, Carleton University Art Gallery, Ottawa, October 2004.

Source: Photograph courtesy of Joe Friday.

40 Installation view, main gallery. Prototype exhibition, Carleton University Art Gallery, Ottawa, October 2004.

Source: Photograph courtesy of Michelle McGeough.

41 Installation view, left to right: Brian Jungen, Prototype for a New Understanding \#7; Ian Wallace, In the Studio (1995), colour photograph; Simon Starling, Bicycle Wheel (Failed)(2004), platinum/Palladium print; N.E. Thing Co., ACT \#50 - 
Saskatchewan Wheat Pool (1968), black and white photograph; and Karl Blossfeldt, Rough Horsetail (1989), photograph. Prototype exhibition, Carleton University Art Gallery, Ottawa, October 2004.

Source: Photograph courtesy of Michelle McGeough.

42 Installation view, left to right: Simon Starling, Home-made Eames; Brian Jungen, Prototype for a New Understanding \#7; Joanne Tod, Johannesburg Suite; and Kirsten Pieroth, Untitled (2003), beehive, bench and torn photograph. Prototype exhibition, Carleton University Art Gallery, Ottawa, October 2004.

Source: Photograph courtesy of Joe Friday.

43 Installation view, front hallway with, from left to right: Shirin Neshat, Rapture; and Brian Jungen, Prototype for a New Understanding \#7. Beattie House, Ottawa, January 2005.

Source: Photograph courtesy of Michelle McGeough.

44 Installation view, front hallway with, left: Ken Lum, Untitled Language Painting. Beattie House, Ottawa, January 2005.

Source: Photograph courtesy of Michelle McGeough.

45 Installation view, Alex Morrison, Every House I Have Ever Lived in Drawn From Memory. Beattie House, Ottawa, January 2005.

Source: Photograph courtesy of Michelle McGeough.

46 Installation view, from top to bottom: David Shrigley, Drink This (1998), c-print; Joyce Weiland, The Arctic Belongs to Itself; and Douglas Gordon, Signature.

Beattie House, Ottawa, January 2005.

Source: Photograph courtesy of Michelle McGeough.

47 Installation view, over doorway, Spring Hurlbut, Ritual Scream. Beattie House, Ottawa, January 2005.

Source: Photograph courtesy of Michelle McGeough.

48 Installation view, Kiki Smith, My Secret Business. Beattie House, Ottawa, January 2005.

Source: Photograph courtesy of Michelle McGeough.

49 Installation view, Simon Starling, Bicycle Wheel (Failed). Beattie House, Ottawa, January 2005.

Source: Photograph courtesy of Michelle McGeough. 
50 Installation view, N.E. Thing Co., ACT \#50 - Saskatchewan Wheat Pool. Beattie House, Ottawa, January 2005.

Source: Photograph courtesy of Michelle McGeough.

51 Interior view, diningroom. Beattie House, Ottawa, January 2005.

Source: Photograph courtesy of Michelle McGeough.

52 Installation view, Douglas Gordon, Croque Mort. Beattie House, Ottawa, January 2005.

Source: Photograph courtesy of Michelle McGeough.

53 Installation view, Thomas Ruff, Nudes vin05. Beattie House, Ottawa, January 2005.

Source: Photograph courtesy of Michelle McGeough.

54 Installation view, bottom: Ian Wallace, In the Studio. Beattie House, Ottawa, November 2006.

Source: Photograph courtesy of John Inca Anderson.

55 Installation view, top: Jana Sterbak, Cones on Fingers. Beattie House, Ottawa, January 2005.

Source: Photograph courtesy of Michelle McGeough.

56 Installation view, Fiona Banner, Corrections to the Text of Apocalypse Now. Beattie House, Ottawa, January 2005.

Source: Photograph courtesy of Michelle McGeough.

57 Installation view, Tracey Moffatt, Piss Bags and Kwong Sisters. Beattie House, Ottawa, January 2005.

Source: Photograph courtesy of Michelle McGeough.

58 Installation view, bottom: Karl Blossfeldt, Rough Horsetail. Beattie House, Ottawa, January 2005.

Source: Photograph courtesy of Michelle McGeough.

59 Interior view, spare bedroom. Beattie House, Ottawa, January 2005.

Source: Photograph courtesy of Michelle McGeough. 


\section{FIGURES}

Figure 1

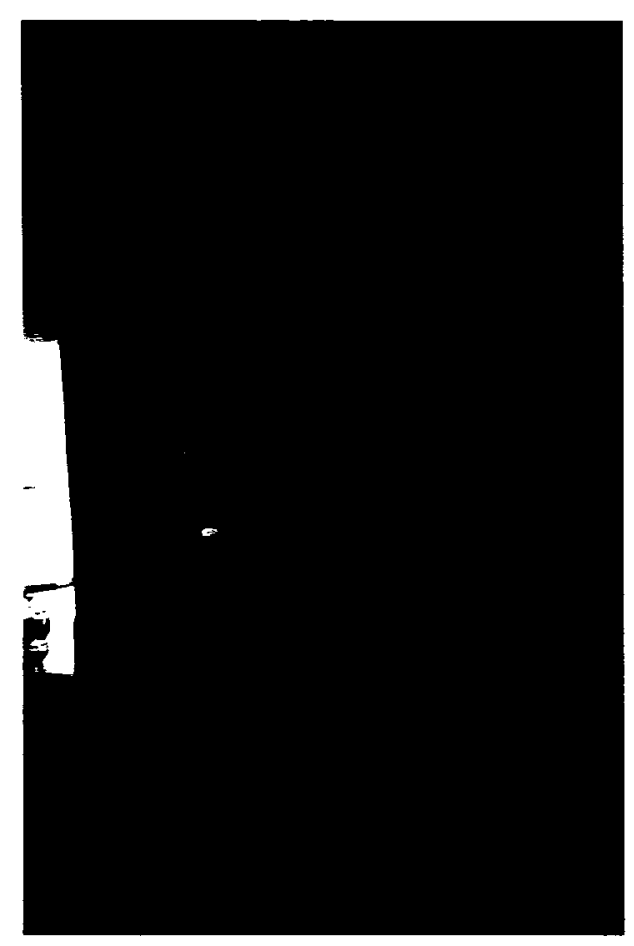

Figure 2

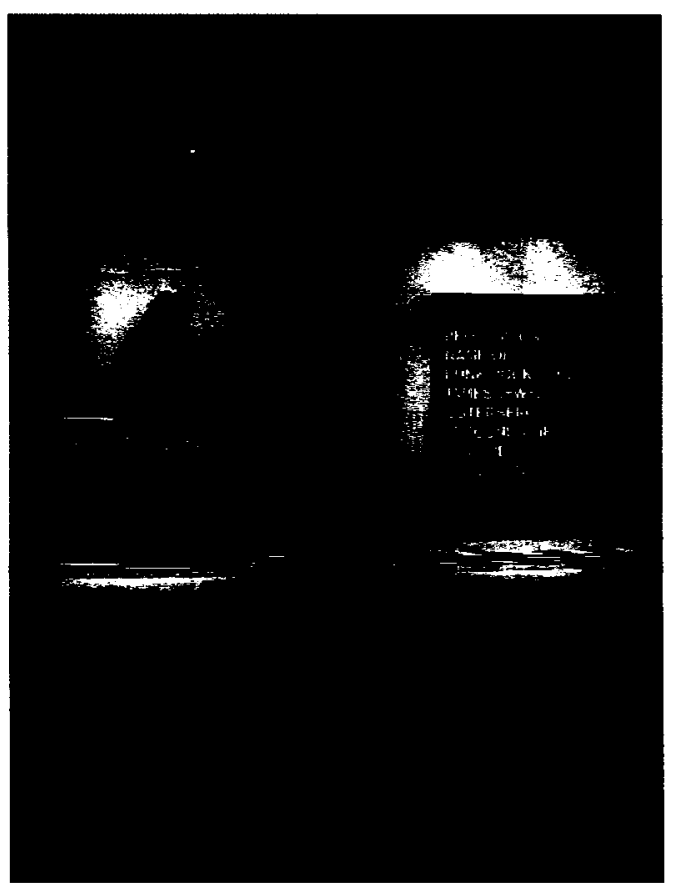


Figure 3

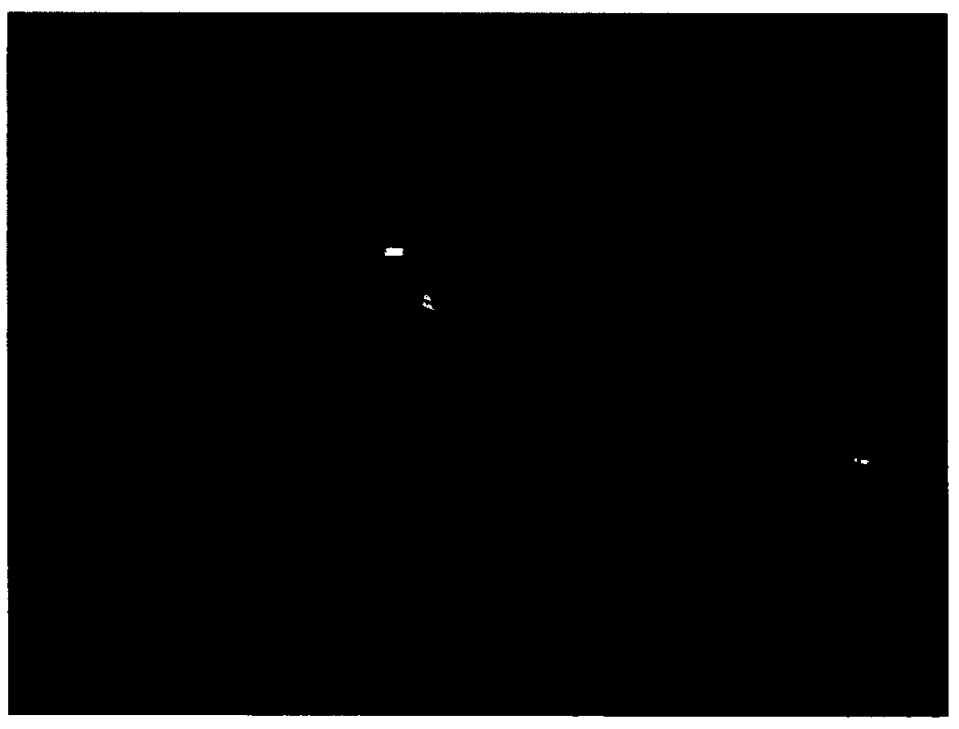

Figure 4

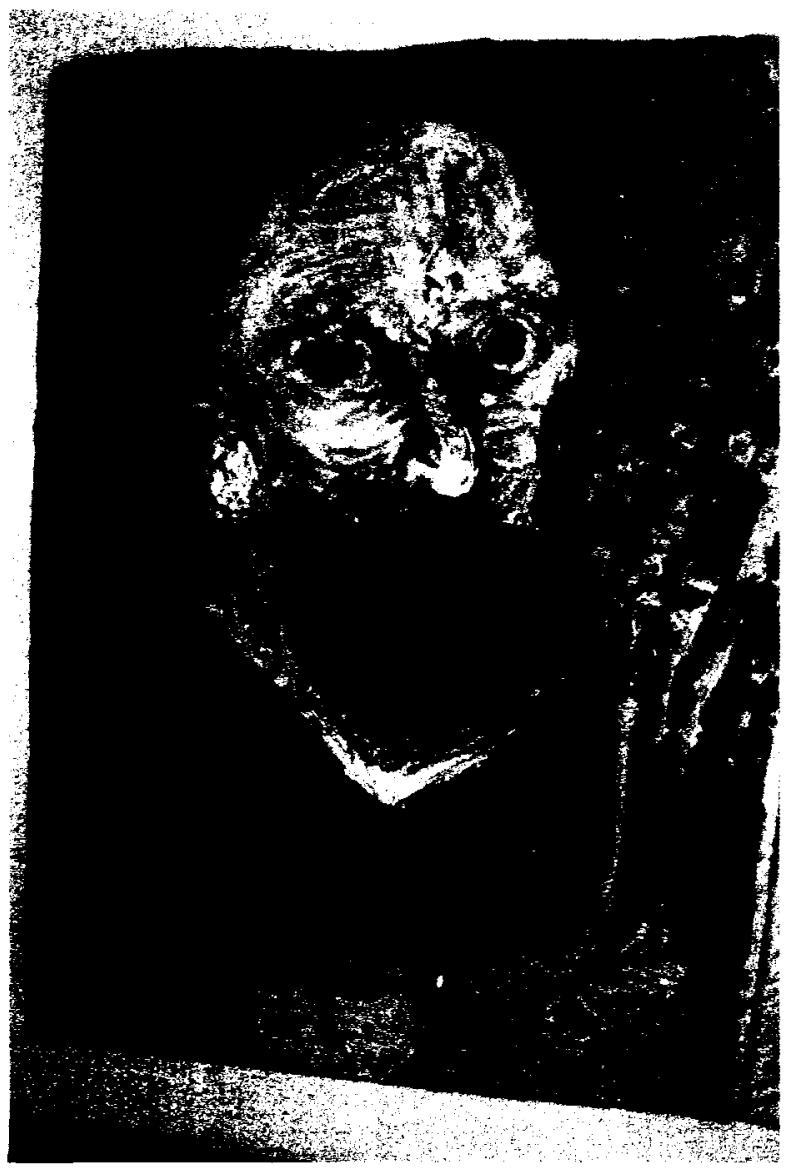


Figure 5

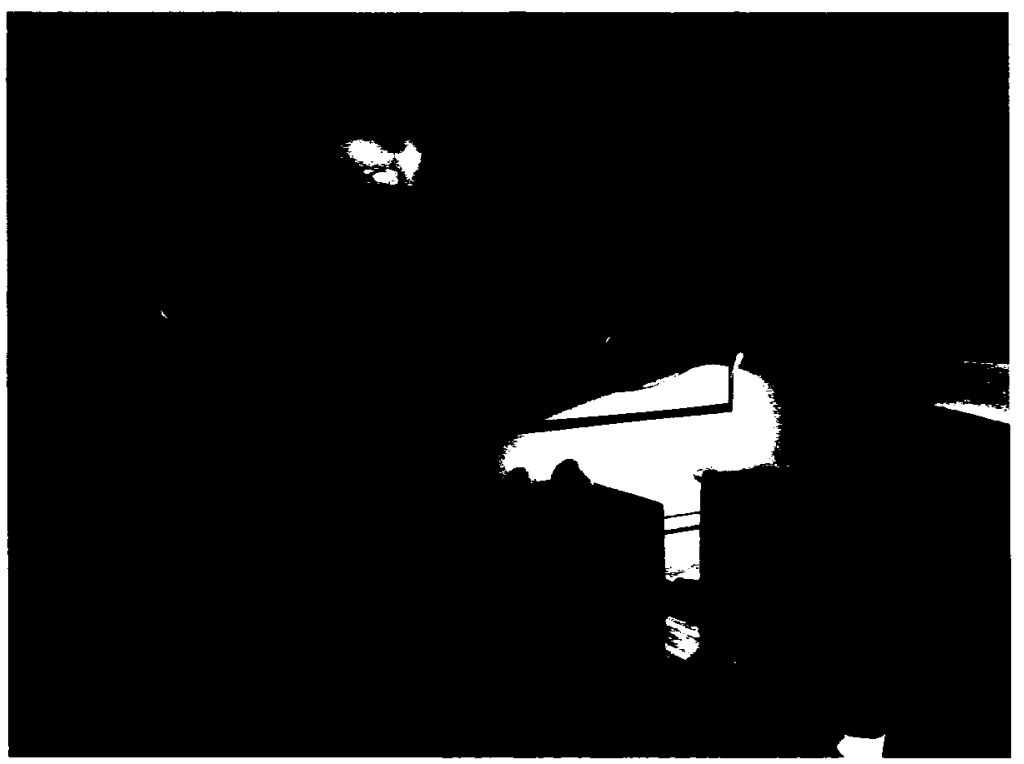

Figure 6

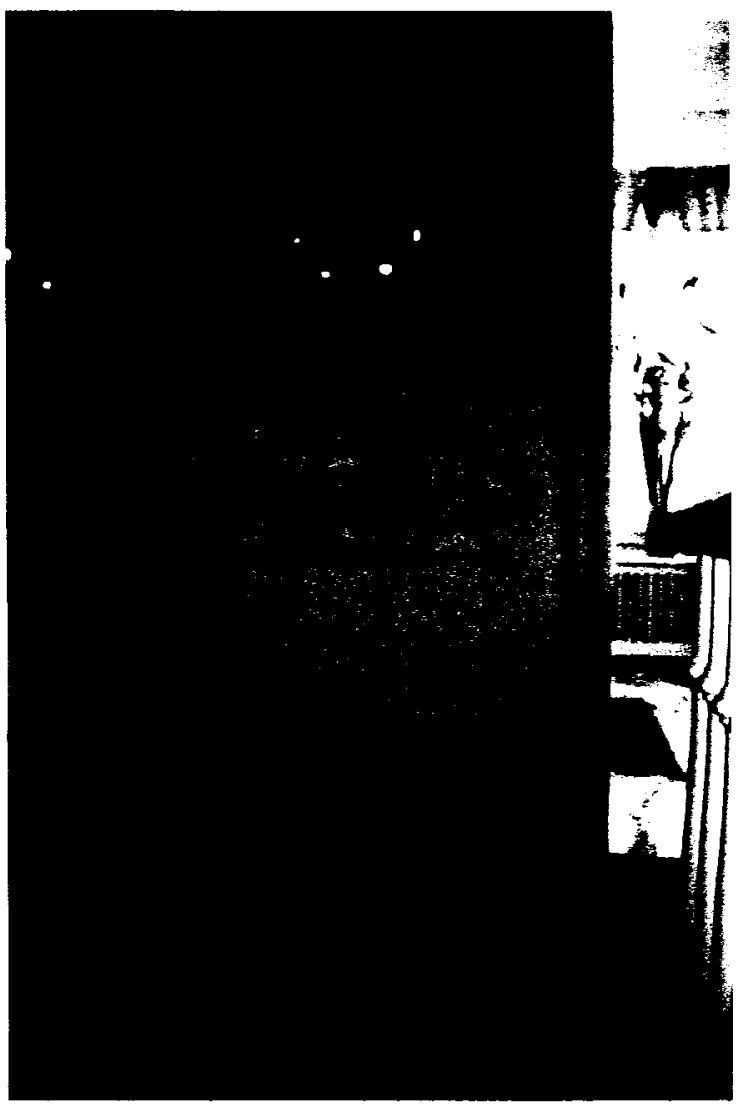


Figure 7

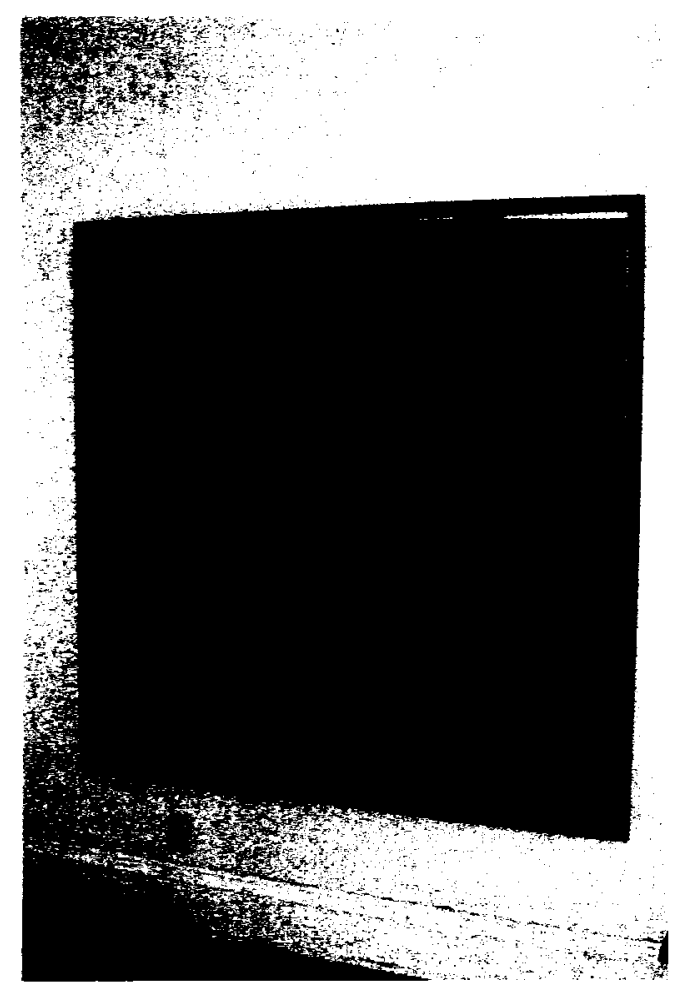

Figure 8

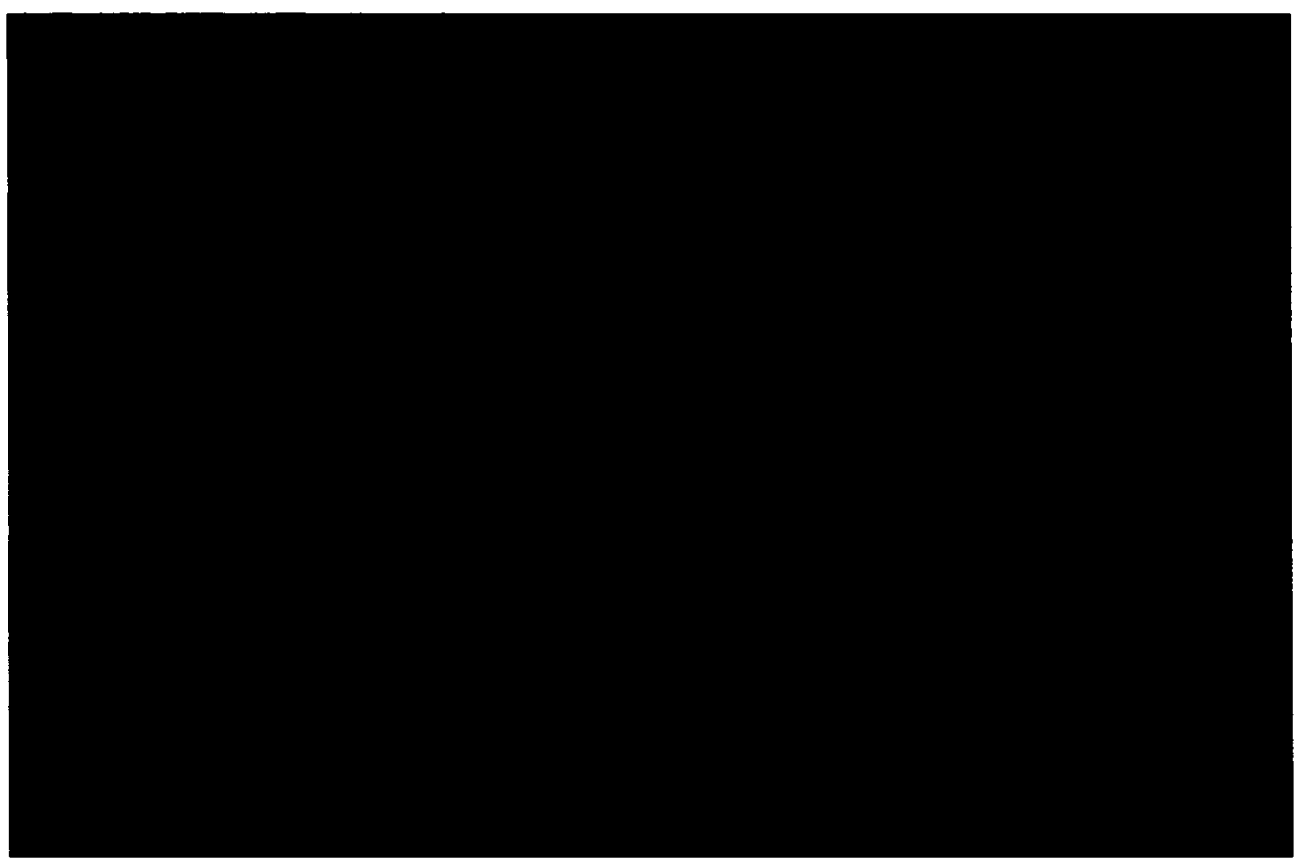


Figure 9

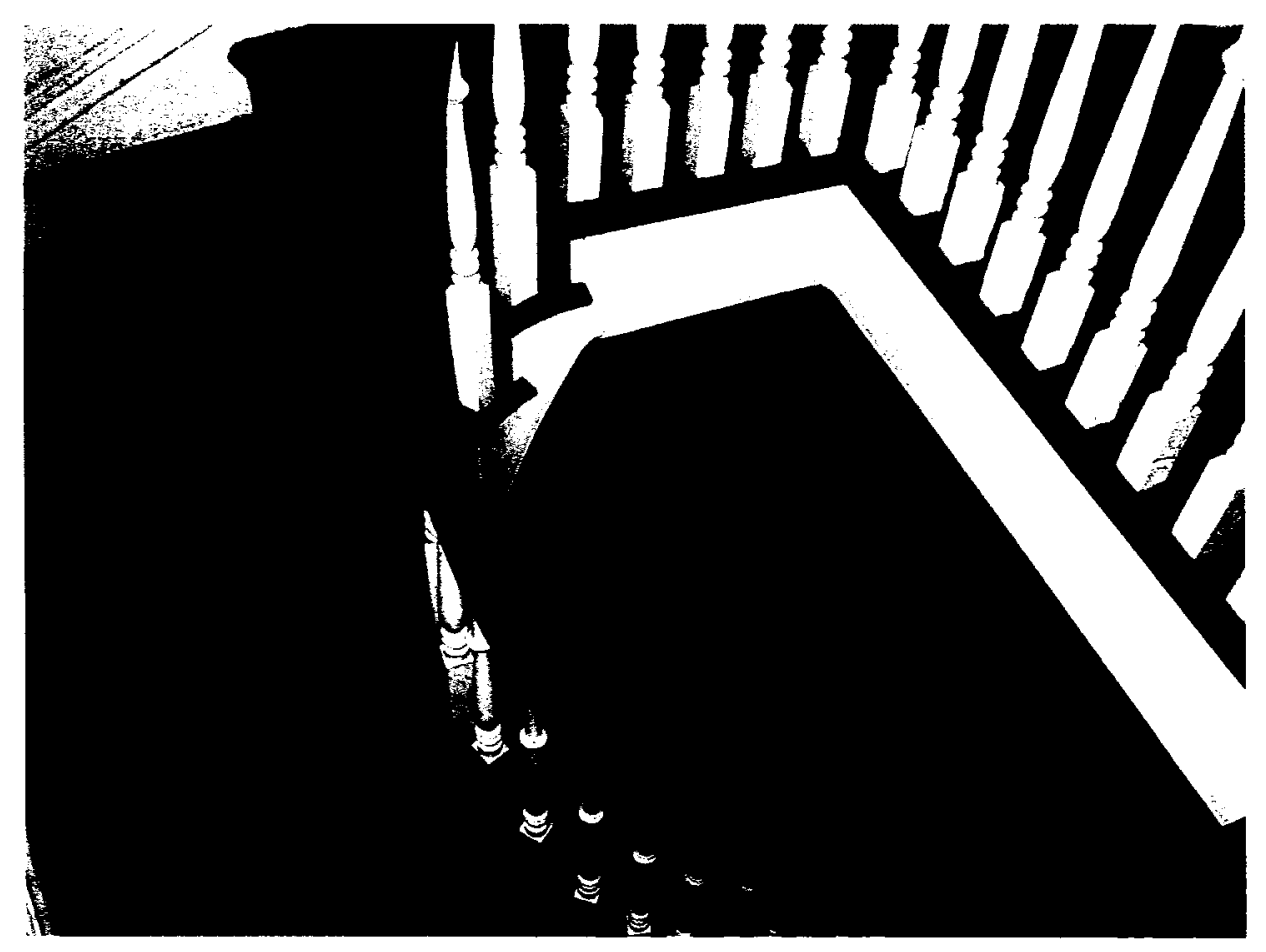

Figure 10

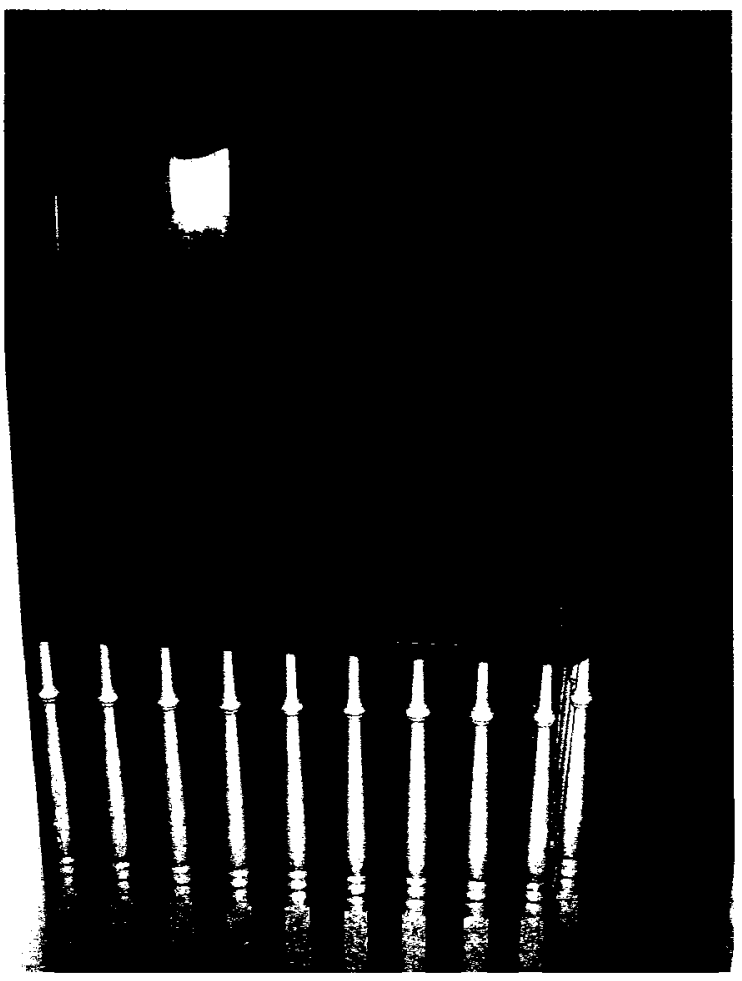


Figure 11

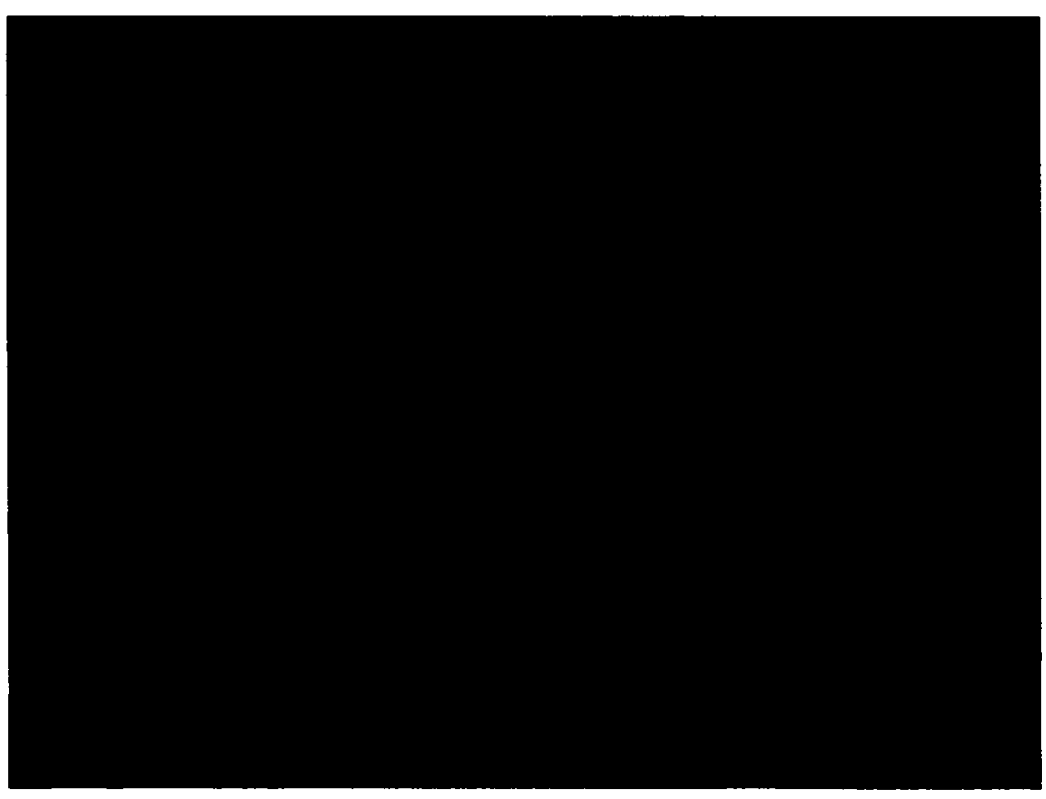

Figure 12

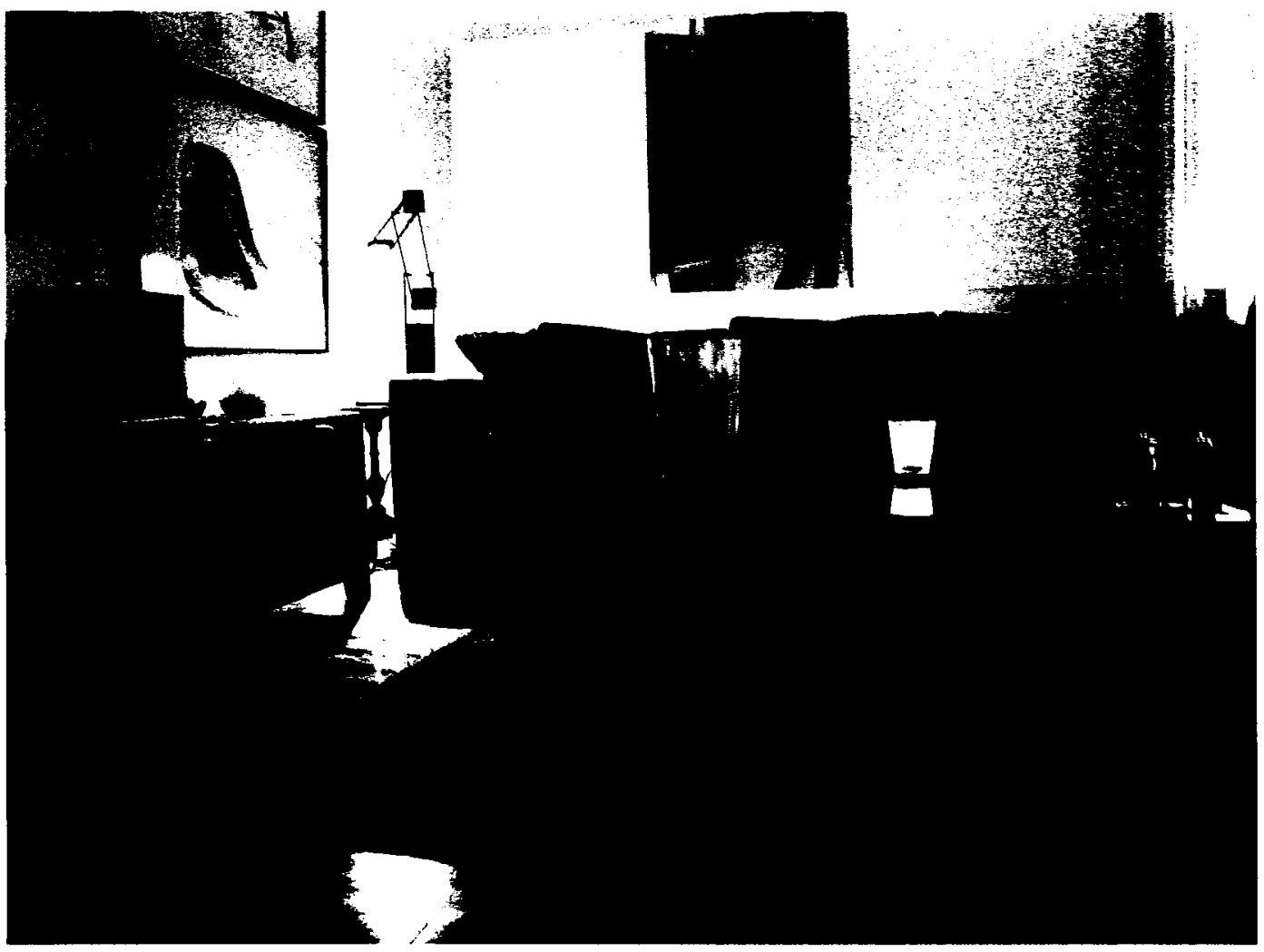


Figure 13

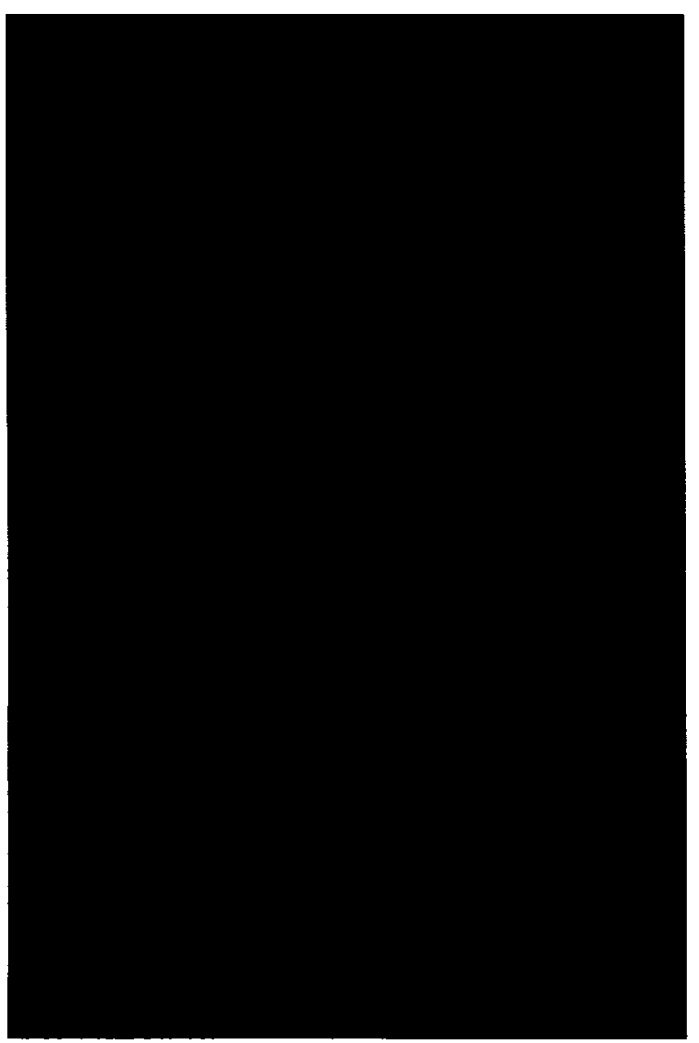

Figure 14

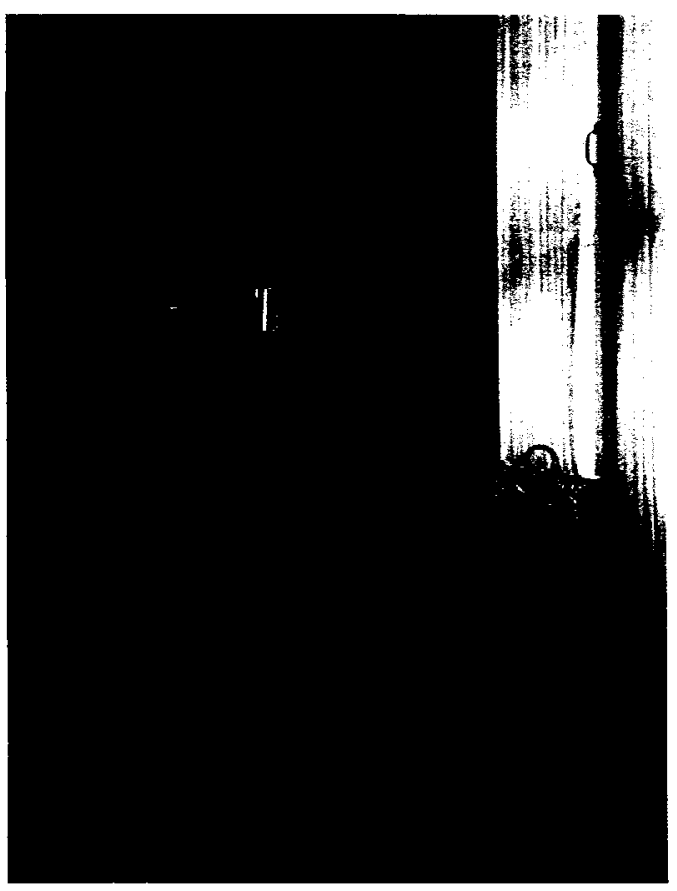


Figure 15

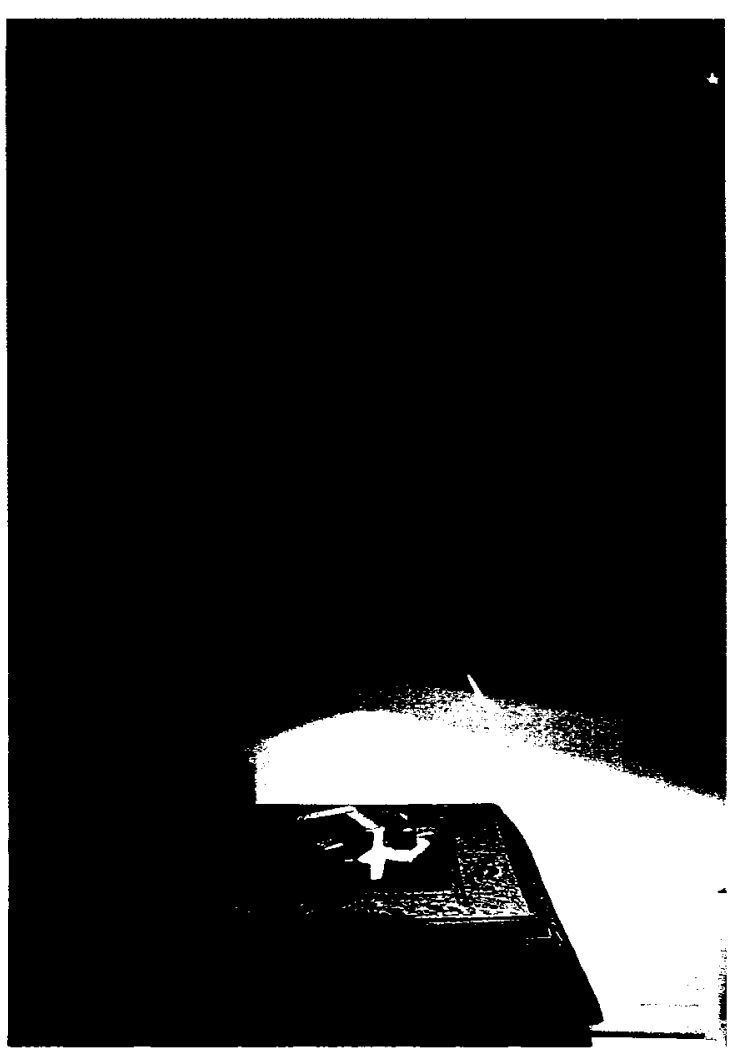

Figure 16

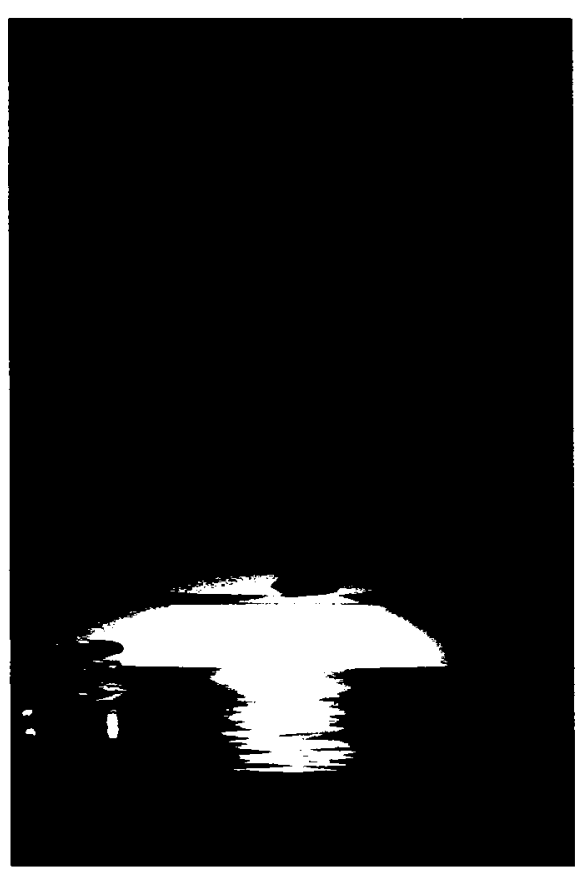


Figure 17

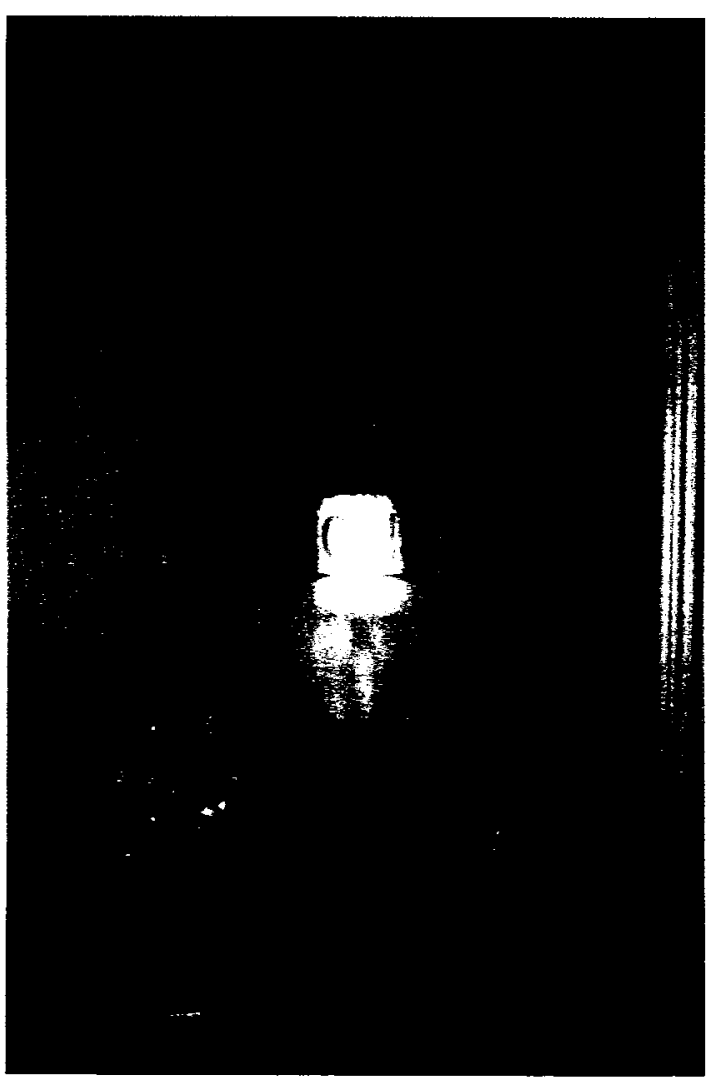

Figure 18

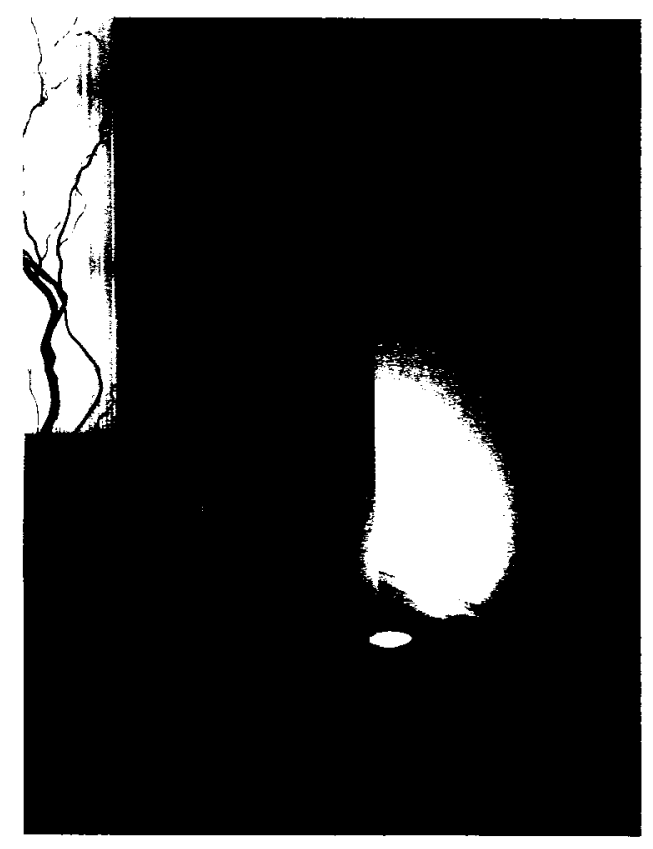


Figure 19

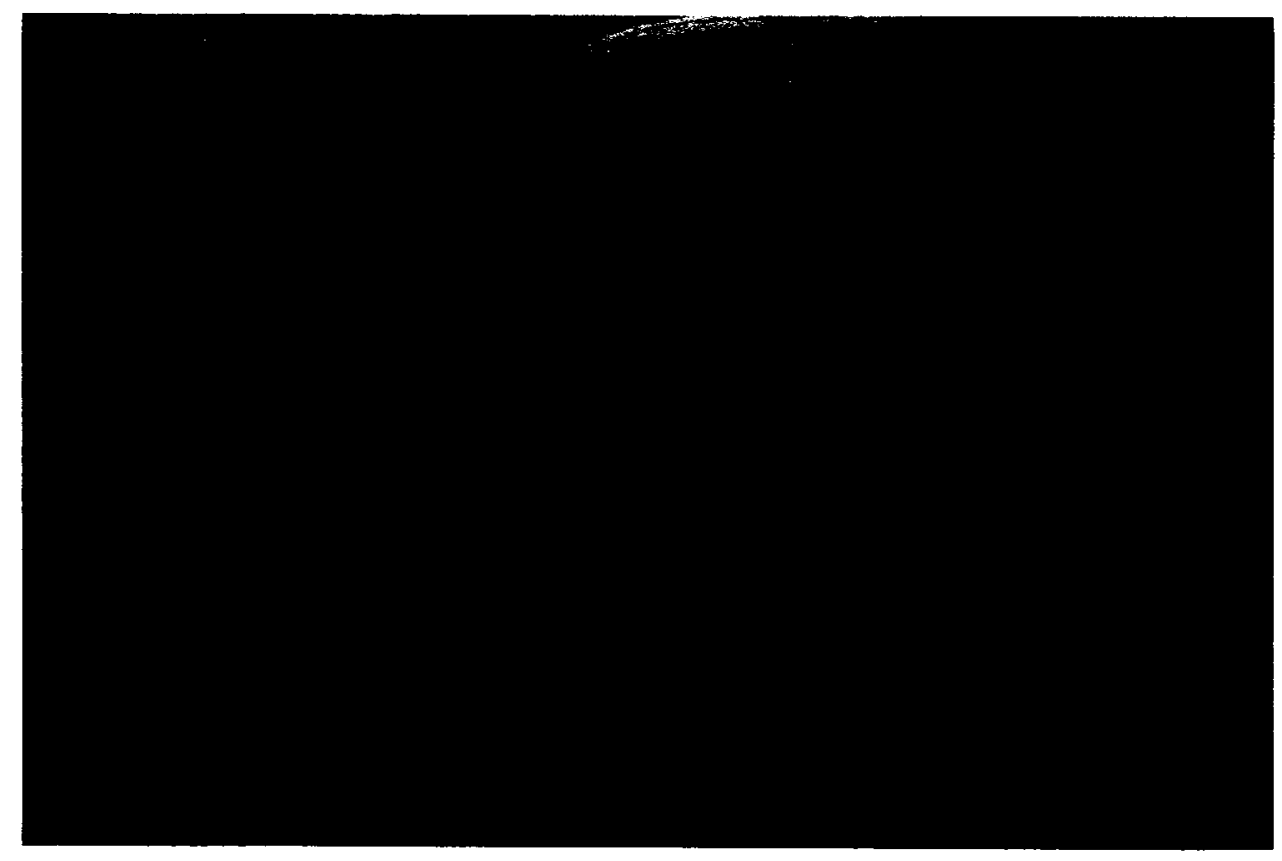

Figure 20

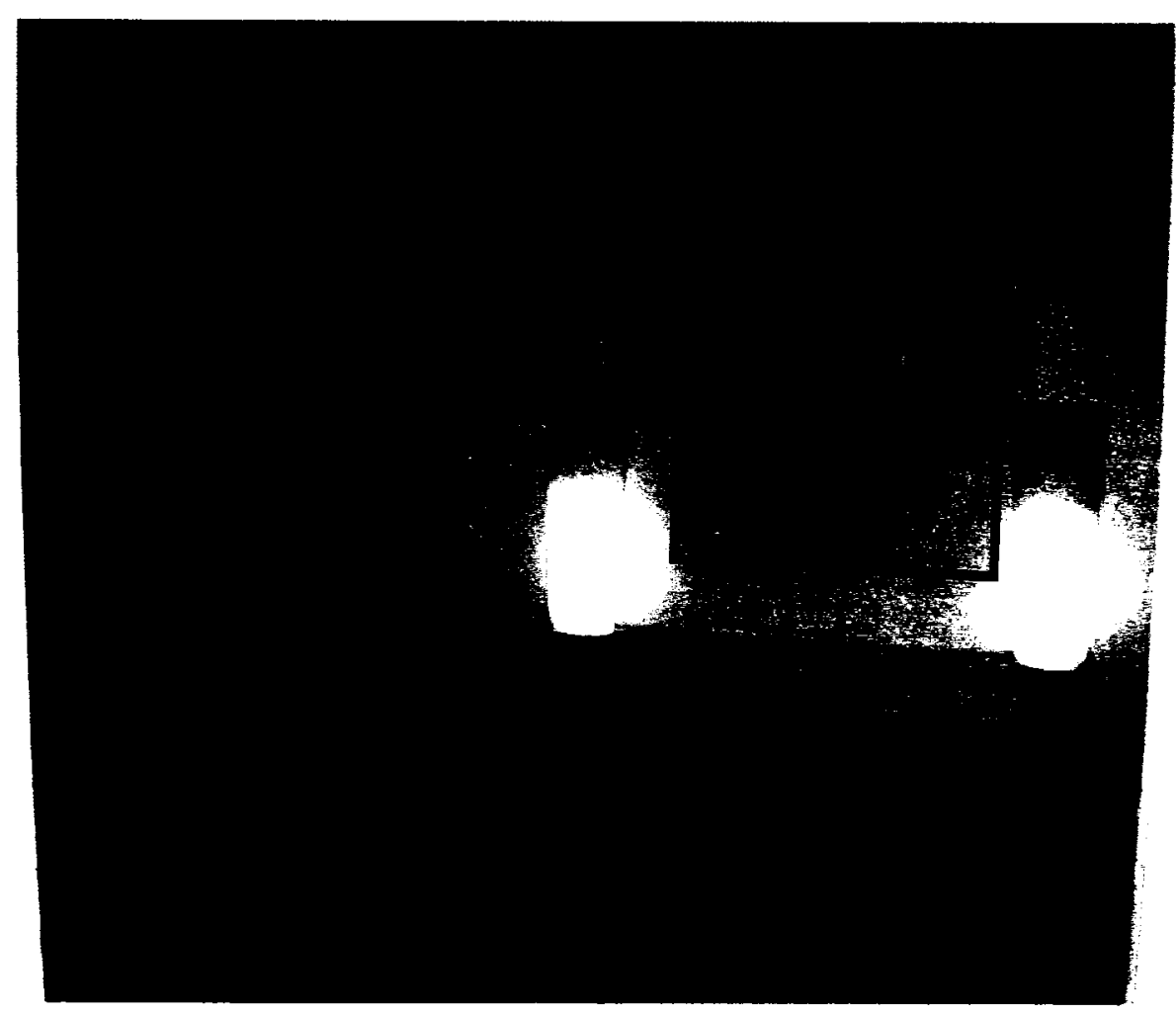


Figure 21

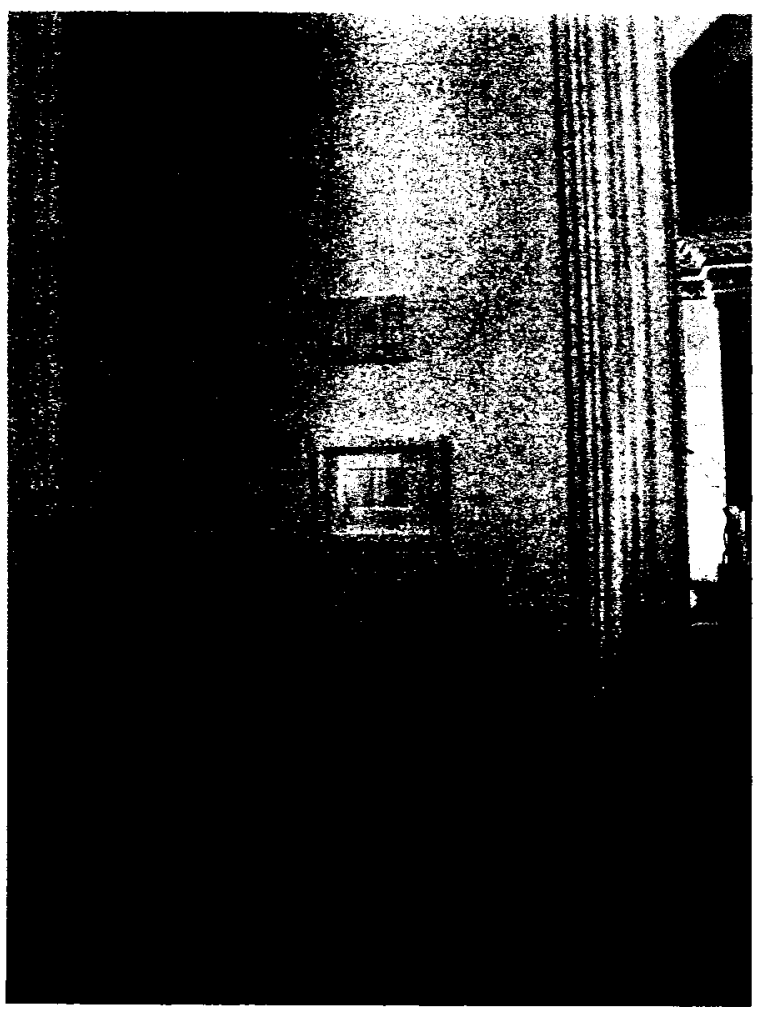

Figure 22

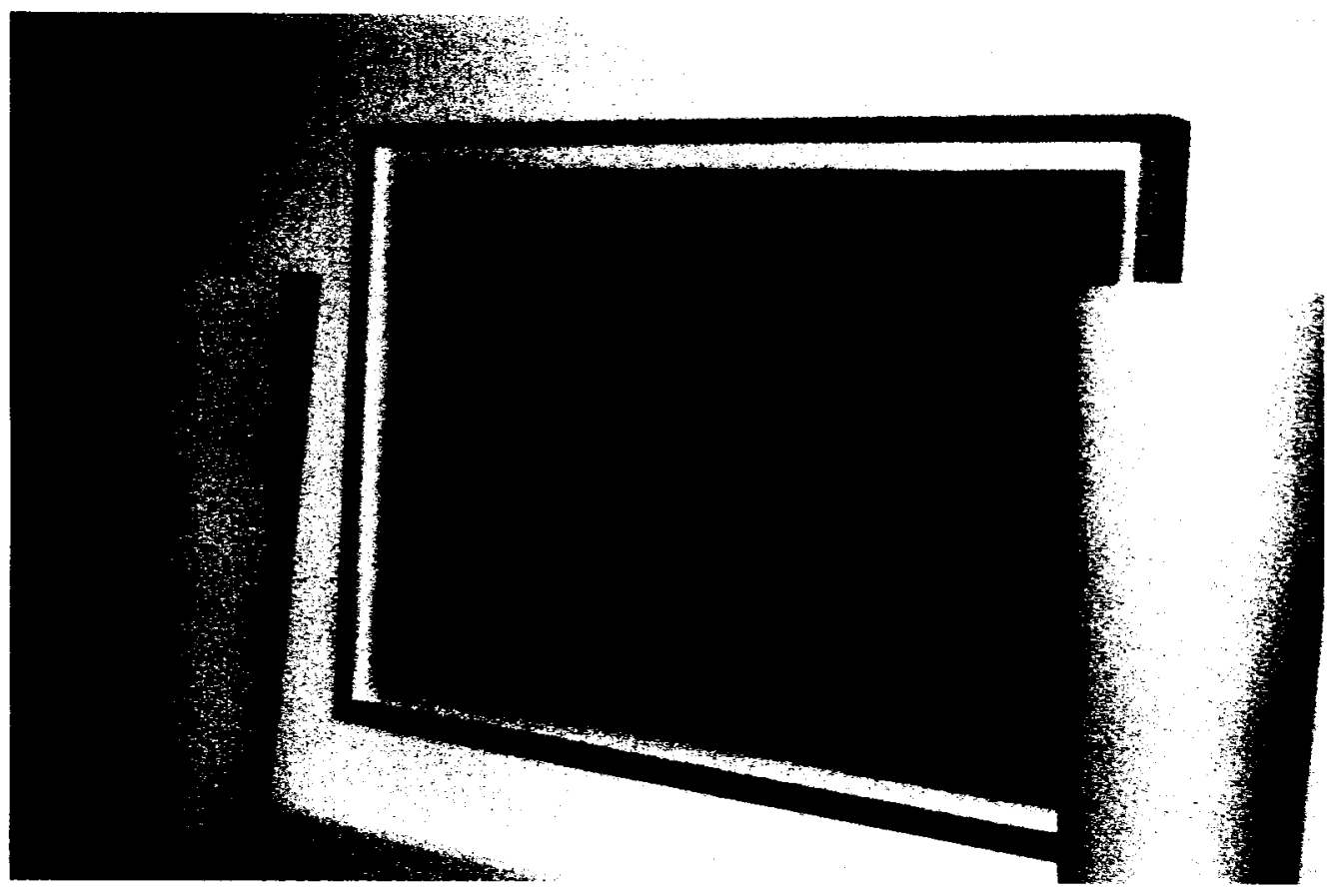


Figure 23

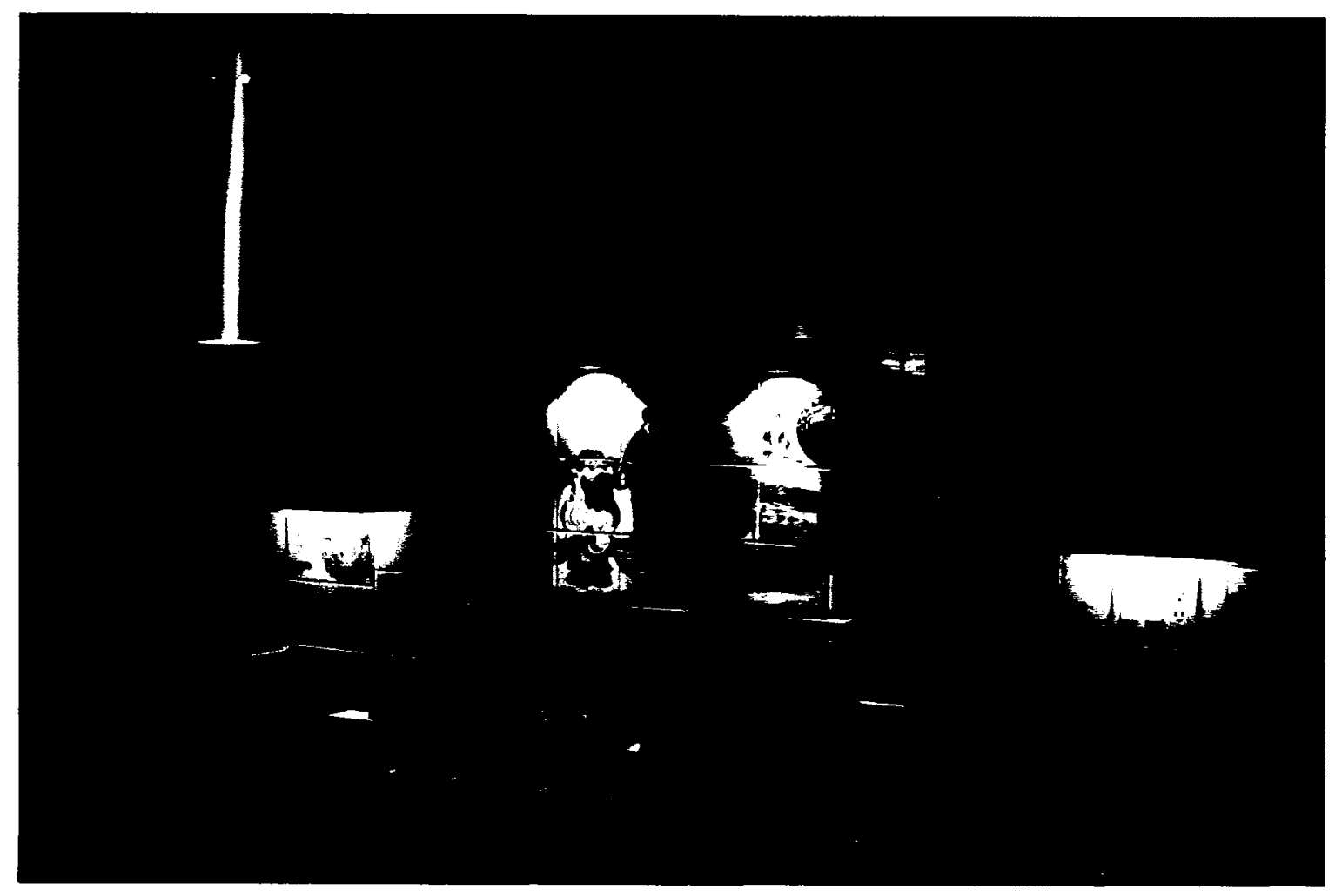

Figure 24

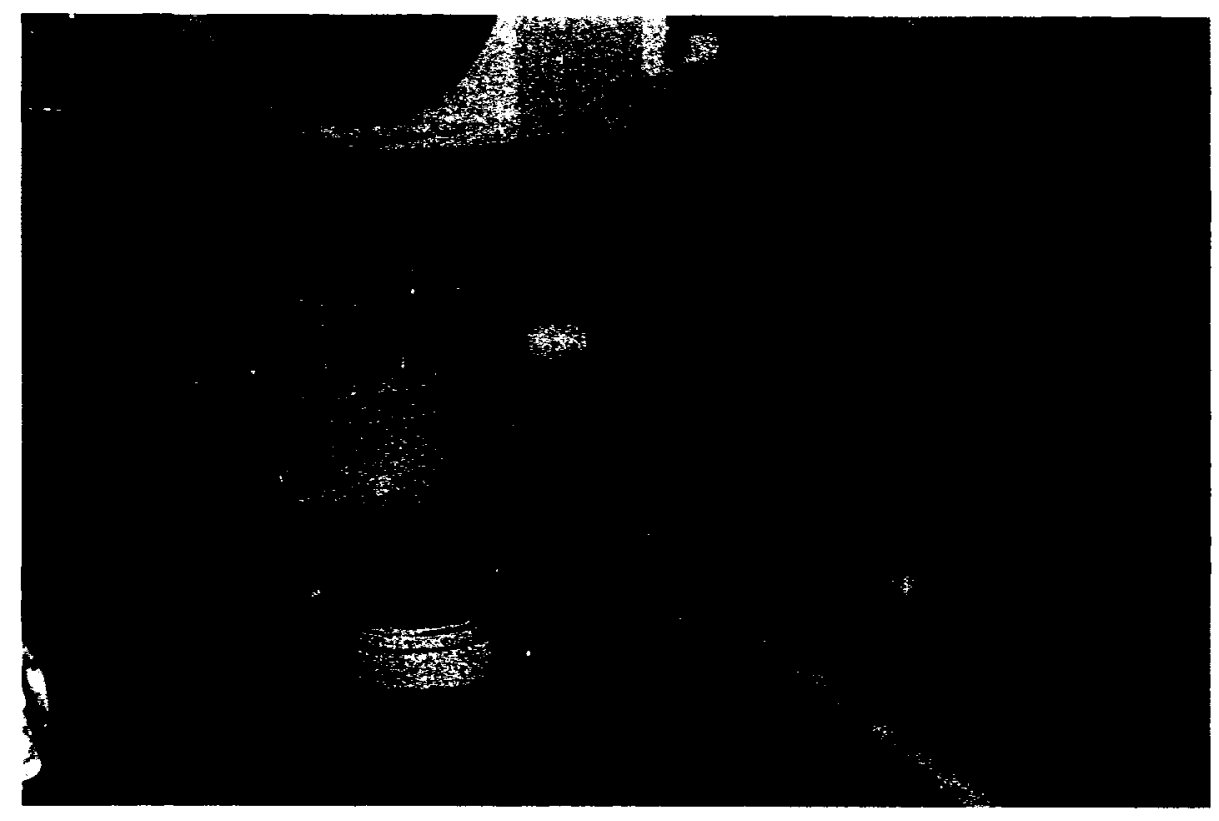


Figure 25

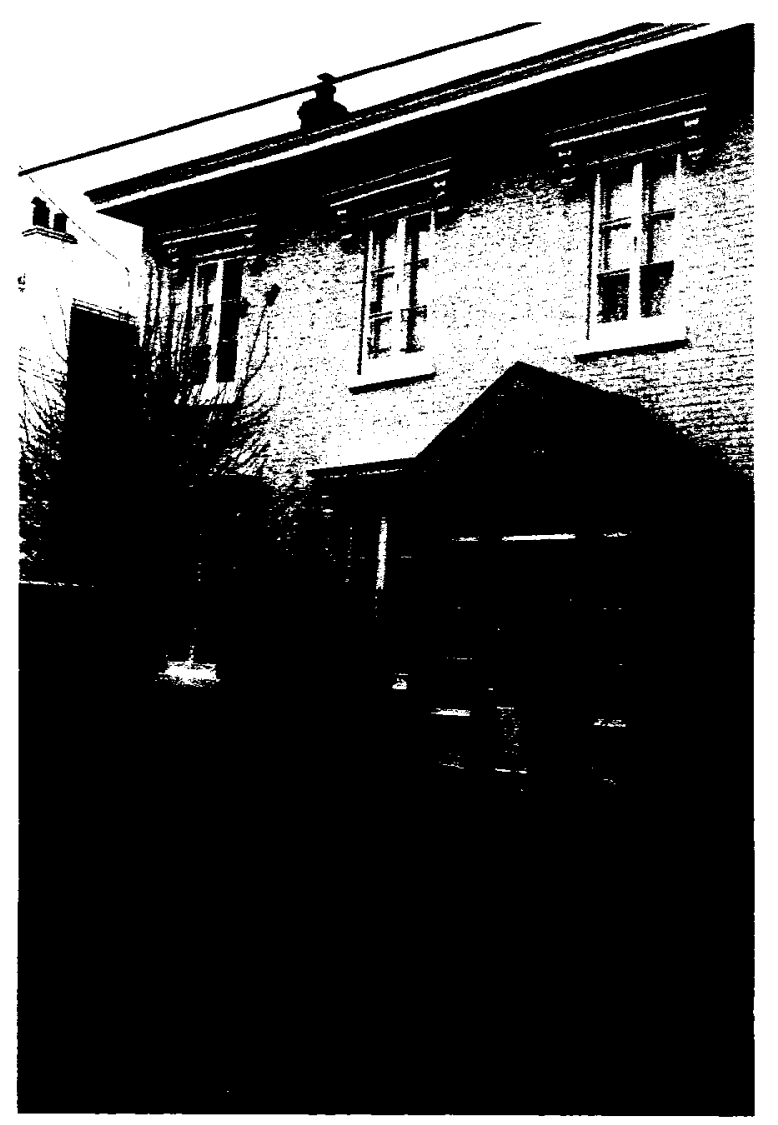

Figure 26

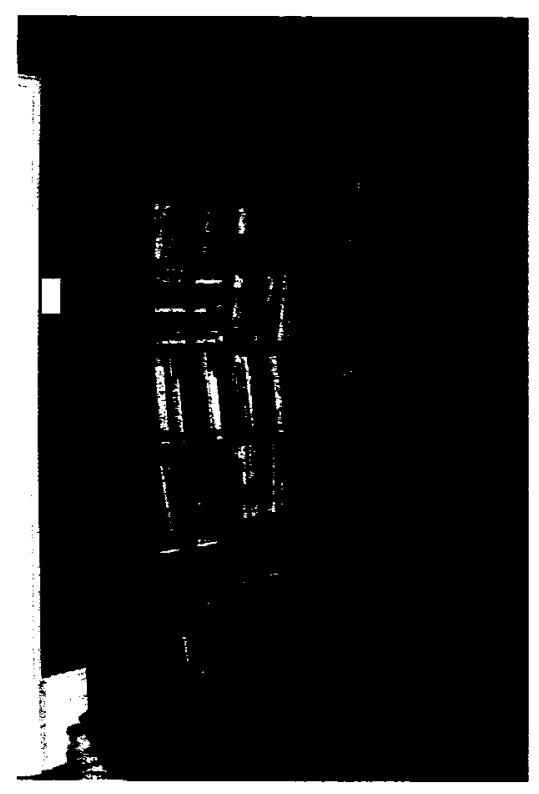


Figure 27

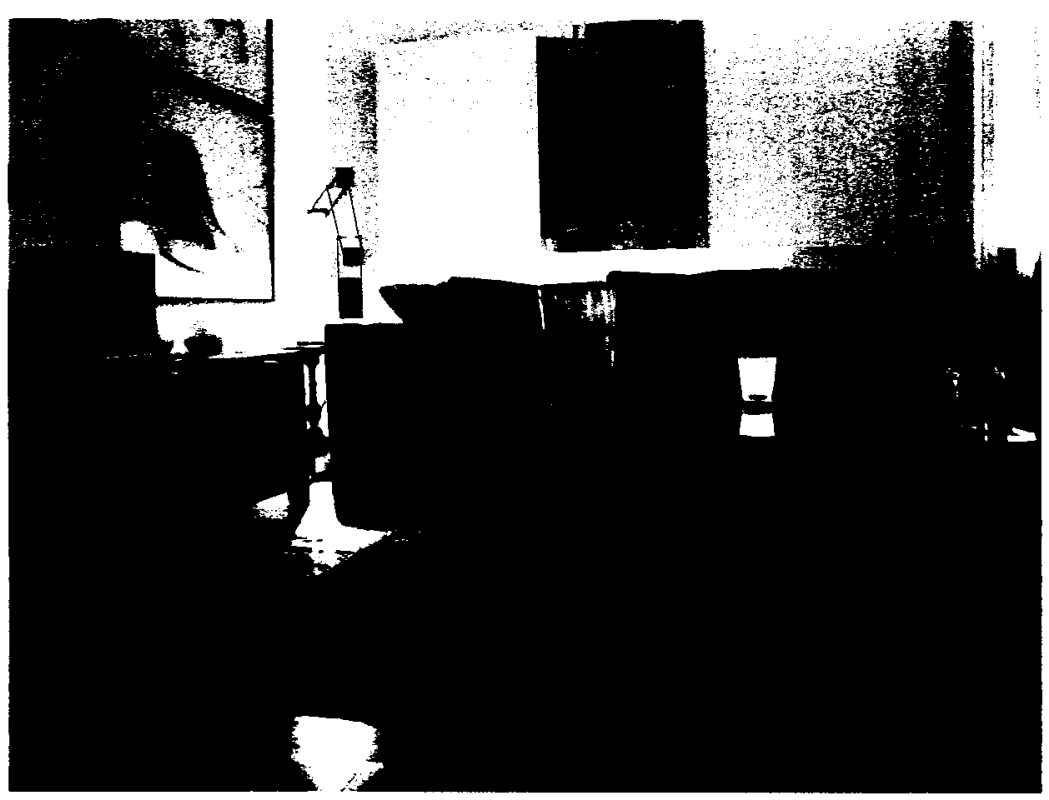

Figure 28

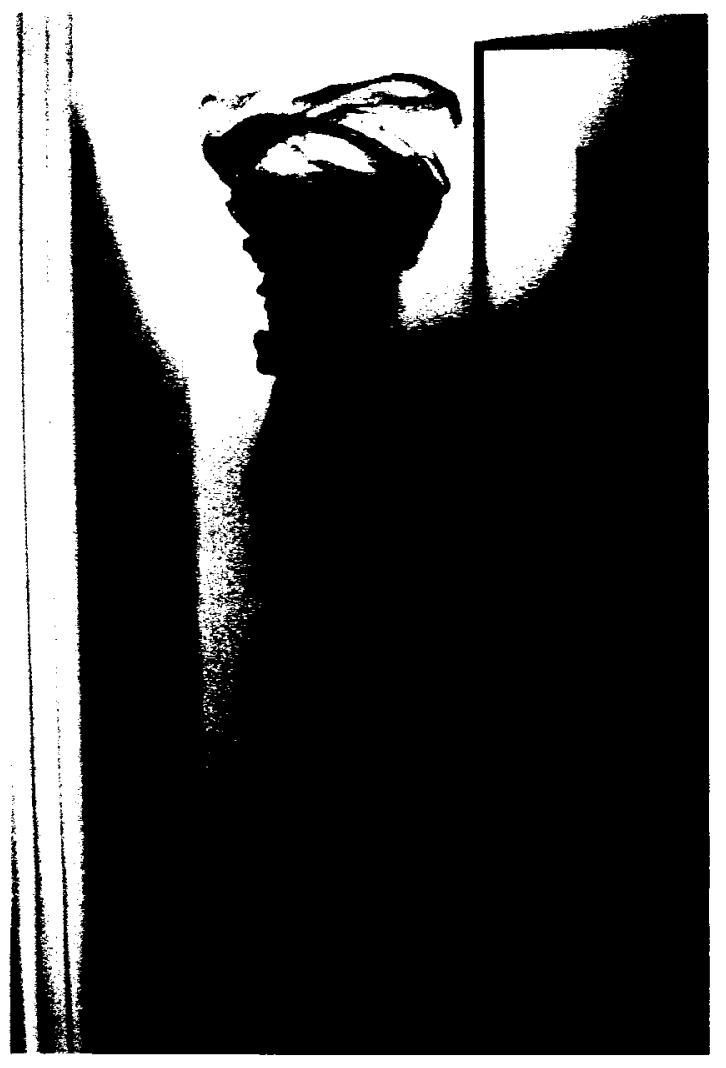


Figure 29

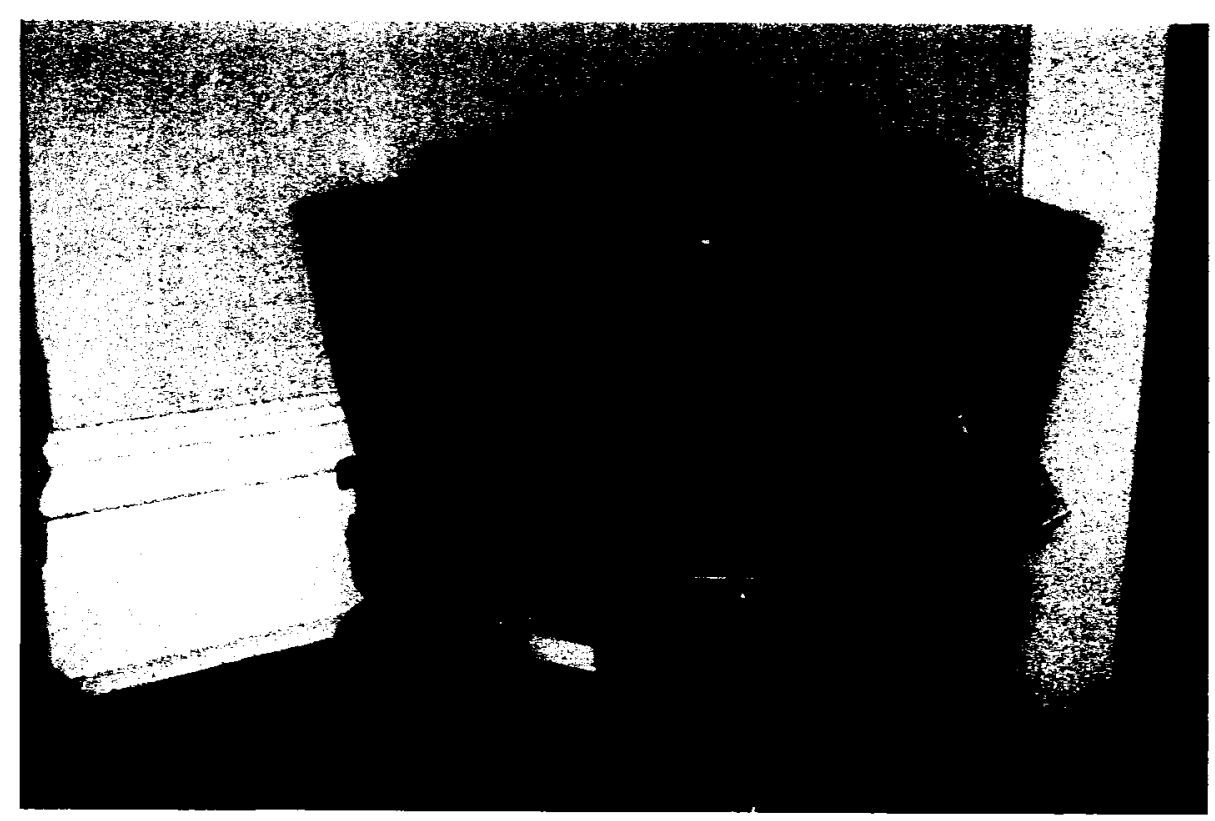

Figure 30

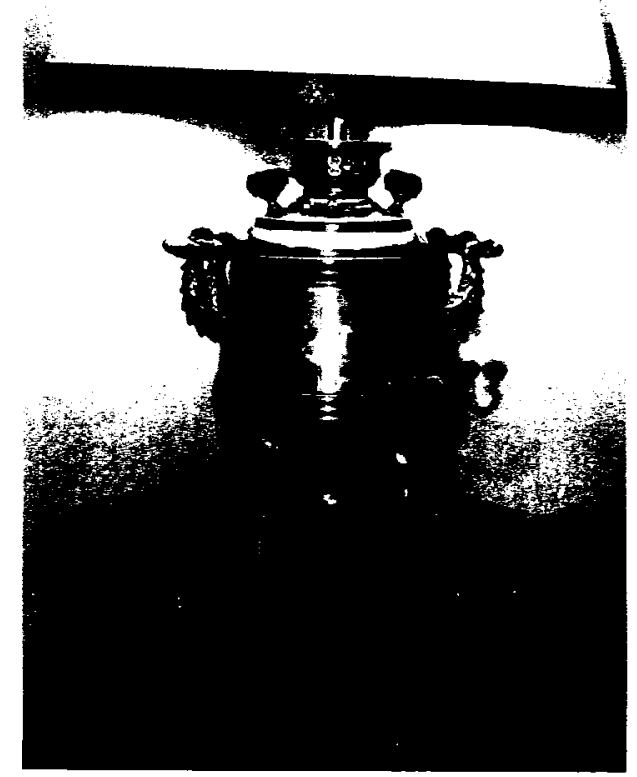


Figure 31

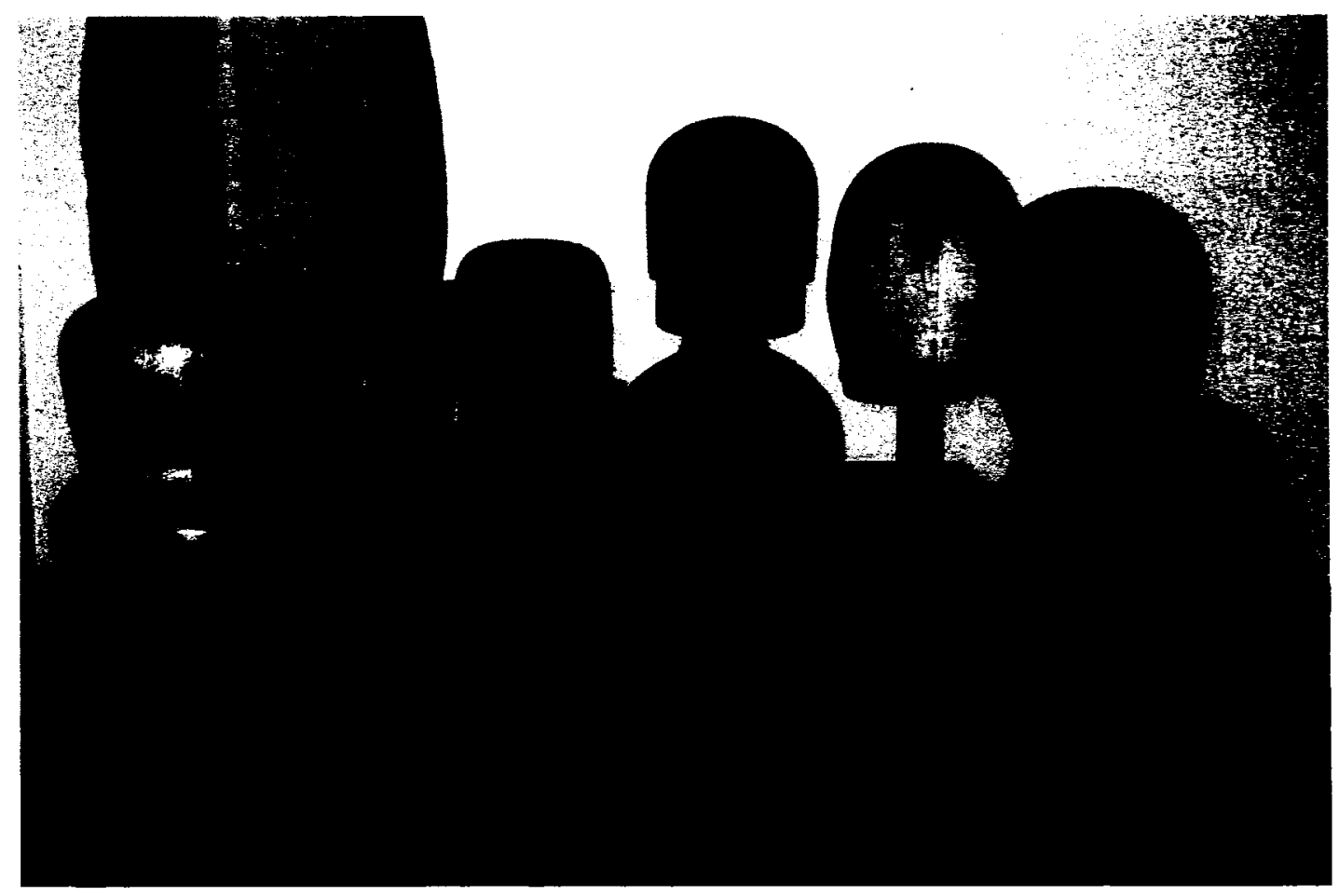

Figure 32

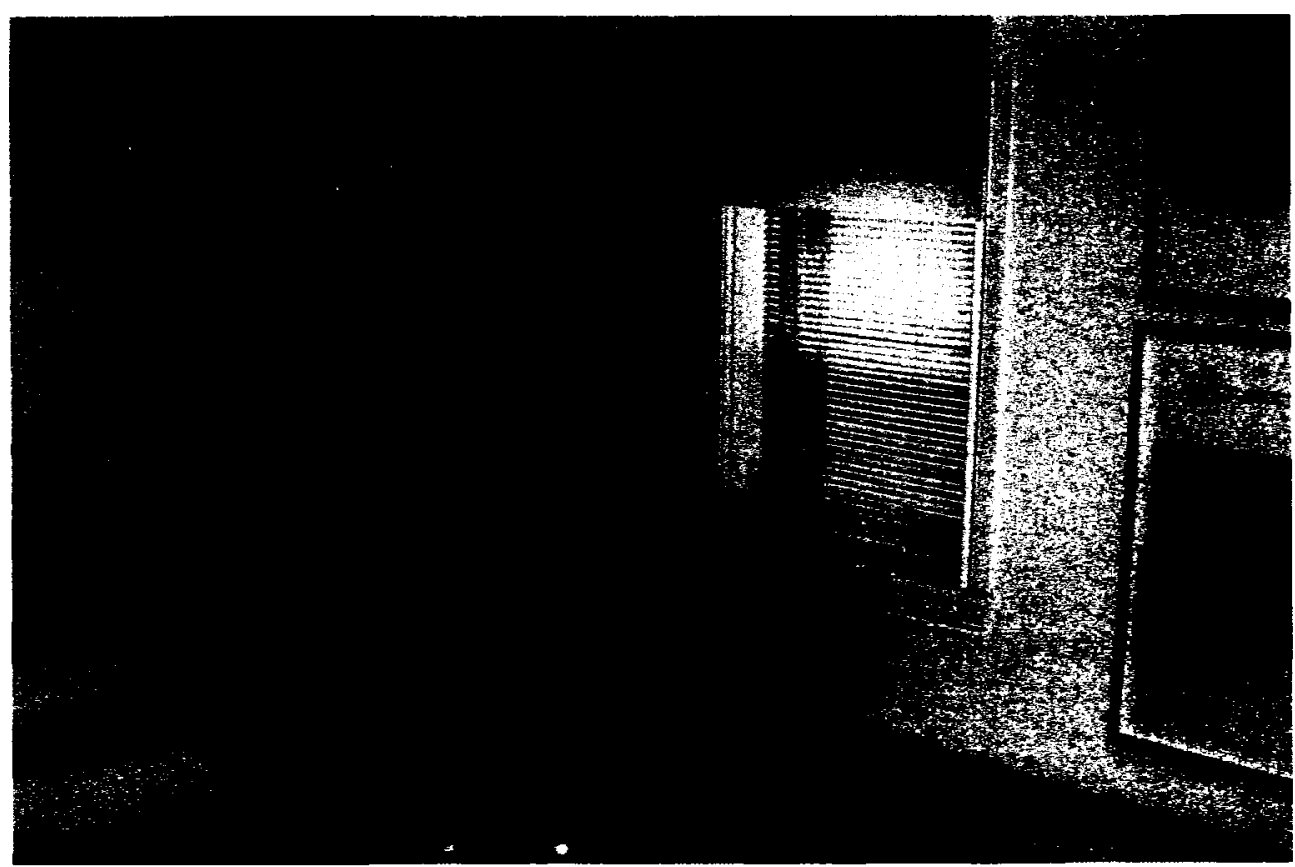


Figure 33

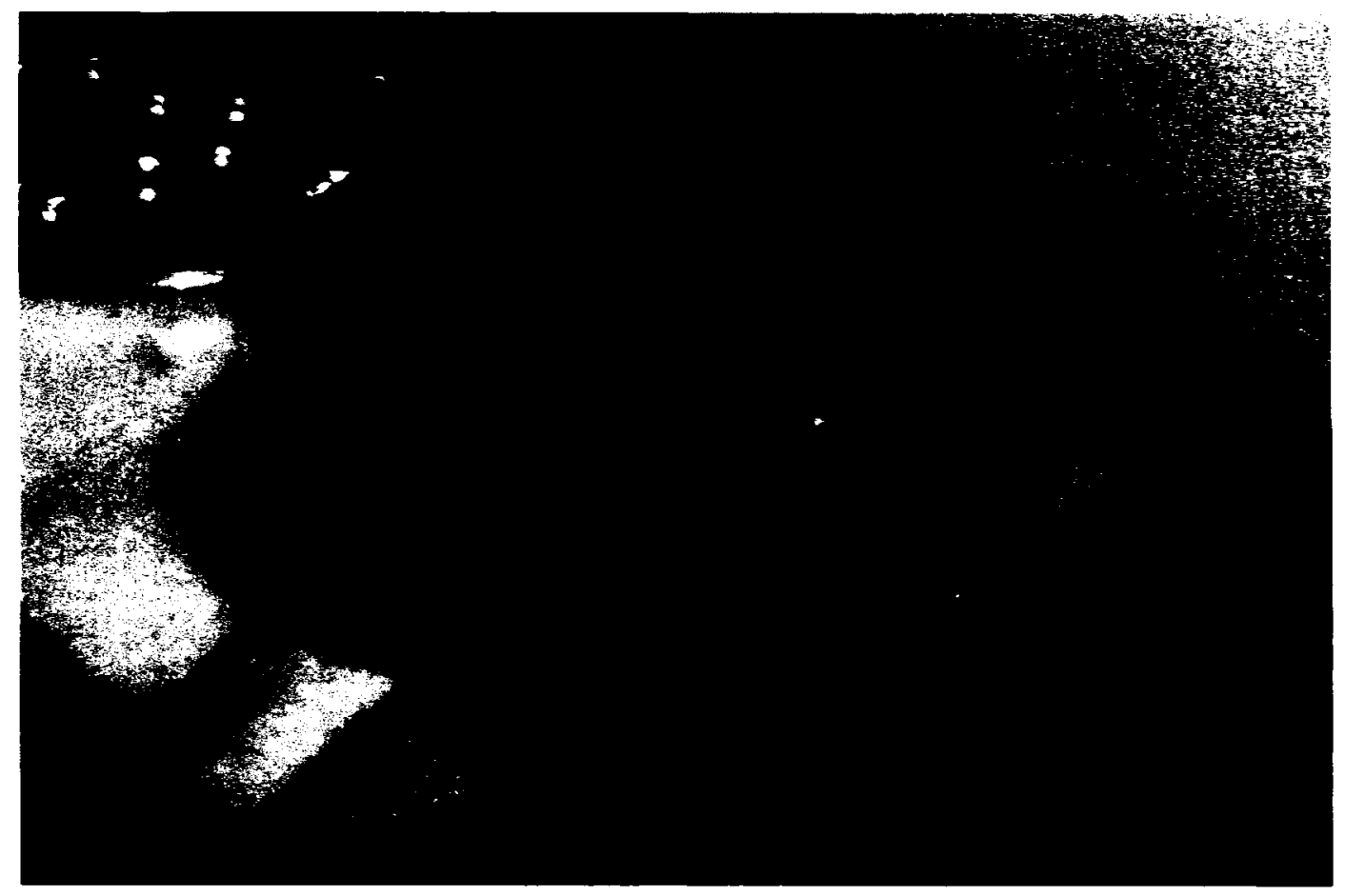

Figure 34

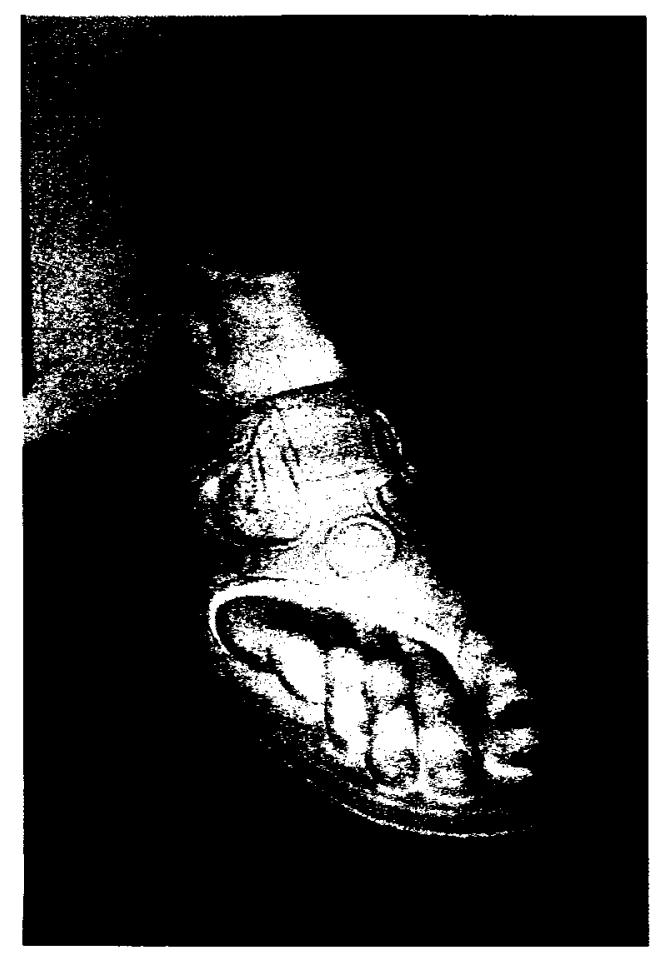


Figure 35

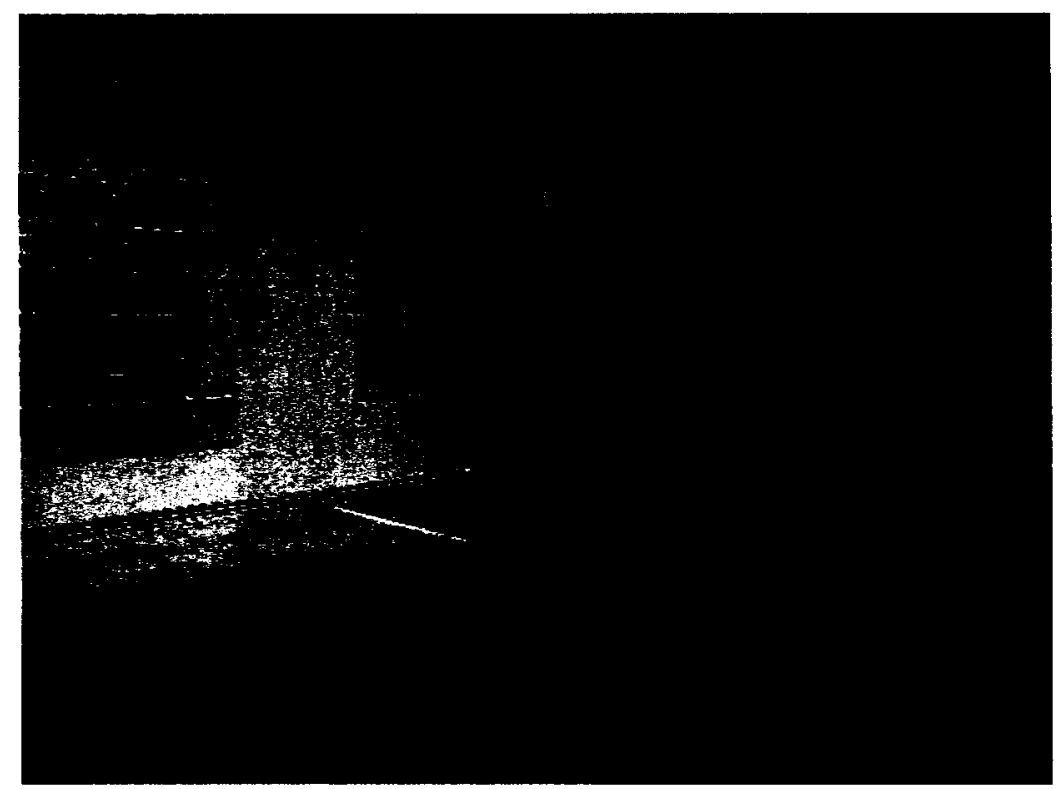

Figure 36

8 
Figure 37

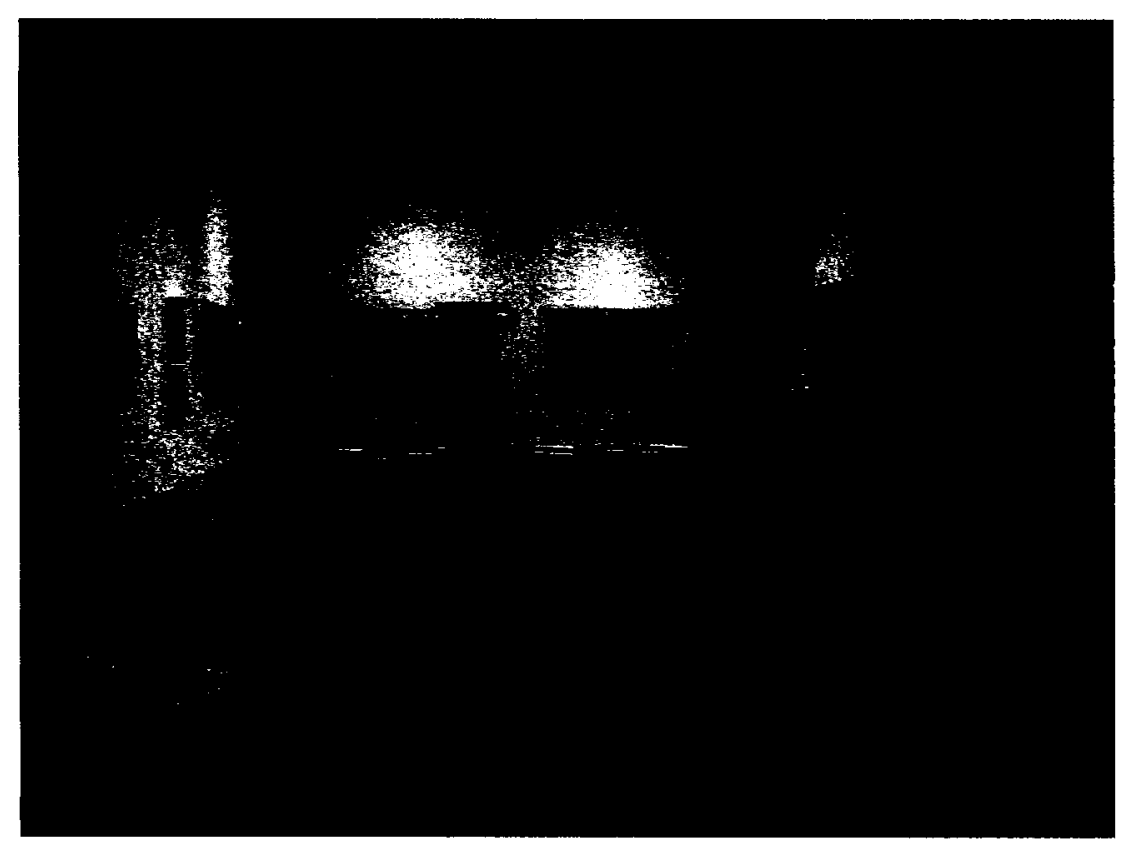

Figure 38

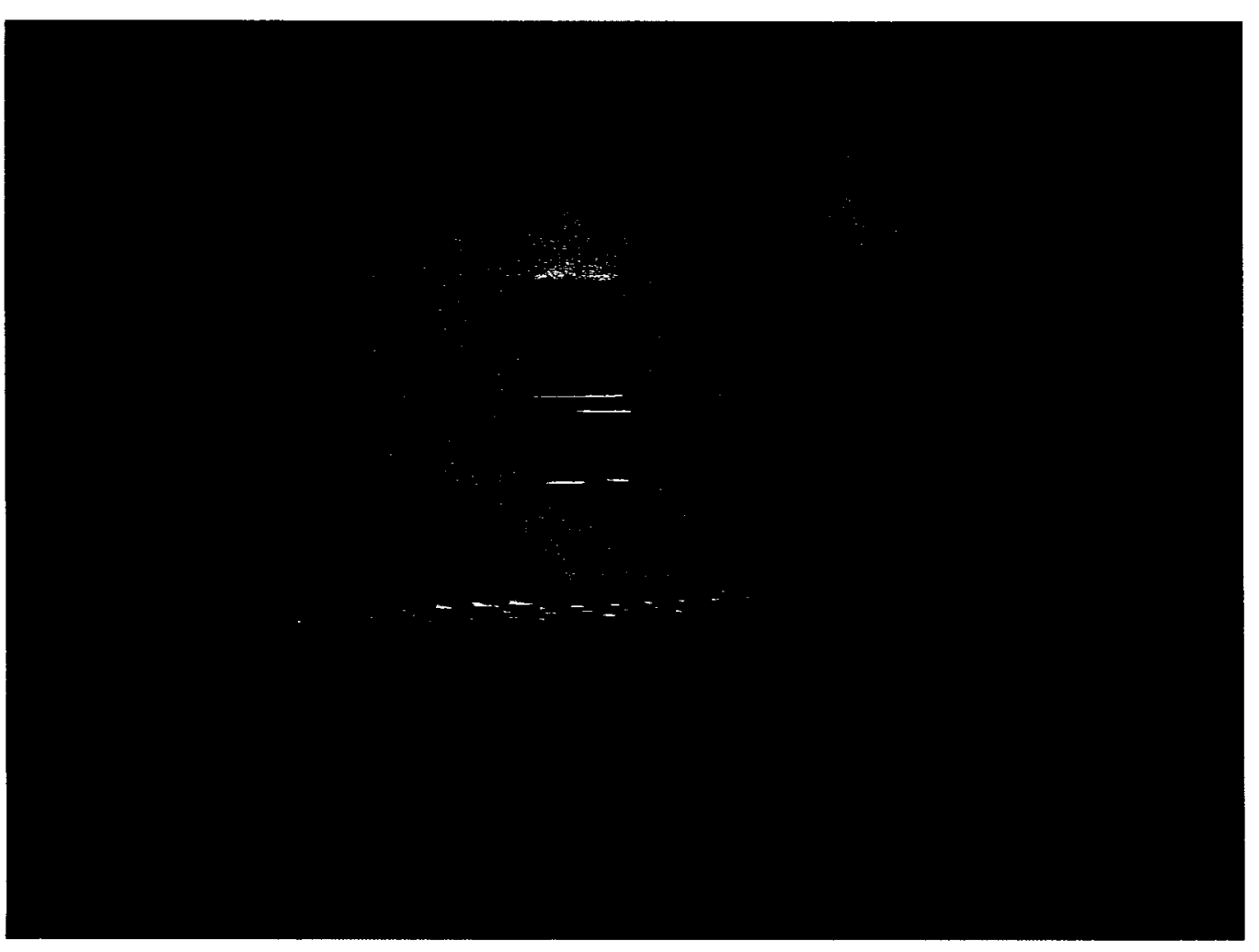


Figure 39

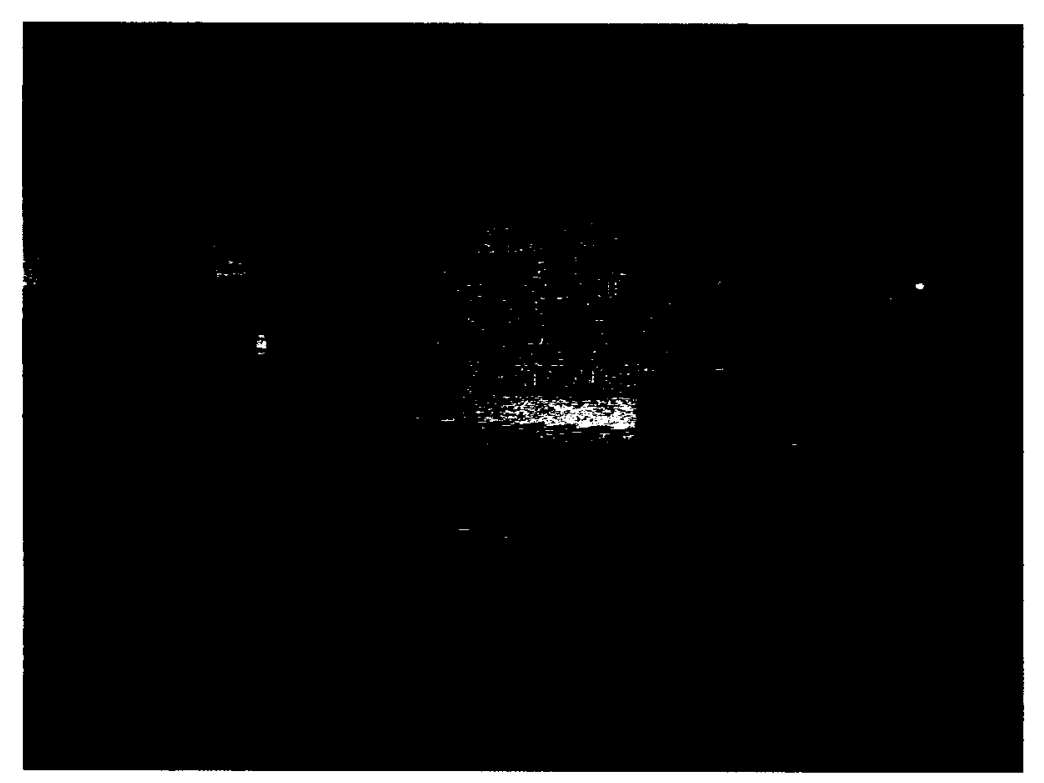

Figure 40

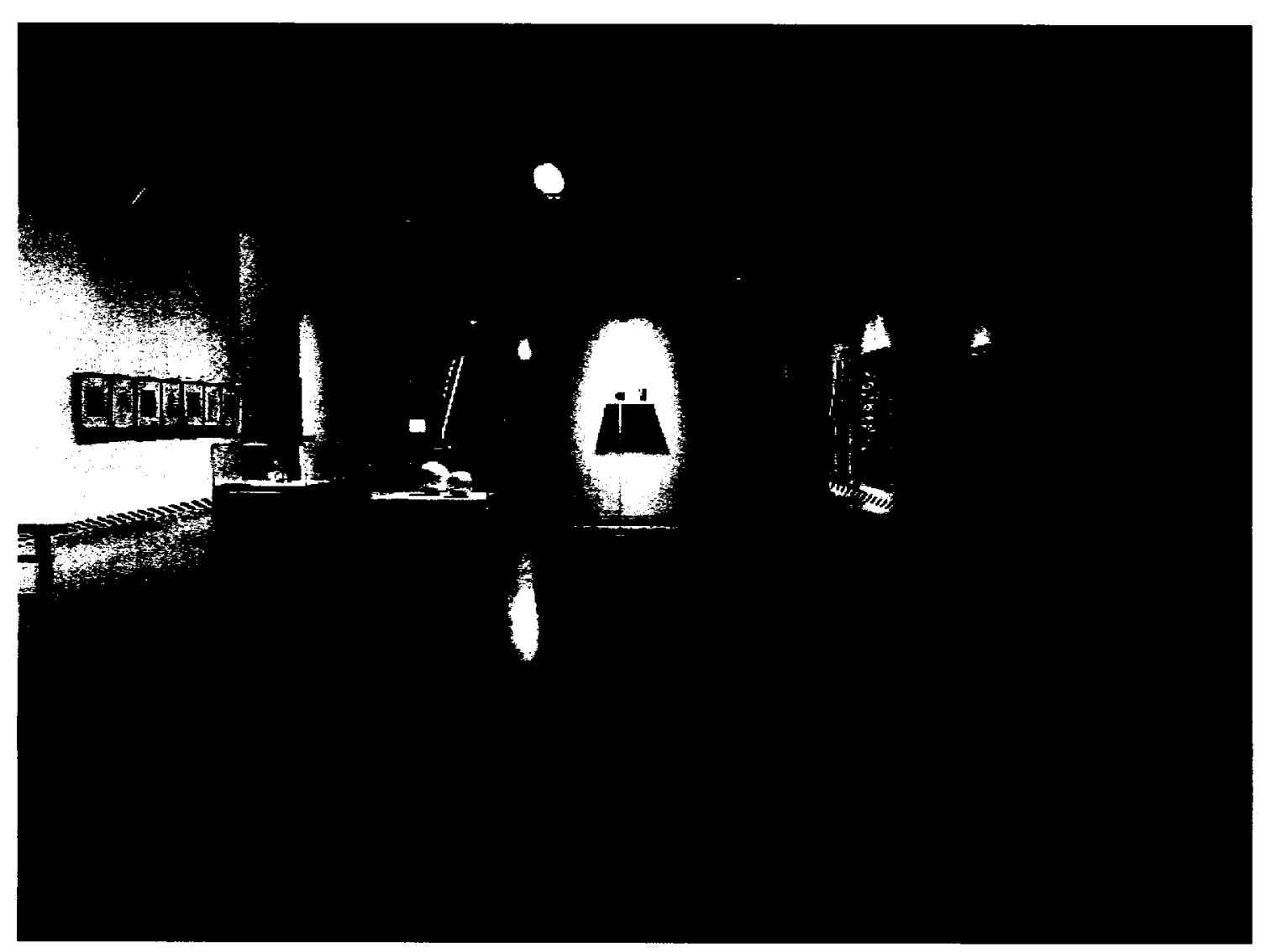


Figure 41

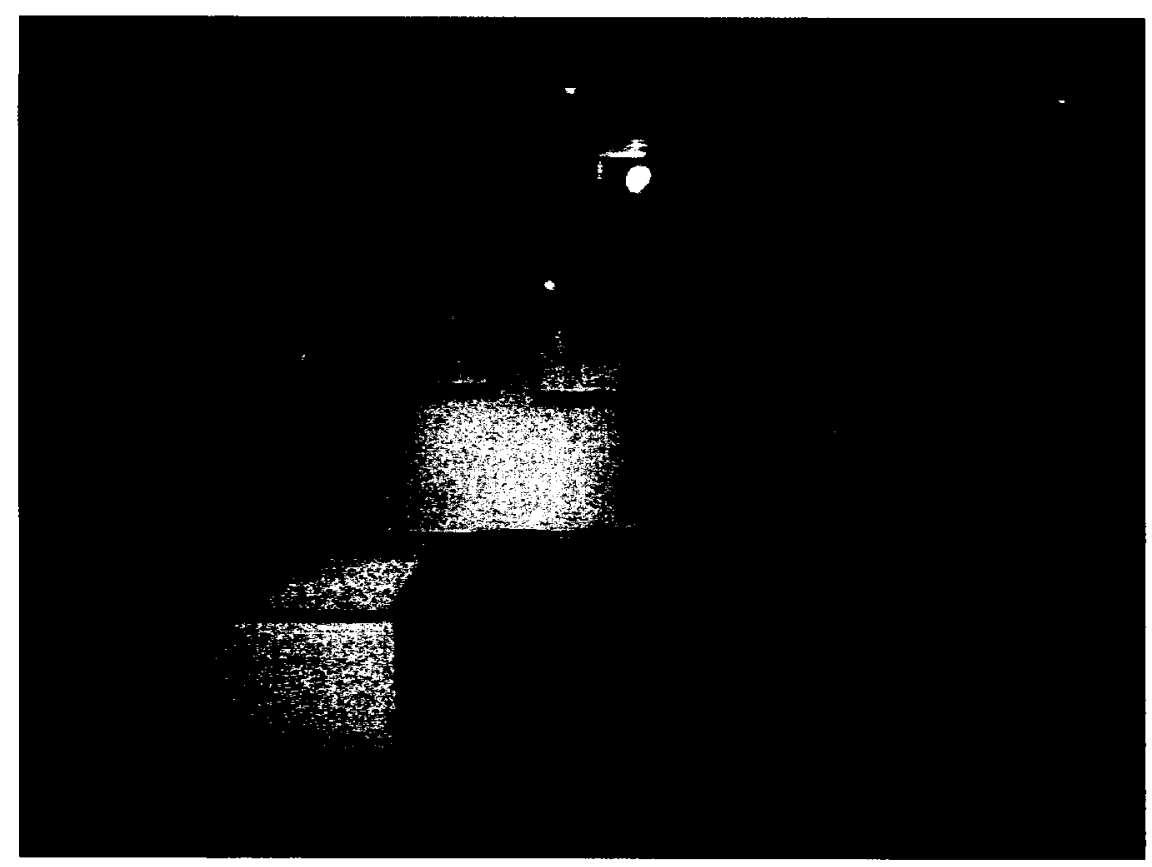

Figure 42

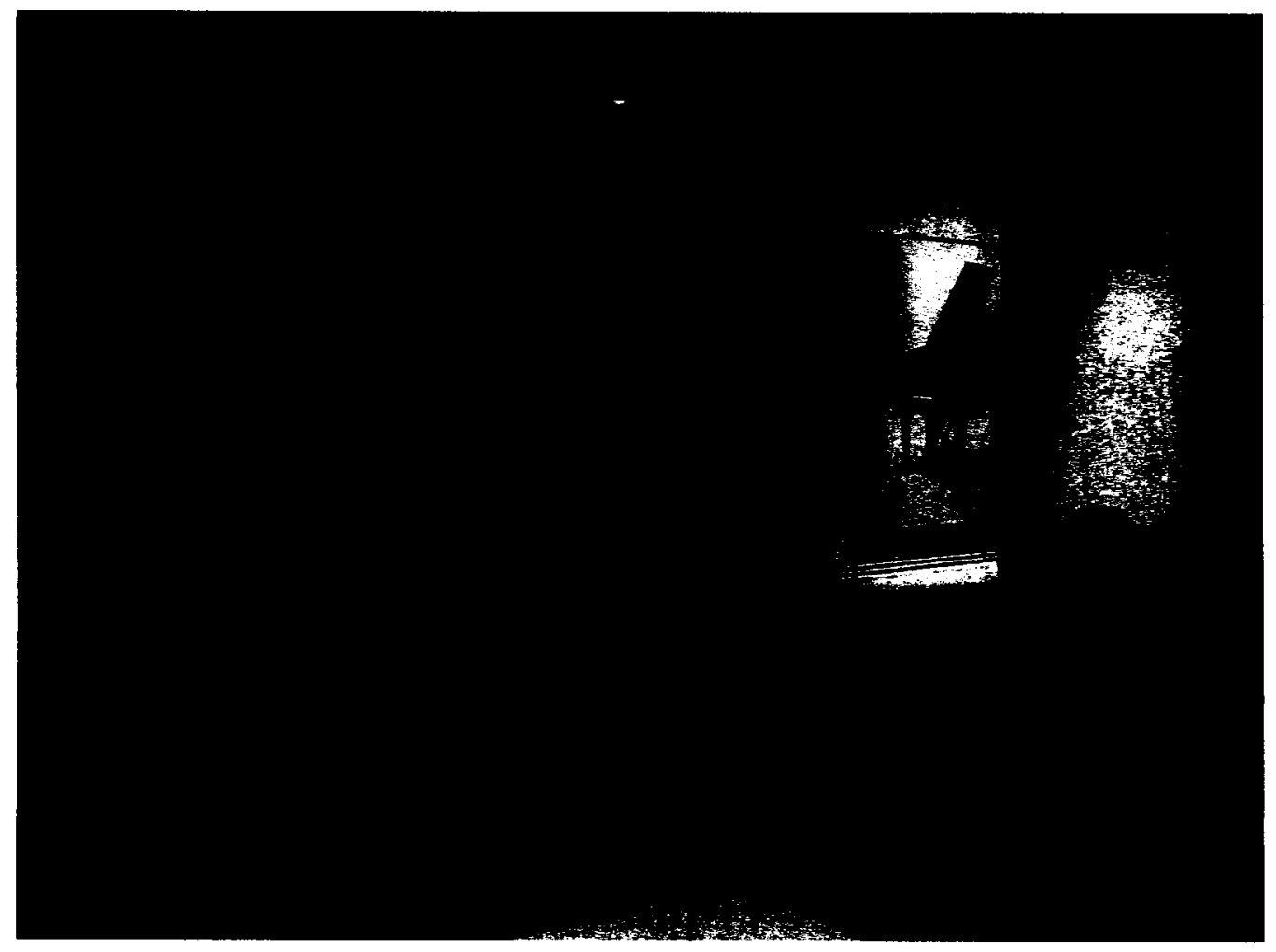


Figure 43

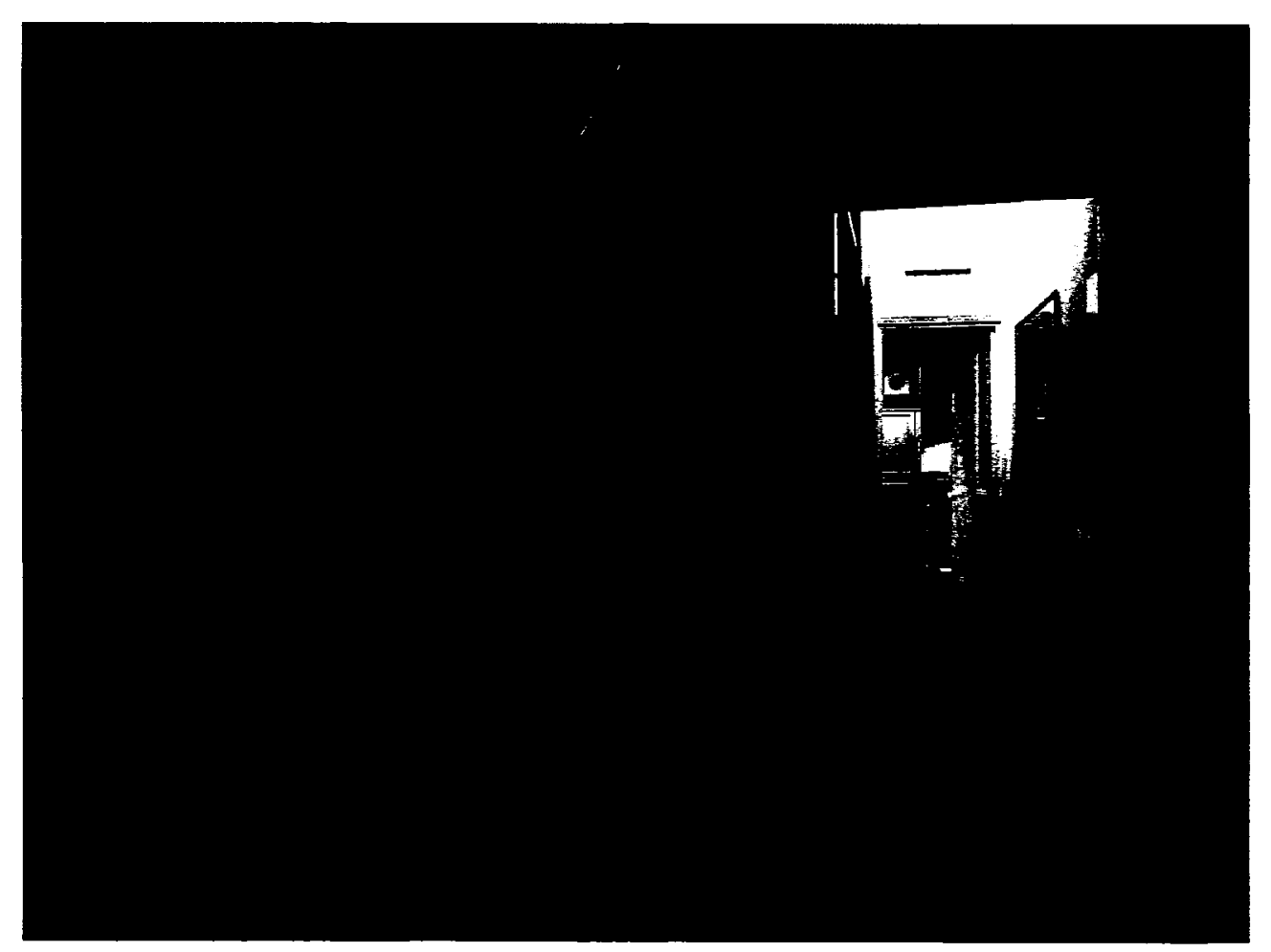

Figure 44

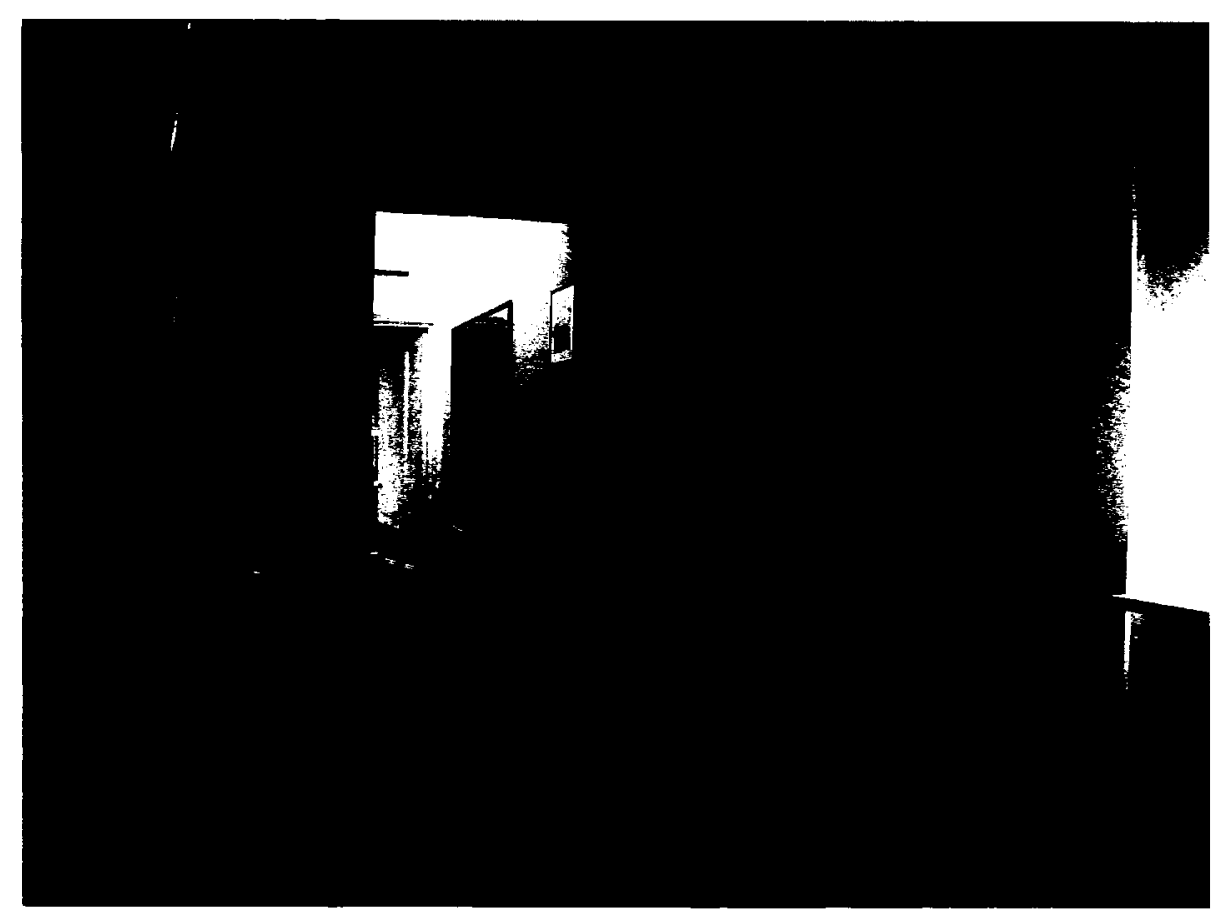


Figure 45

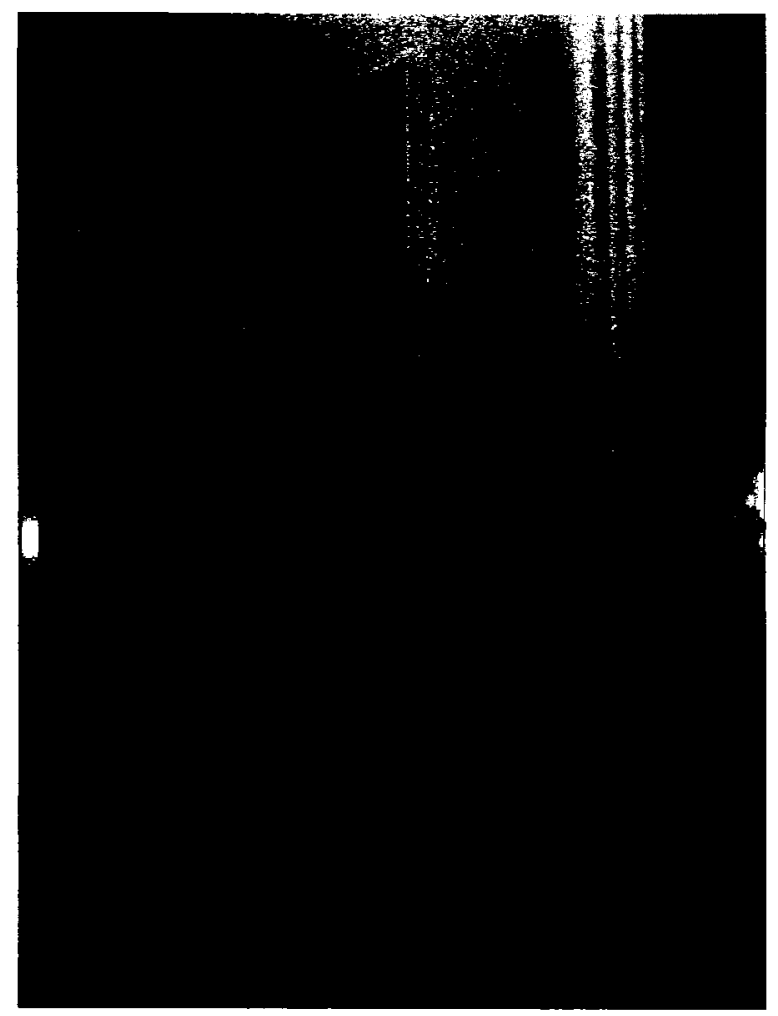

Figure 46

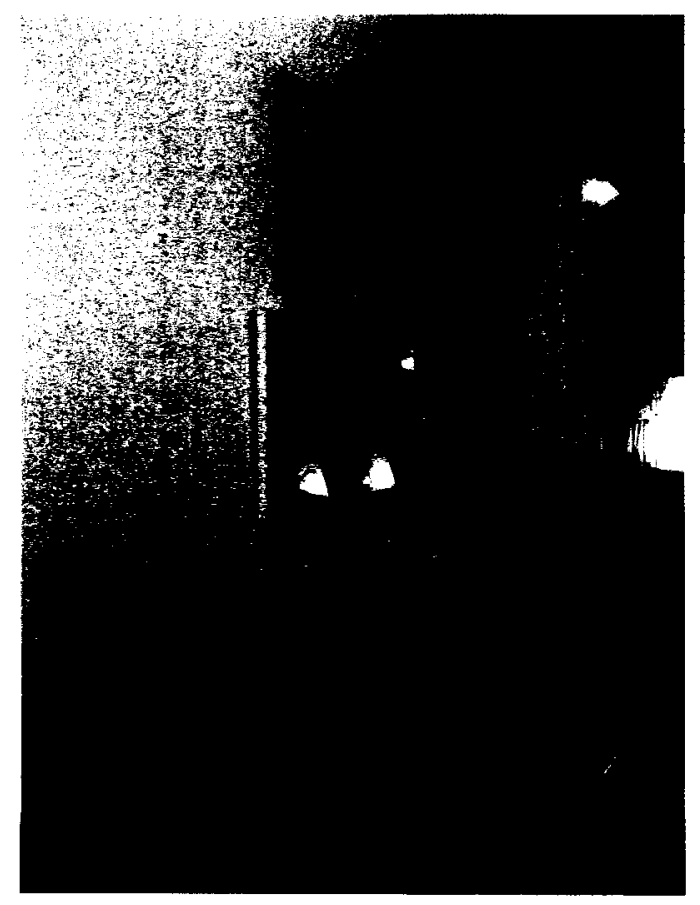


Figure 47

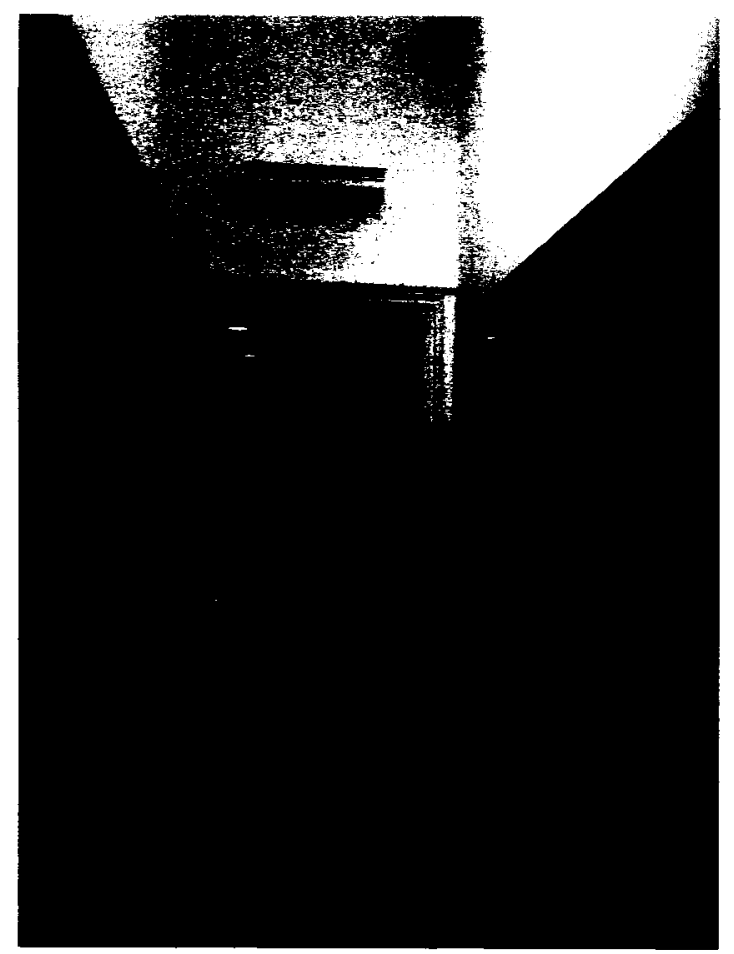

Figure 48

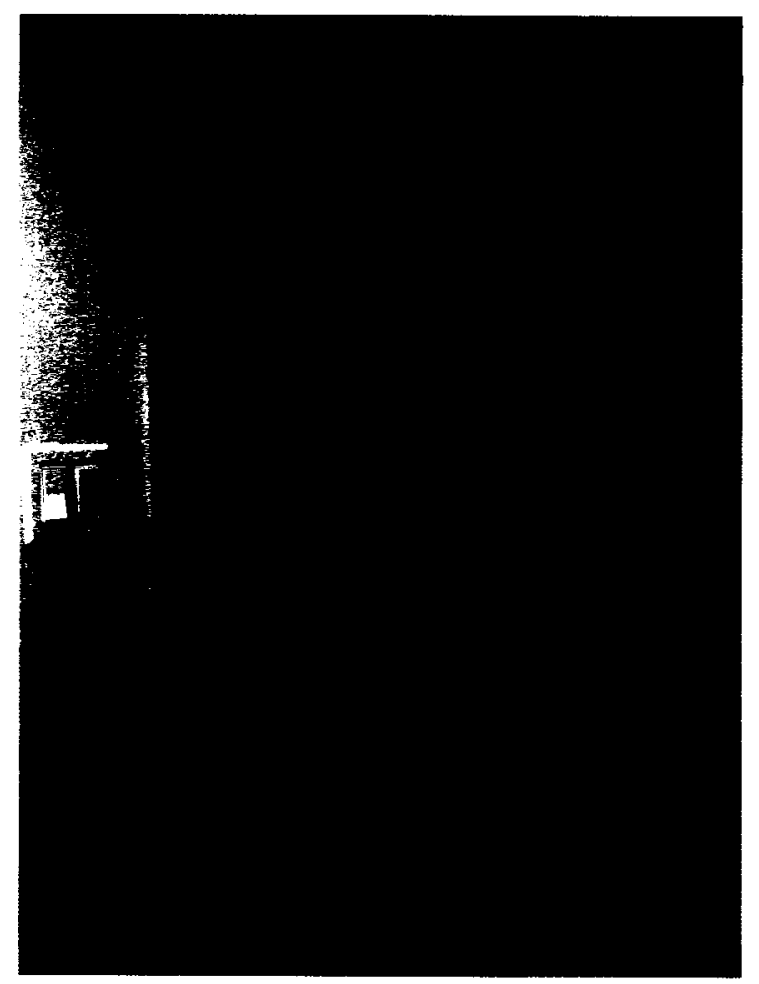


Figure 49

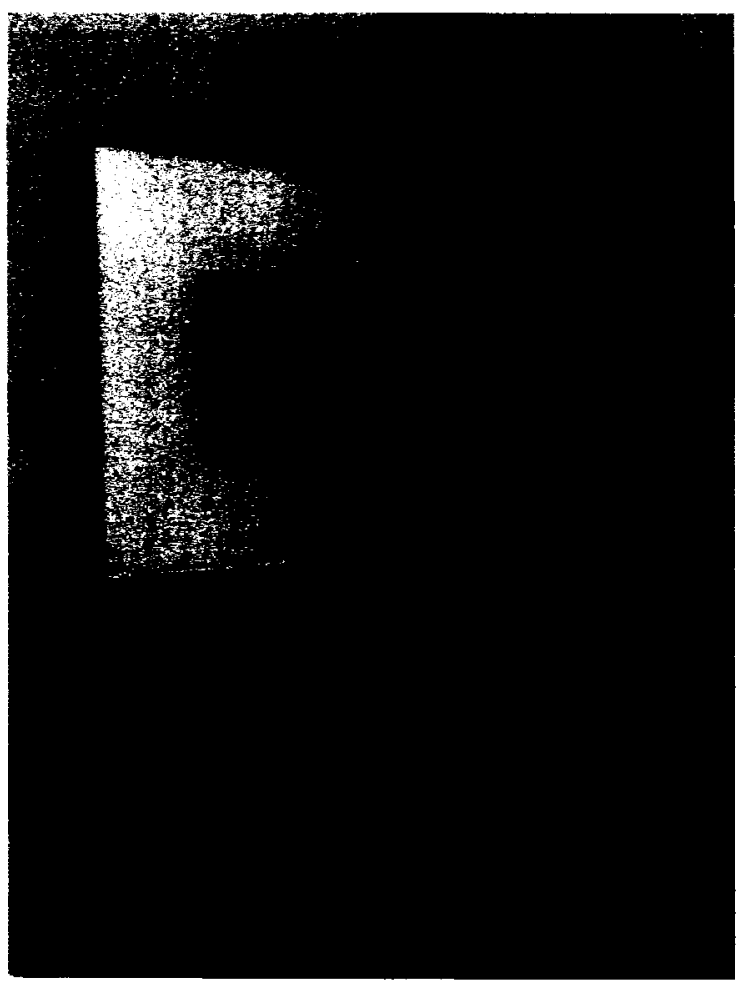

Figure 50

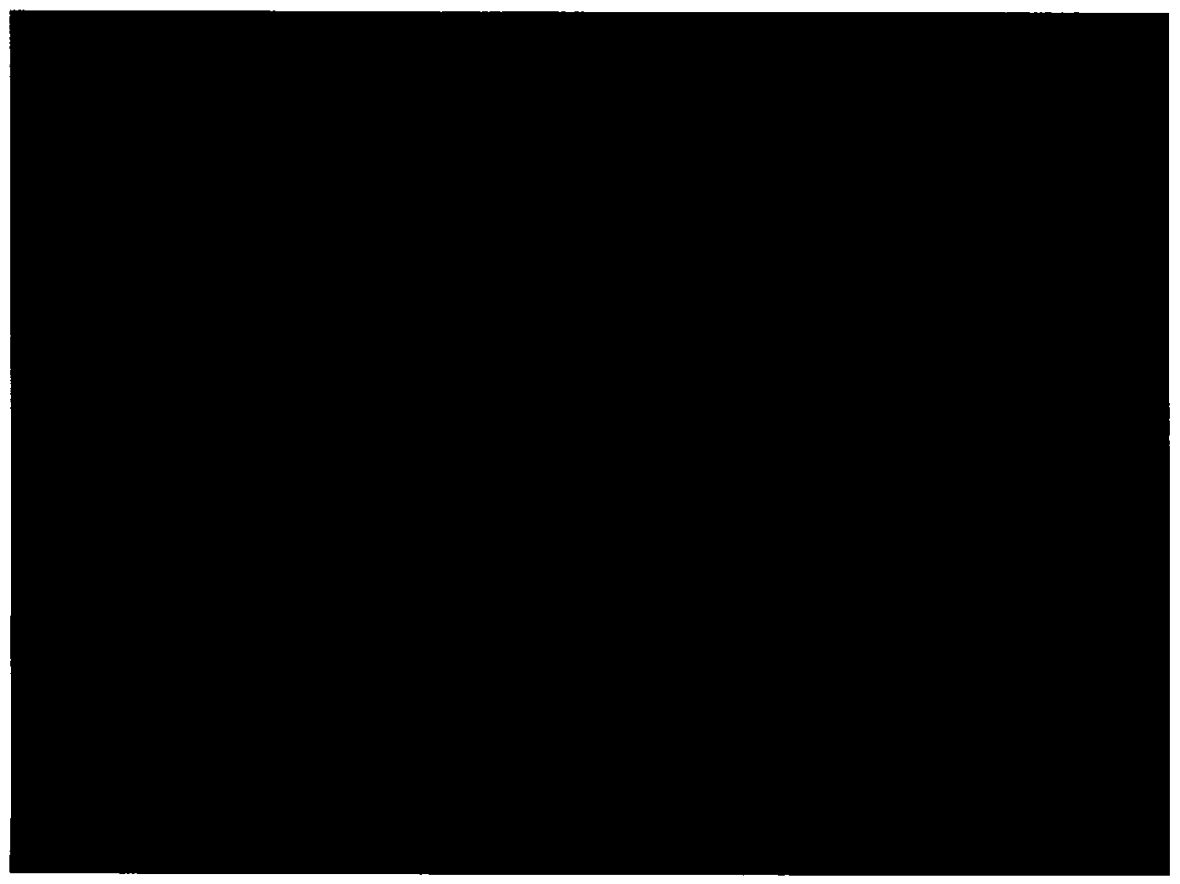


Figure 51

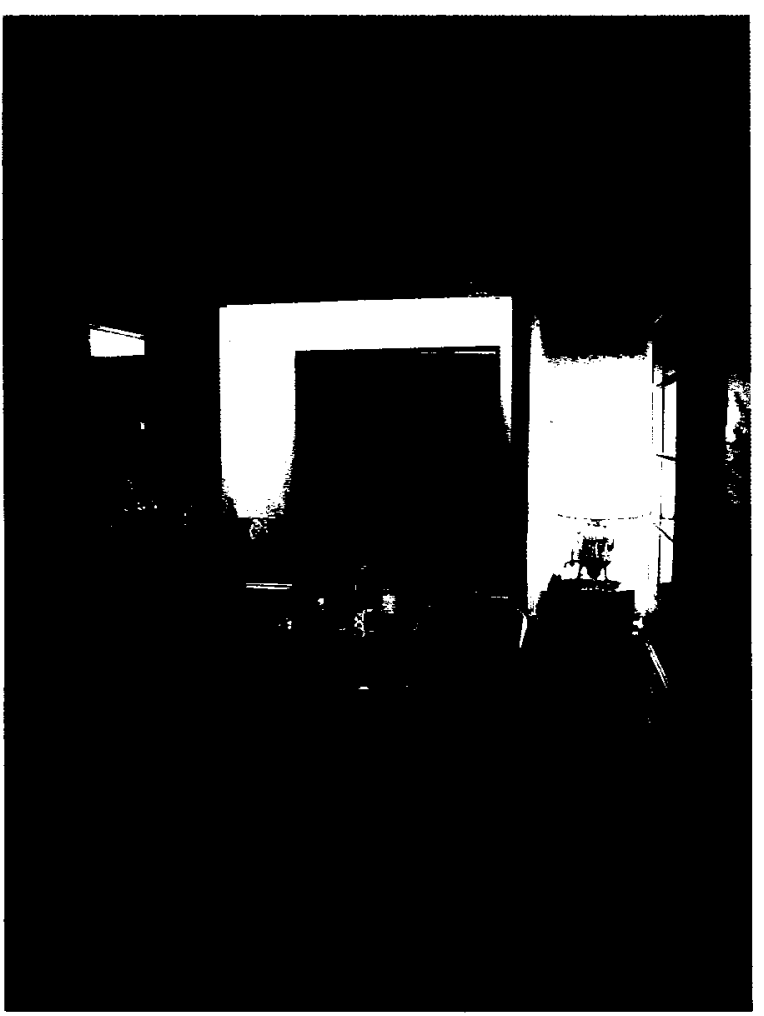

Figure 52

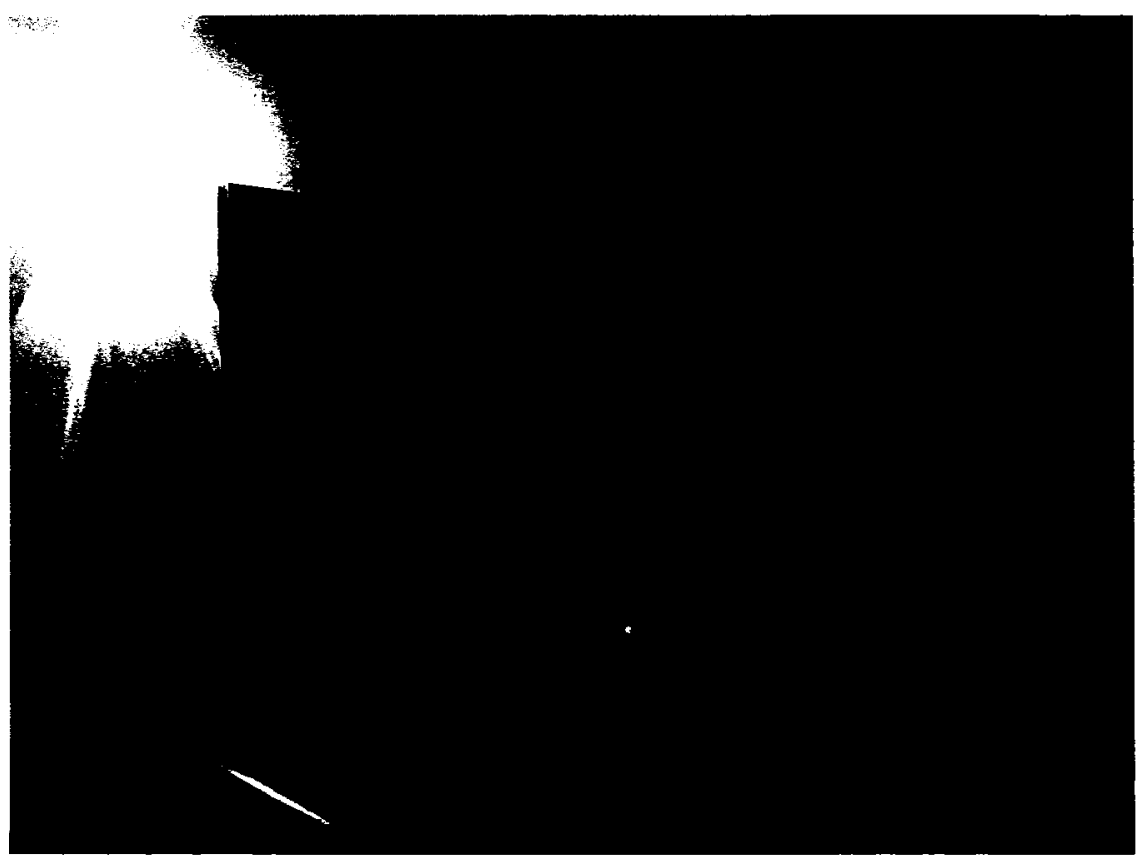


Figure 53

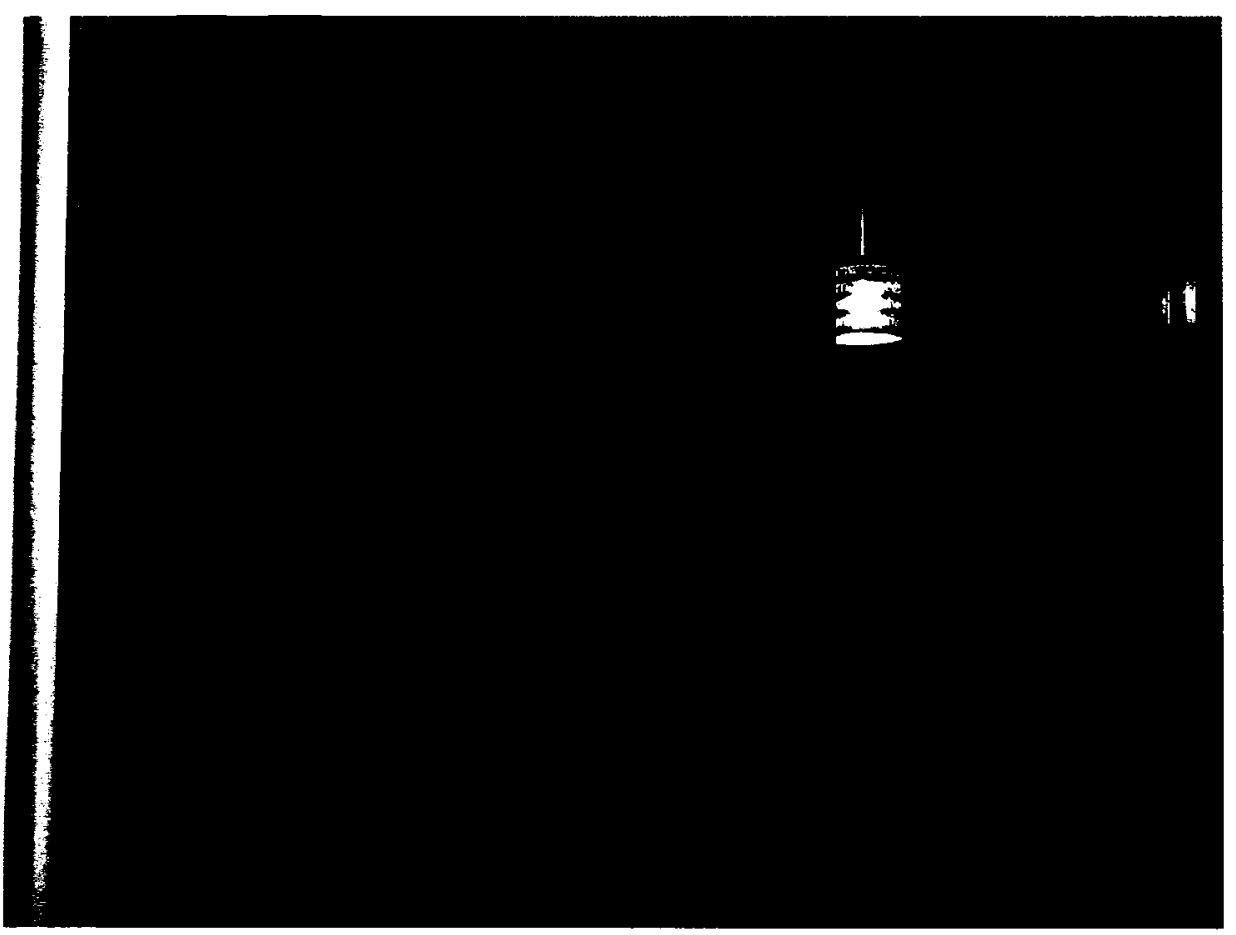

Figure 54

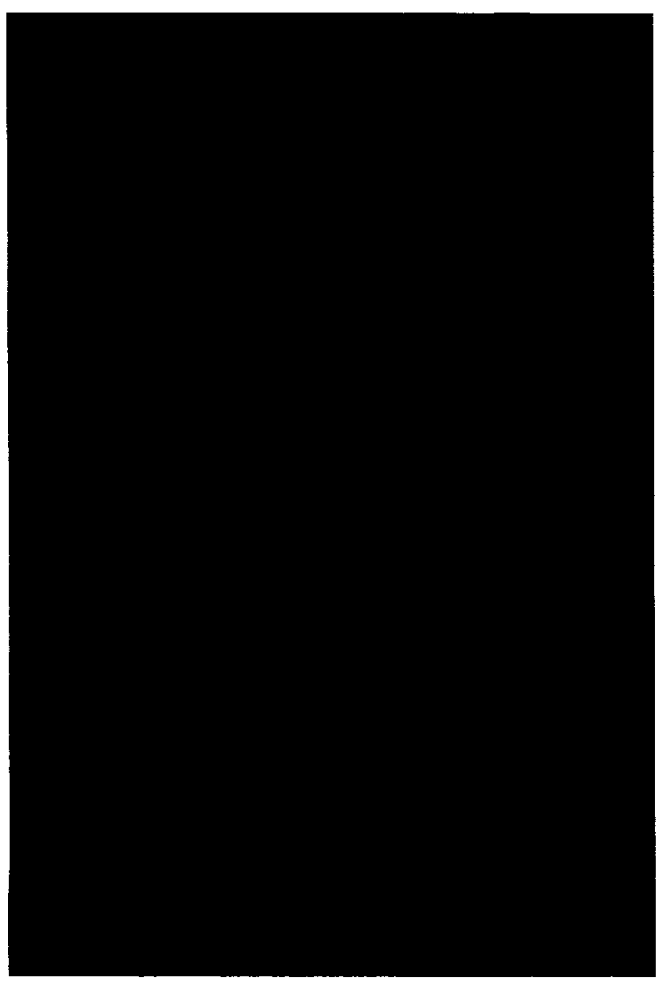


Figure 55

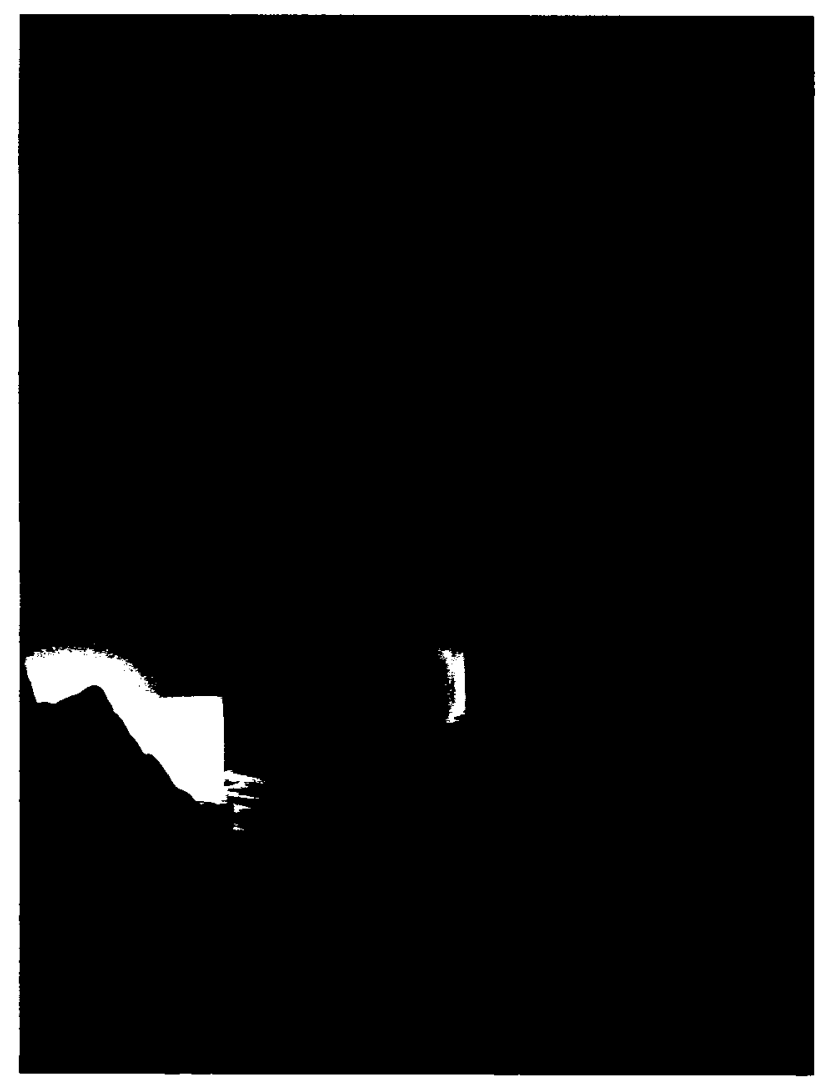

Figure 56

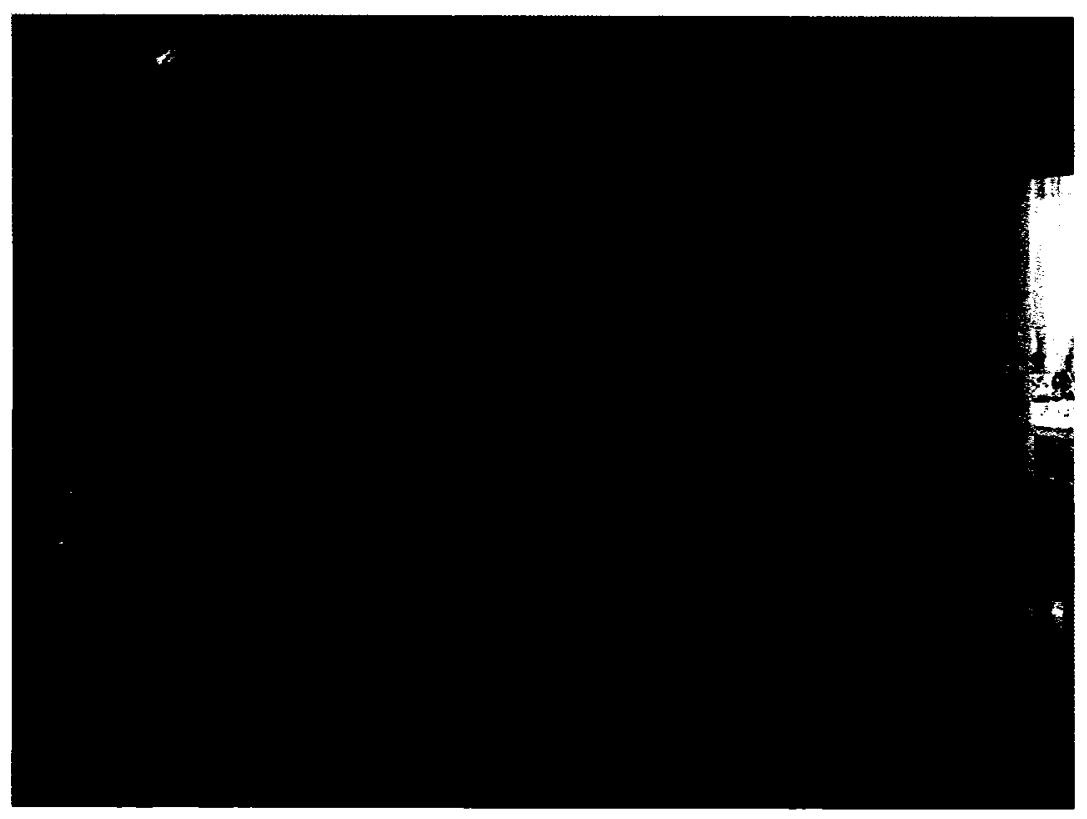


Figure 57

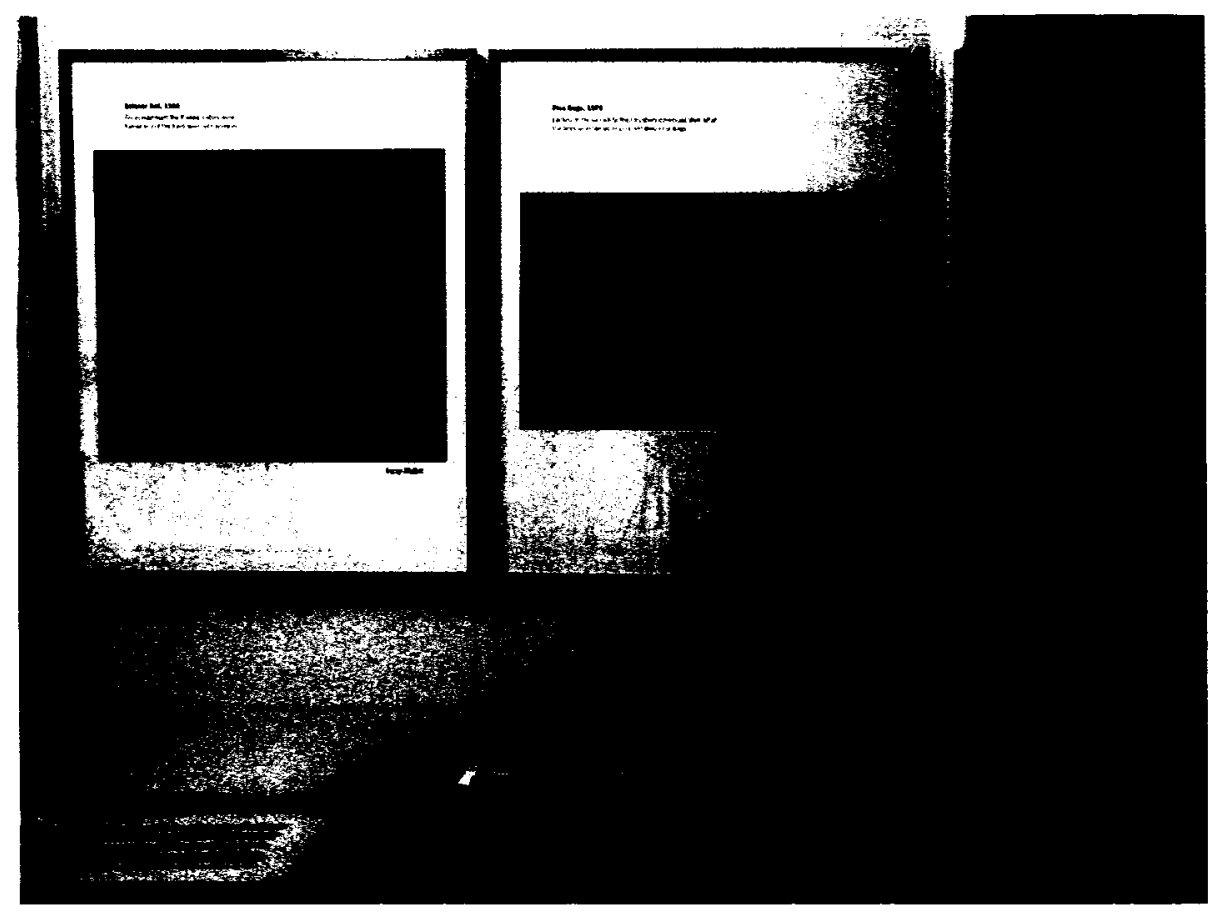

Figure 58

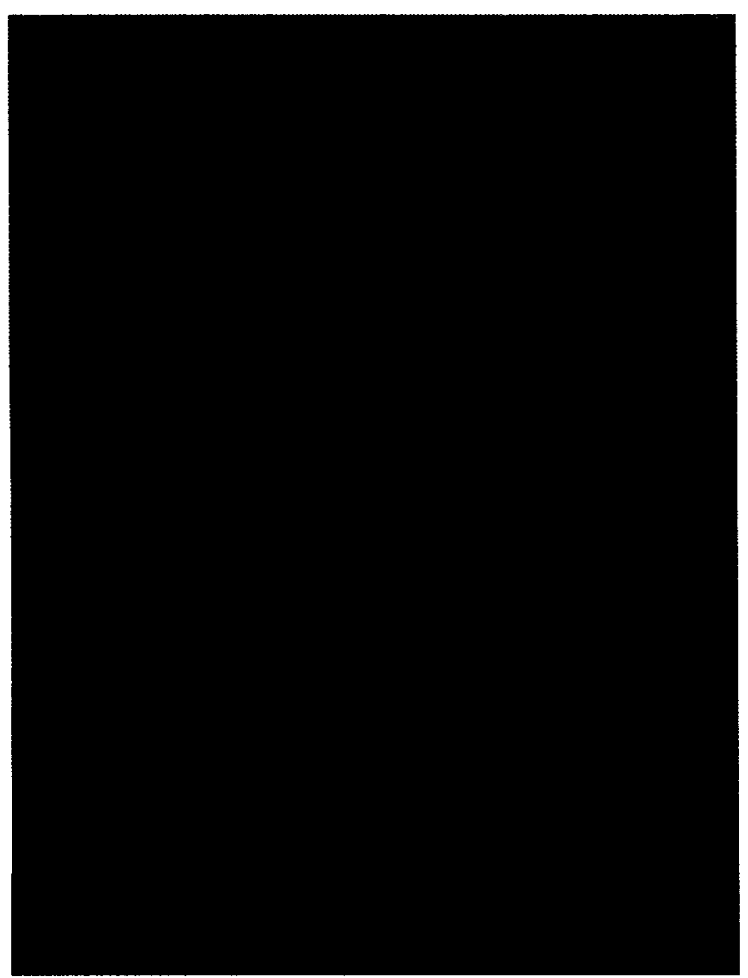


Figure 59

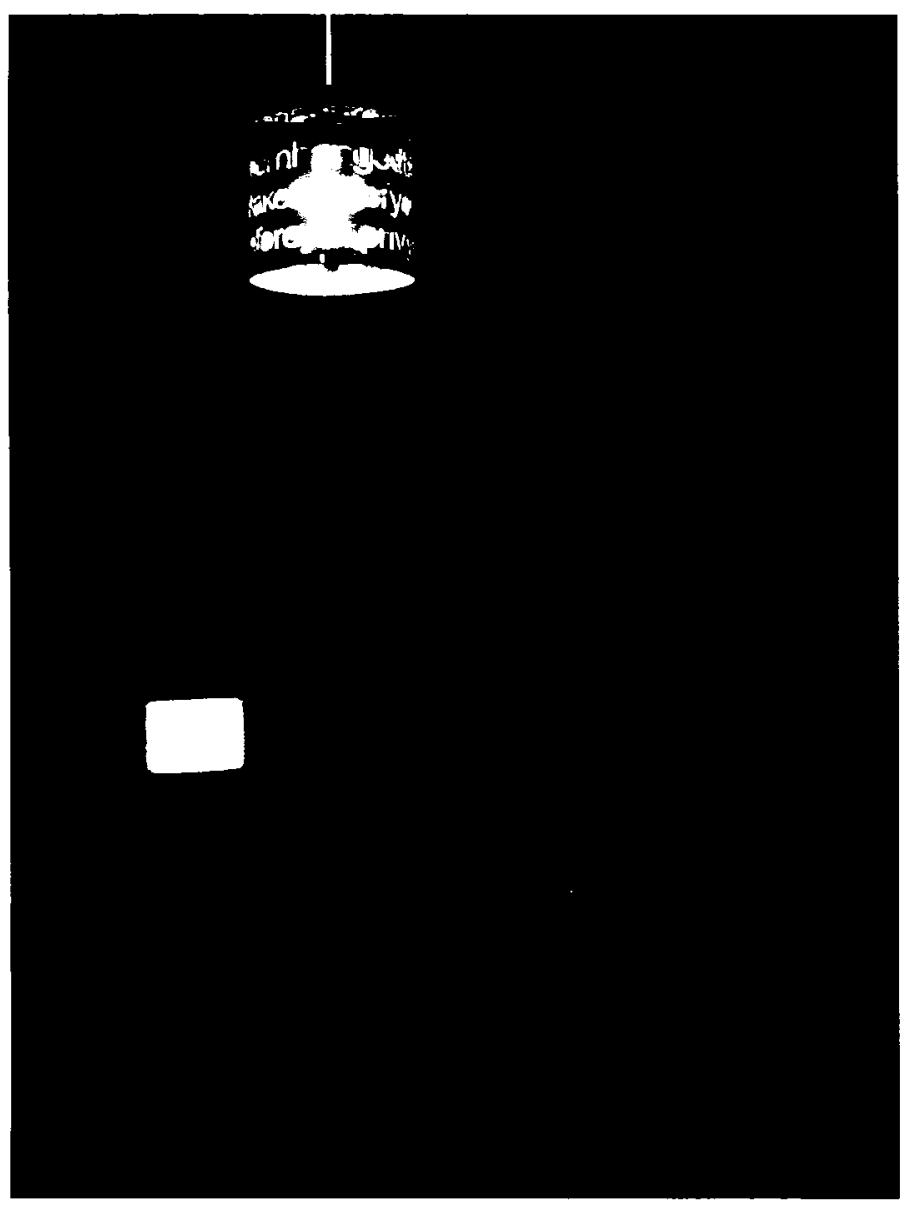




\section{APPENDIX A}

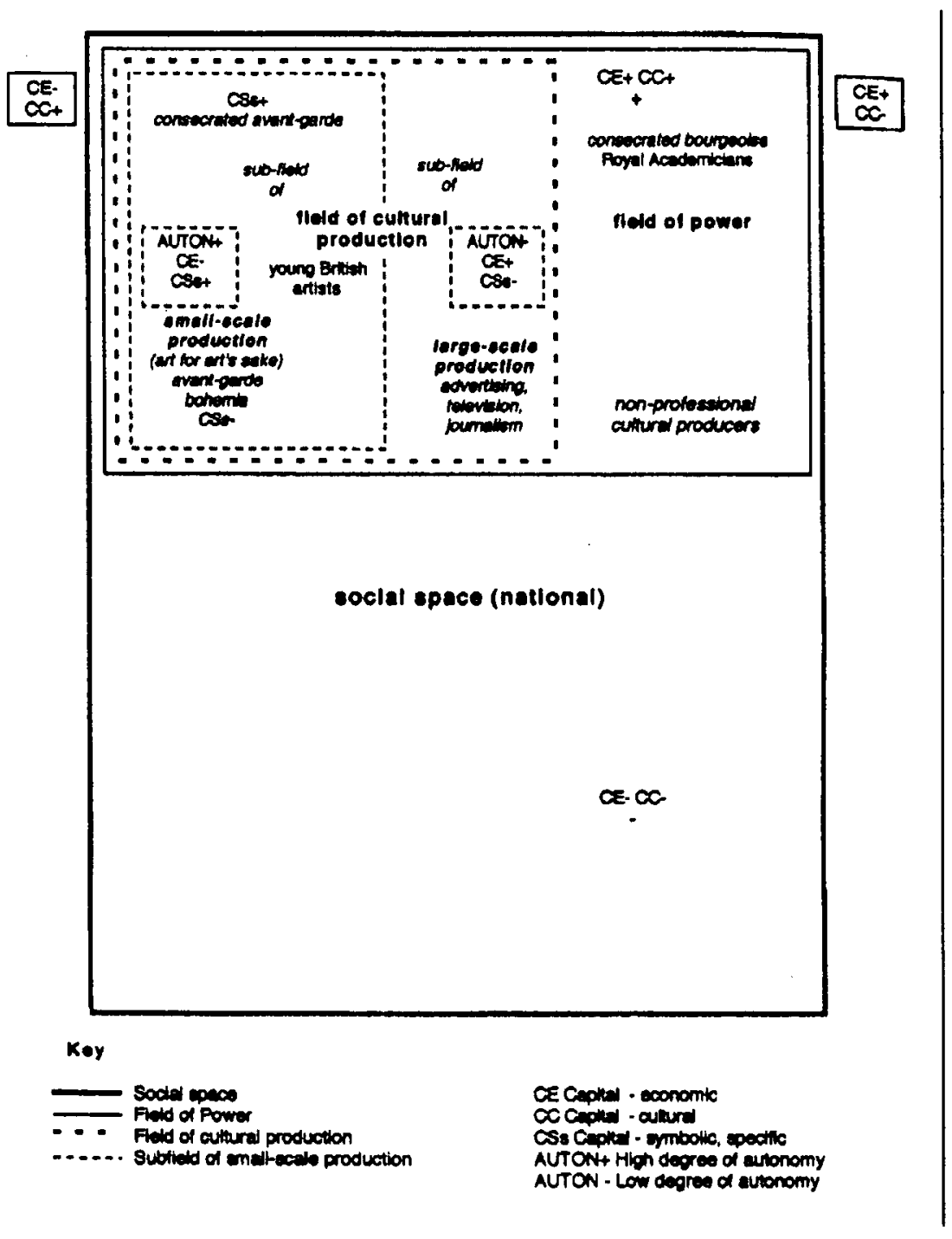

The field of cultural production in the field of power and in social space.

Source: Roger Cook, "The Mediated Manufacture of an 'Avant-Garde': a Bourdieusian Analysis of the Field of Contemporary Art in London, 19979," in Reading Bourdieu on Society and Culture, ed. Bridget Fowler (Oxford: Blackwell Publishers, 2000), 168. 


\section{BIBLIOGRAPHY}

\section{Primary Sources}

Audette, Louis. Letter to Robert Bailey, Commissioner, Community Development, City of Ottawa. 12 September 1980. File on 451 Besserer St., City of Ottawa, Ottawa, Ontario.

Beck, Claudia and Andrew Gruft. Telephone interview with author. 15 February 2005.

Brown, Bill and John McKinven. Interview with author. 18 March 2005.

Campbell, Deborah. Telephone interview with author. 4 February 2005.

File on 451 Besserer St. Compiled May 1975. City of Ottawa, Ottawa, Ontario.

Friday, Joe and Catriona Jeffries. Interview with Eleanor Wachtel. The Arts Today. CBC Radio. 18 November 2003.

Friday, Joe. Interview with author. 19 February 2004.

-. E-mail correspondence with author. 20 April 2004.

—. E-mail correspondence with author. 30 May 2005.

-. E-mail correspondence with author. 27 August 2006.

—. E-mail correspondence with author. 29 August 2006.

-. E-mail correspondence with author. 30 August 2006.

—. E-mail correspondence with author. 5 September 2006.

—. E-mail correspondence with author. 7 September 2006.

—. E-mail correspondence with author. 9 September 2006.

—. E-mail correspondence with author. 15 October 2006.

Jeffries, Catriona. Telephone interview with author. 20 April 2005.

Koh, Germaine. Lecture. University of Ottawa. Ottawa, 20 January 2004. 
-. Written interview with author. 28 May 2005.

-. Curator talk. Carleton University Art Gallery. Ottawa, 17 October 2004.

Marks, Paul. Telephone interview with author. 13 April 2005.

-. Written interview with author. 29 May 2005.

Scott, Kitty. Interview with author. 8 February 2005.

\section{Secondary Sources}

Ardenne, Paul. "Simon Starling's Nest of Associations."Art Press 273 (2001): 47-50.

"Artists: Pieroth, Kirsten." Manifesta 5 (date unknown). February 2006 $<$ http://www.manifesta.es/eng/artistas/artistas/pieroth.htm>.

Baekeland, Frederick. "Psychological Aspects of Art Collecting." Psychiatry 44 (February 1981): 45-59.

Beck, Claudia. "The Chaos of Memories: Some Personal Remarks about Collecting Photographs." Vancouver Collects. Vancouver: Vancouver Art Gallery, 2001. 9098.

Belk, Russell W. "Collectors and Collecting." Interpreting Objects and Collections. Ed. Susan M. Pearce. New York: Routledge, 1994. 317-326.

Benjamin, Walter. "Eduard Fuchs: Collector and Historian." The Essential Frankfurt School Reader. Eds. Andrew Arato and Eike Gebhardt. New York: Urizen Books, 1978. 225-253.

—. "Unpacking My Library: A Talk About Collecting." Selected Writings 1927-34, v. 2. Eds. Michael W. Jennings, Howard Eiland, and Gary Smith. Cambridge, Mass.: Belknap Press, 1999. 486-493.

Birnbaum, Daniel. "Transporting Visions: Daniel Birnbaum on the Art of Simon Starling." Artforum 42.6 (February 2004): 105-109.

Blair, Gladys. "Historic Home: 451 Besserer St."Ottawa Journal 14 March 1970, Saturday Section: n.p. 
Blom, Philipp. To Have and to Hold: An Intimate History of Collectors and Collecting. London: Penguin Books, 2003.

Bourdieu, Pierre. Distinction: A Social Critique of the Judgment of Taste. Trans. Richard Nice. Cambridge, MA: Harvard University Press, 1984.

-. The Logic of Practice. Trans. Richard Nice. Stanford, CA: Stanford University Press, 1990.

-. The Field of Cultural Production. Ed. Randal Johnson. New York: Columbia University Press, 1993.

Brown, Nicholas and Imre Szeman, eds. Pierre Bourdieu: Fieldwork in Culture. New York: Rowman and Littlefield Publishers, 1999.

Campbell, Deborah. "Passion + Intellect." Canadian Art 21.1 (Spring 2004): 62-65.

—. "Joe Friday: Just the Facts." Canadian Art 21.2 (Summer 2004): 64-67.

-. "Paul Marks: The Collector in the Age of Mechanical Reproduction." Canadian Art 21.3 (Fall 2004): 116-120.

- "Exchanges + Gatherings: In the Studio with Ian Wallace." Canadian Art 21.4 (Winter 2004): 60-64.

Canada. Statistics Canada. Population and Dwelling Counts, for Canada, Provinces and Territories, and Census Subdivisions (Municipalities), 2001 and 1996 Censuses (16 August 2002). 29 August 2006 $<$ http://www12.statcan.ca/english/census01/products/standard/popdwell/Table-CS D-P.cfm? $\mathrm{T}=1 \& \mathrm{PR}=35 \& \mathrm{SR}=526 \& \mathrm{~S}=1 \& \mathrm{O}=\mathrm{A}>$.

Coates, Louisa. Ottawa: A Guide to Heritage Structures. Ottawa: City of Ottawa, 2000.

Contemporary Art Gallery. I don't know if Thomas Edison invented the excuse: Kirsten Pieroth. Poster. Vancouver: Contemporary Art Gallery, 2004.

Cook, Roger. "The Mediated Manufacture of an 'Avant-Garde': a Bourdieusian Analysis of the Field of Contemporary Art in London, 1997-9." Reading Bourdieu on Society and Culture. Ed. Bridget Fowler. Oxford: Blackwell Publishers, 2000. 164-185.

Dietrich, Dorothea. "Micro-Vision: Karl Blossfeldt's Urformen der Kunst." Art on Paper 3.1 (September/October 1998): 35-40. 
Edmonton Art Gallery. Hoarders, Packrats and Connoisseurs. Edmonton: Edmonton Art Gallery, 1994.

Elsner, John and Roger Cardinal, eds. The Cultures of Collecting. Cambridge, Mass.: Harvard University Press, 1994.

Esterow, Milton. "The ARTnews 200 Top Collectors." ARTnews 105.7 (Summer 2006): 135-136, 138-142, 144, 146-147.

Falkenstein, Michelle. "Waiting for an A+ Picture." ARTnews 103.3 (March 2004): 108109.

Fisher, Jennifer. Aesthetic Contingencies: Relational Enactments in Display Culture. Dissertation, Concordia University, 1996.

Garneau, David. "Beyond the One-Liner: The Masks of Brian Jungen." Border Crossings 19.4 (November 2000): 91-93.

Gessell, Paul. "This Man is Looking for Art." Ottawa Citizen 18 September 2004: F1-F2.

Greenberg, Reesa. "The Exhibited Redistributed: A Case for Reassessing Space." Thinking About Exhibitions. Eds. Reesa Greenberg, Bruce W. Ferguson, and Sandy Nairne. New York: Routledge, 1996. 349-367.

Grenville, Bruce. "Body." Body: New Art from the UK. Vancouver: Vancouver Art Gallery, 2005. 8-15.

Haacke, Hans. "A Public Servant." October 101 (summer 2002): 4-6.

Heather, Rosemary. "mnemonic construction in progress." Every House I have Ever Lived in Drawn from Memory. Halifax: Eyelevel Gallery, 1998. n.p.

Hipsky, Marty. "Romancing Bourdieu: A Case Study in Gender Politics in the Literary Field." Pierre Bourdieu: Fieldwork in Culture. Eds. Nicholas Brown and Imre Szeman. New York: Rowman and Littlefield Publishers, 1999. 186-206.

Historical and Architectural Committee of Action Sandy Hill. Walking in Sandy Hill. Ottawa: Heritage Ottawa, 1977.

Hoffman, Jens. "Brian Jungen: Prototypes for a New Understanding." Flash Art 231 (July - September 2003): 86-88. 
Holton, Robert. "Bourdieu and Common Sense." Pierre Bourdieu: Fieldwork in Culture. Eds. Nicholas Brown and Imre Szeman. New York: Rowman and Littlefield Publishers, 1999. 87-99.

Horrigan, Bill. "A Double Tour." Shirin Neshat: Two Installations. Columbus, Ohio: The Wexner Center for the Arts, 2000. 6-17.

Jenkins, Richard. Pierre Bourdieu. New York: Routledge, 1992.

Jennings, Sarah. "Ydessa Hendeles: A Collector Who Curates." ArtNews 93.40 (December 1994): 97-98.

Johnson, Randal. Editor's Introduction. The Field of Cultural Production. By Pierre Bourdieu. Ed. Randal Johnson. New York: Columbia University Press, 1993.

Kiendl, Anthony, ed. Obsession, Compulsion, Collection: On Objects, Display Culture, and Interpretation. Banff, Alta: Banff Centre Press, c2004.

Kimmelman, Michael. "Art in Review: Simon Starling." New York Times (12 March 2004). February 2006

$<$ http://www.nytimes.com/2004/03/12/arts/design/12GALL.html?ex=1394514000 \&en $=c 2$ ff643dd73b8185\&ei $=5007 \&$ partner=USERLAND $>$.

Koh, Germaine. Prototype: Contemporary Art from Joe Friday's Collection. Unpublished catalogue essay. Ottawa: Carleton University Art Gallery, 2004.

Kronsky, Betty. "The Psychology of Art." American Artist 49.510 (January 1985): 16, 9698.

Lane, Jeremy F. Pierre Bourdieu: A Critical Introduction. Sterling, Virginia: Pluto Press, 2000.

Leaning, John and Lyette Fortin. Our Architectural Ancestry. Ottawa: Haig and Haig Publishing Co., 1983.

Loranger, Georges. An Essay on Private and Public Art Collecting in Canada: The Tip of the Canadian Icejam. Toronto: G. Loranger, 1985.

Mangiacasale, Angela. "Ageless Beauty." The Ottawa Citizen 10 May 1997: D1.

Mays, John Bentley. "Bears." Canadian Art 19.3 (Fall 2002): 92-97. 
Maraniello, Gianfranco di. "Simon Starling's "Formation"." MACRO (date unknown). February 2006

$<$ http://www.macro.roma.museum/english/press/starling/maraniello_starling.pdf $>$.

McGrath, Jerry. "Ritual Ornament/Elemental Dream." Parachute 72 (October-December 1993): 10-13.

Milroy, Sarah. "With Ydessa the Mind Makes Leaps." The Globe and Mail 6 May 2006: R8-R9.

Moore, Jerry D. Visions of Culture: An Introduction to Anthropological Theories and Theorists. $2^{\text {nd }}$ ed. Toronto: Altamira Press, 2004.

Muensterberger, Werner. Collecting: An Unruly Passion, Psychological Perspectives. Princeton: Princeton University Press, 1994.

Musée d'Art Moderne de la Ville de Paris. Passions Privées: collections particulières d'art moderne et contemporain en France. Paris: Musée d'Art Moderne de la Ville de Paris, 1995.

Parsons, Vic. Ken Thomson: Canada's Enigmatic Billionaire. Toronto: Burgher Books, c1996.

Poole, Lucianne. "On Campus: The Collector." Carleton University Magazine Online Fall 2004. 12 October 2004 $<$ http://www.magazine.carleton.ca/2004_Fall/1361pf.htm>.

Prior, Nick. "A Different Field of Vision: Gentlemen and Players in Edinburgh, 18261851." Reading Bourdieu on Society and Culture. Ed. Bridget Fowler. Oxford: Blackwell Publishers, 2000. 142-163.

Reid, Dennis. Collector's Canada: Selections from a Toronto Private Collection. Toronto: Art Gallery of Ontario, 1988.

Stewart, Susan. On Longing: Narratives of the Miniature, the Gigantic, the Souvenir, the Collection. Baltimore: Johns Hopkins University Press, c1984.

Sullivan, Eve. "The Juvenilia of Tracey Moffatt." Art and Australia 41.2 (2003): 232-239.

Taylor, C.J. Canadian Inventory of Historic Buildings: Historical Building Report. February 1975. LACAL file, City of Ottawa, Ottawa, Ontario. 
Théberge, Pierre. "The Ydessa Hendeles Art Foundation: Building a Museum as a Life Process." Parachute 54 (March - June 1989): 28-33.

Tousley, Nancy. "Spotlight: Brian Jungen: Cool, Cooler, Coolest." Canadian Art 20.2 (Summer 2003): 38-44.

Vancouver Art Gallery. Vancouver Collects. Vancouver: Vancouver Art Gallery, 2001.

-. Real Pictures: Photographs from the Collection of Claudia Beck and Andrew Gruft. Vancouver: Vancouver Art Gallery, 2005.

Wallace, Ian. Ian Wallace: Corner of the Studio; El Taller. Cantabria, Spain: Sala Robayera, 1994.

Webb, Jen et al. Understanding Bourdieu. London: Sage Publications, 2002. 